Florida International University

FIU Digital Commons

FIU Electronic Theses and Dissertations

University Graduate School

$10-4-2018$

\title{
An Alternative Narrative of Integration In Germany through an Ethnographic Exploration of Cuban Immigration
}

Ana M. Rusch

Florida International University, ARusc001@fiu.edu

Follow this and additional works at: https://digitalcommons.fiu.edu/etd

Part of the Human Geography Commons, Latin American Studies Commons, Migration Studies

Commons, and the Social and Cultural Anthropology Commons

\section{Recommended Citation}

Rusch, Ana M., "An Alternative Narrative of Integration In Germany through an Ethnographic Exploration of Cuban Immigration" (2018). FIU Electronic Theses and Dissertations. 3918.

https://digitalcommons.fiu.edu/etd/3918

This work is brought to you for free and open access by the University Graduate School at FIU Digital Commons. It has been accepted for inclusion in FIU Electronic Theses and Dissertations by an authorized administrator of FIU Digital Commons. For more information, please contact dcc@fiu.edu. 


\section{FLORIDA INTERNATIONAL UNIVERSITY}

Miami, Florida

\section{AN ALTERNATIVE NARRATIVE OF INTEGRATION IN GERMANY \\ THROUGH AN ETHNOGRAPHIC EXPLORATION OF CUBAN IMMIGRATION}

A dissertation submitted in partial fulfillment of the

requirements for the degree of

DOCTOR OF PHILOSOPHY

in

GLOBAL AND SOCIOCULTURAL STUDIES

By

Ana Mary Rusch 
To: Dean John F. Stack, Jr.

Steven J. Green School of International and Public Affairs

This dissertation, written by Ana Mary Rusch, and entitled An Alternative Narrative of Integration in Germany through an Ethnographic Exploration of Cuban Integration, having been approved in respect to style and intellectual content, is referred to you for judgment.

We have read this dissertation and recommend that it be approved.

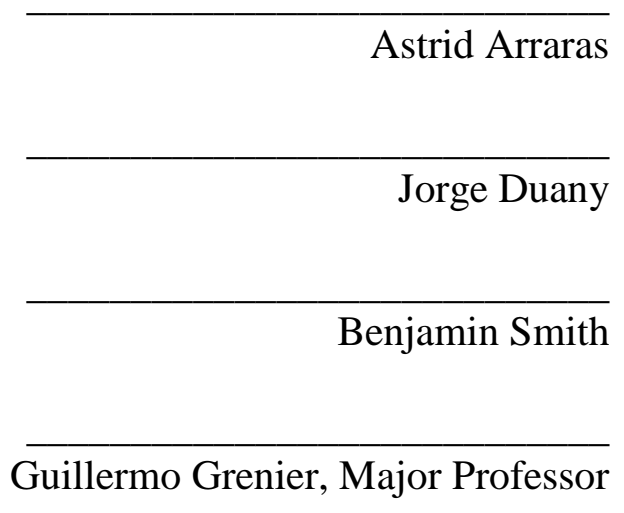

Date of Defense: October 4, 2018

The dissertation of Ana Mary Rusch is approved.

Dean John F. Stack, Jr. Steven J. Green School of International and Public Affairs

Andrés G. Gil Vice President for Research and Economic Development and Dean of the University Graduate School

Florida International University, 2018 
(C) Copyright 2018 by Ana Mary Rusch

All rights reserved. 


\section{DEDICATION}

This dissertation was inspired by my amazing mother Lilian. I dedicate this dissertation to her and my wonderful family; My grandparents Nieves and Miguel, my aunts Sandra and Ana, and my sister Yilyen. Everything I am and all that I have accomplished is because of you all. Thank you for your infinite love, encouragement, and for always believing in me. I am forever thankful. 


\section{ACKNOWLEDGMENTS}

I wish to thank my committee from the bottom of my heart for their unwavering support, patience, and reassurance. I am eternally grateful.

Dr. Benjamin Smith and Dr. Astrid Arraras inspired me as undergraduate student and encouraged me throughout every single step in my graduate career. Dr. Jorge Duany always had his door open for me and ready to give the best advice and help. Finally, I want to thank my major professor Dr. Guillermo Grenier who was paramount in my success. Even from my first day as a graduate student as I sat in his office lost and nervous, he saw my potential and guided me ever since with neverending humor, reassurance, and support.

I also wish to thank the Department of Global and Sociocultural Studies at Florida International University. It is a privilege and an honor to be a part of this department that pushes for excellence and encourages the best in its students. I have grown not only as an academic but as a person because of this department. It gifted me the freedom to explore my academic interests, the resources to find success both as an academic and as a professional, and the highest level of inspiration. 


\section{ABSTRACT OF THE DISSERTATION}

AN ALTERNATIVE NARRATIVE OF INTEGRATION IN GERMANY THROUGH AN ETHNOGRAPHIC EXPLORATION OF CUBAN INTEGRATION

by

Ana Mary Rusch

Florida International University, 2018

Miami, Florida

Professor Guillermo Grenier, Major Professor

This ethnographic study on Cuban immigrants in Germany explored the dynamics of integration through an understudied population. Most of the research conducted on integration in Germany has been on Turkish immigrants, Germany's majority immigrant group. To contribute to Integration Studies, this research focused on a minority and lesser studied immigrant group, Cuban immigrants. Cuban immigrants in Germany not only have a different historical and geopolitical relationship with Germany than its majority group but they also subscribe to different cultural and ethnoreligious categories. Because of these varying circumstances, Cubans act as a counterexample to the majority immigrant group, creating an alternative narrative to integration in Germany.

This dissertation addressed the methodology used in this study, explored the complexity of identity, examined German immigration and integration policies, reviewed the Cuban diaspora in the United States and globally, and presented an ethnography of Cuban integration in Germany. Effectively contributing to not only Integration Studies but also to Cuban Diaspora Studies, and Identity Studies. 


\section{TABLE OF CONTENTS}

CHAPTER

PAGE

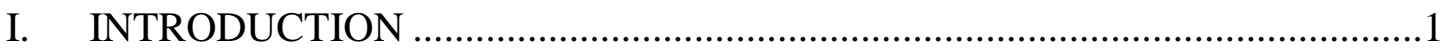

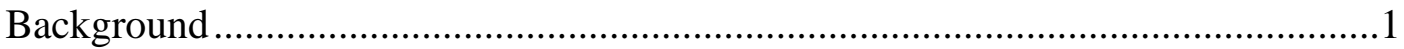

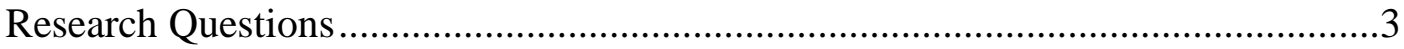

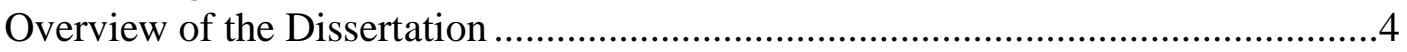

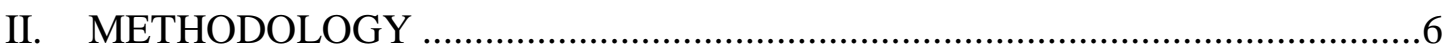

Selection of Berlin, Germany as Field Site......................................................6

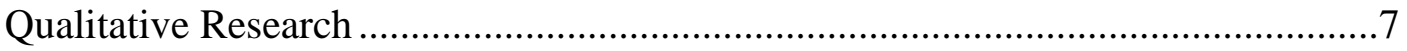

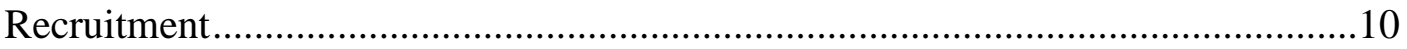

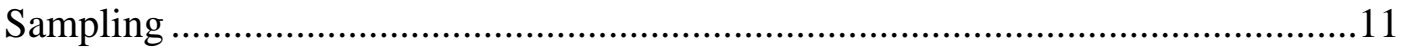

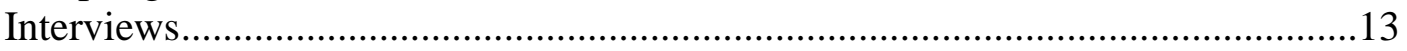

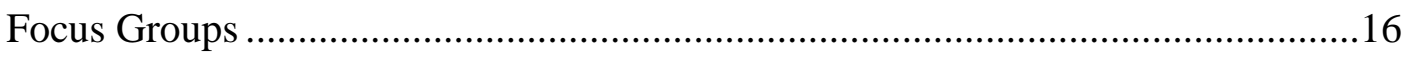

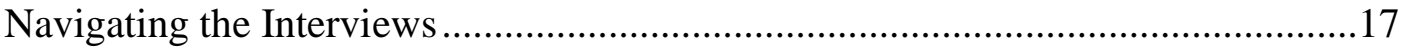

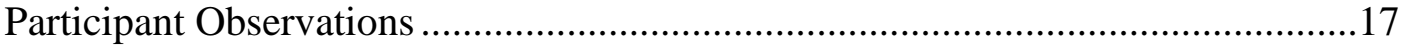

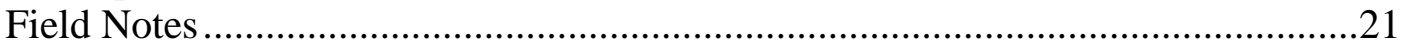

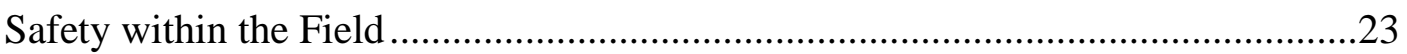

Being Female in the Field ...............................................................................24

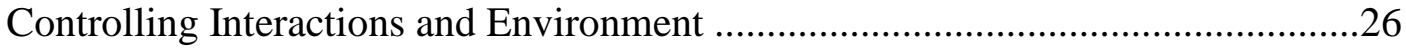

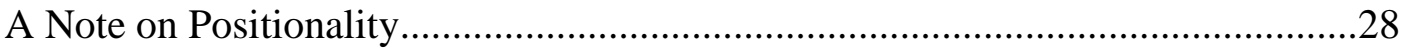

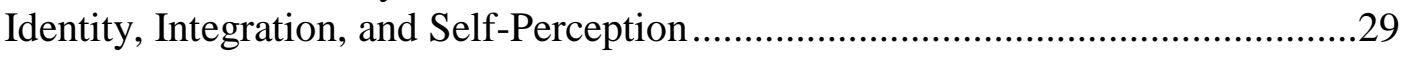

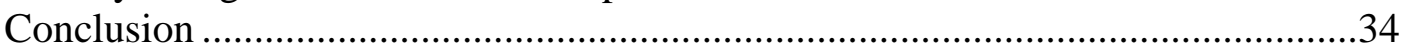

III. GERMAN IDENTITY, INTEGRATION, \& IMMIGRATION POLICIES \&

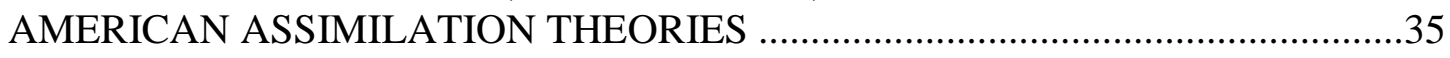

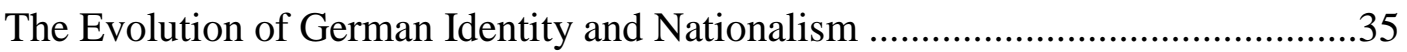

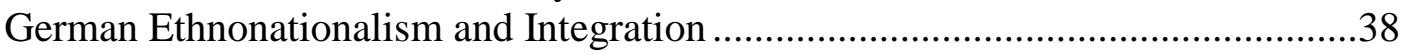

Overview of Germany's Immigration Policies ................................................40

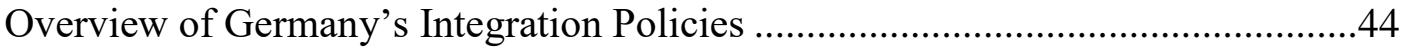

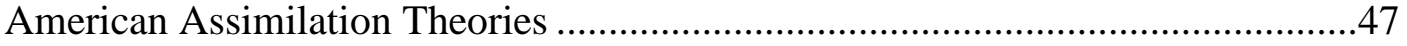

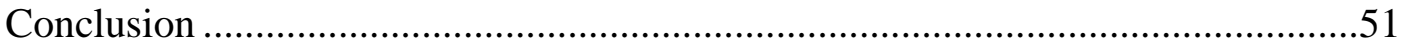

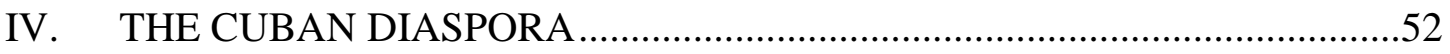

The Cuban Diaspora in the United States ...........................................................52

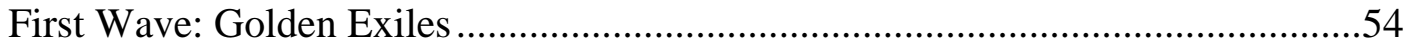

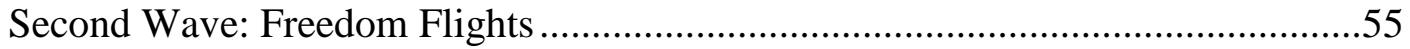

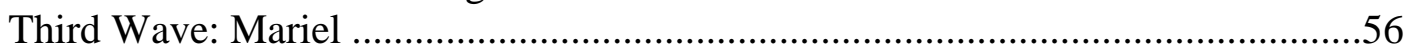

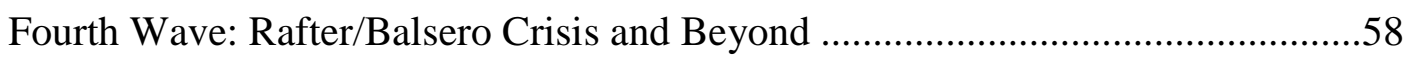

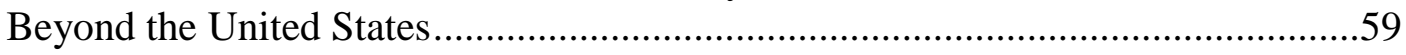

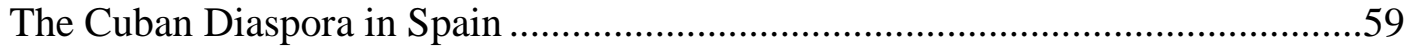

The Cuban Diaspora in a Global Context.........................................................62 
The Post-Revolutionary First Migration Wave: Post-Cuban Revolution and Pre-

German Reunification: Early 1960s to Mid-1990s ................................................66

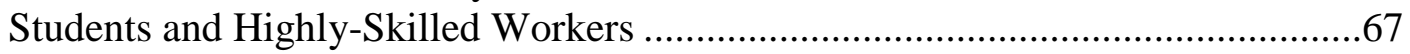

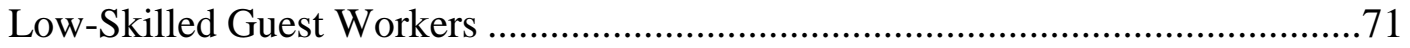

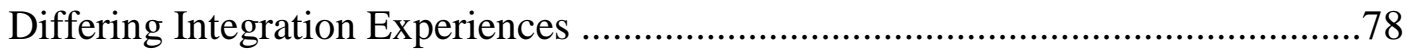

Cuban Returnees: Maybe More Integrated Than They Thought ............................81

Fall of the Berlin Wall and the Second Migration Wave: Post-German

Reunification: Mid-1990s until the Present .................................................... 83

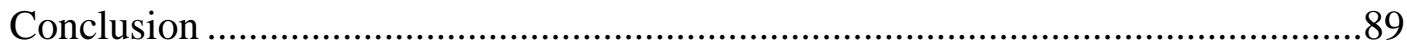

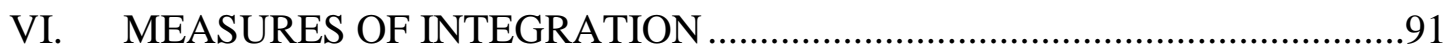

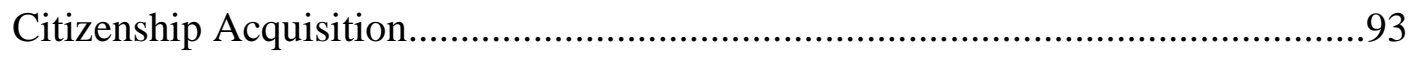

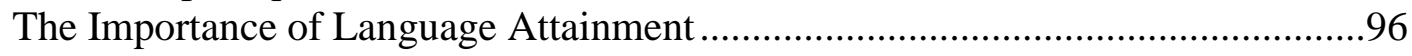

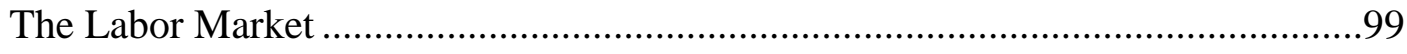

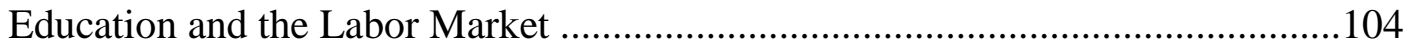

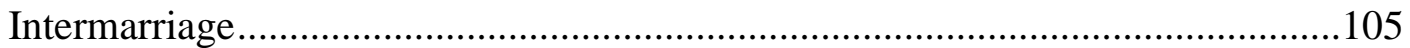

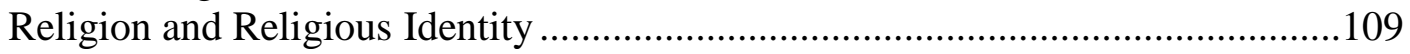

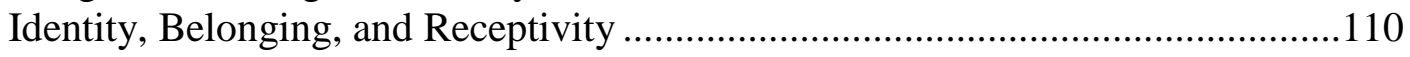

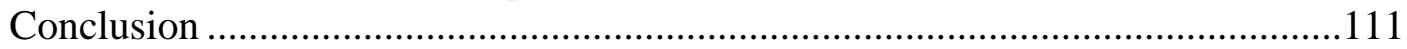

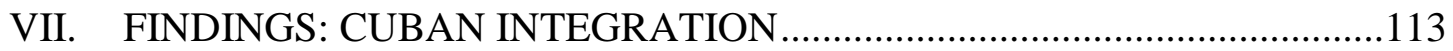

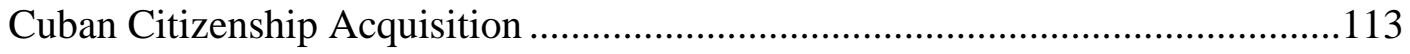

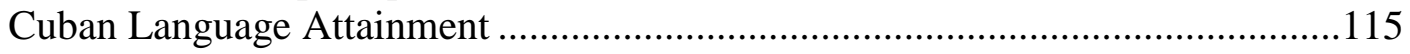

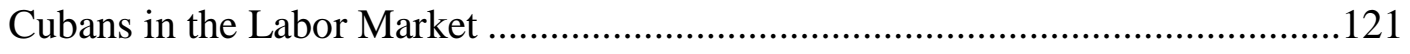

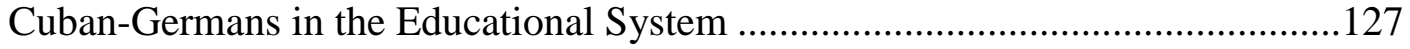

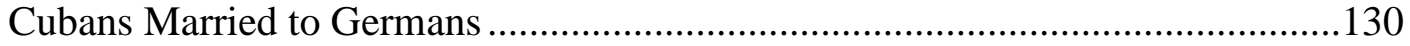

Dating and Marrying a Non-native German Member ...................................... 134

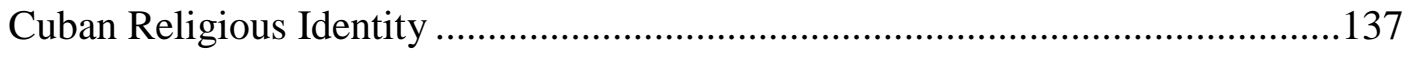

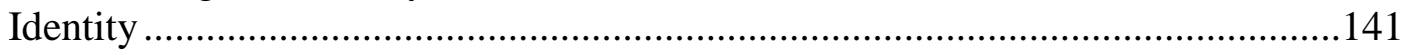

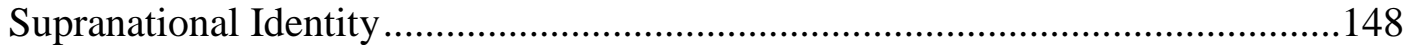

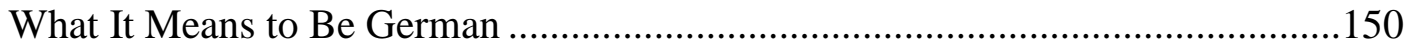

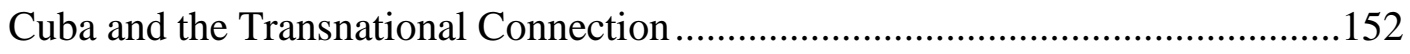

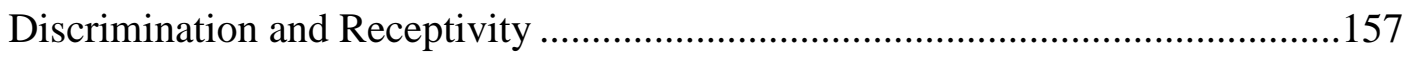

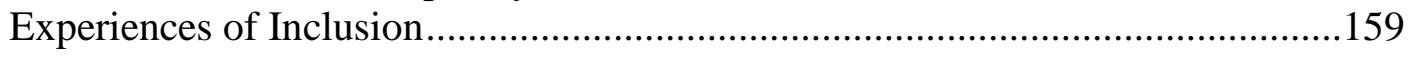

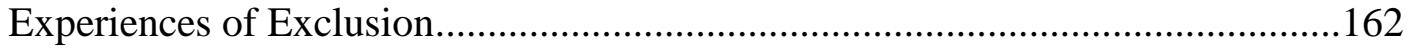

Are Cubans Integrating in Germany? ...................................................... 168

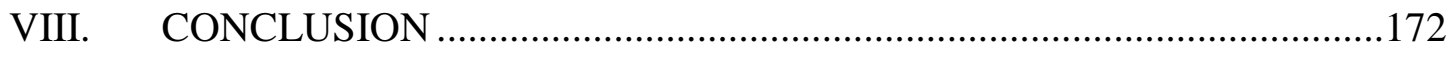

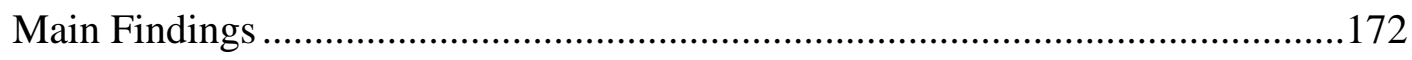

Implications of the Study and Future Research Suggestions ..............................175

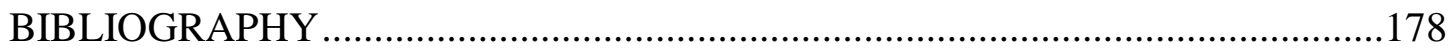




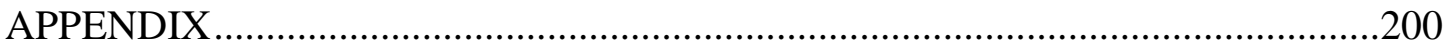

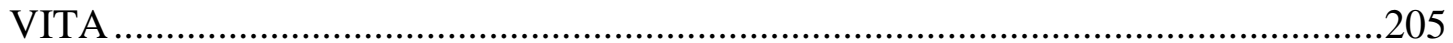




\section{LIST OF FIGURES}

FIGURE

PAGE

1: General Google Search Generated on Cuban Restaurants in Berlin ......................19

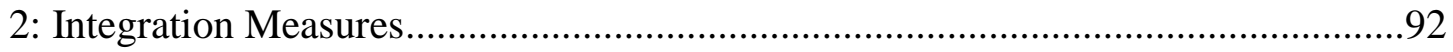

3: Relationship Between Integration Measures .................................................93 


\section{ABBREVIATIONS AND ACRONYMS}

EU

FRG

GDR

IRB

U.S.

WWI

WWII
European Union

Federal Republic of Germany/West Germany

German Democratic Republic/East Germany

Institutional Review Board

United States

World War I

World War II 


\section{INTRODUCTION}

\section{Background}

Immigrant integration has been a popular subject in academia and the media for decades, especially since the mass migration after World War II ${ }^{1}$ (Faist, 1993, p. 306) increased the movement of people across geopolitical borders. This wave of migration has transformed countries of emigration, such as Germany, into countries of immigration (Kurthen, 1995), catapulting integration into the focal point of many academic, political, and societal discussions. Despite the subject's popularity, it has been highly debated across media platforms and political discourse (Boswell \& Hough, 2008; Williams, 2014; see also Kurthen, 1995; Bauder, 2008; Pătrașcu, 2015)

Alongside the miscommunication about immigration that can be found in news and politics, the academic integration literature in Western Europe and the United States has shown significant gaps. While most research focuses on the majority immigrant groups, often missing is the alternative narratives minority immigrant groups present. The goal of this research is to fill in some of the academic gaps while reworking how integration is discussed overall. To contribute to the integration discussion, this research will examine an understudied group that carries unconventional characteristics in one of Europe's most ethnically exclusive states. This study will describe and analyze Cuban immigrant integration in Germany.

\footnotetext{
${ }^{1}$ Will be abbreviated as WWII.
} 
Due to Cuba's relationship with the former Soviet Union, Cuba sent an estimated 56,000 Cuban students to the Soviet bloc between 1961 and 1982, some of whom defected and stayed abroad (Berg, 2011, p. 103). To date, most of the work on the Cuban diaspora has been conducted on the migration and integration patterns of Cubans emigrating to the United States and, to a lesser degree, Spain. The Integration literature on Germany has focused dominantly on the experience of Turkish immigrants, Germany's majority immigrant group. This makes studying Cuban immigrants in Germany a productive task aimed at diversifying both areas of study. In addition, the experience of Cuban immigrants in Germany can say something intellectually different about integration. The metanarrative of integration views Turkish immigrants as fundamentally different from mainstream society and thus incapable of integrating (Boswell \& Hough, 2008, p. 337; see also Verdugo \& Müller 2009; Korteweg \& Yurdakul, 2009; Miller, 2012, p. 55; Çelik 2015; see also Müller, 2001, p. 622; Alba, 2005; Oner 2014). Cubans have an entirely different historical relationship with Germany than does the majority Turkish immigrant group. They are also culturally and ethnoreligious different from the majority immigrant group. Considering Germany's exclusionary history towards foreigners and their identity, studying a group that conflicts with standard views on integration will prove to be intellectually productive. This disruption of thought will contribute to integration studies and will fill in gaps within the immigration literature of not only Germany, but also of the European Union. ${ }^{2}$ Furthermore, while this research contributes mostly to Integration Studies, it will also move forward literature on Identity Studies and

\footnotetext{
${ }^{2}$ Will be abbreviated as EU.
} 
Cuban Diaspora by widening the geographic scope of inquiry as well as the changing context of reception in a historically ethnonationalist state.

\section{Research Questions}

This thesis will contribute to the understanding of the theory and practice of integration of a minority group in an exclusionary state. It is an ethnographic study that explores the lives of Cuban immigrants and their experiences in Germany. Using an ethnographic lens will allow this research to connect the everyday practices of integration of a small immigrant group to wider theories, thus providing a better understanding of integration processes more broadly. The term integration is utilized in this research instead of assimilation because the term assimilation has carried a negative connotation (Glazer, 1993; Brubaker, 2001). Specifically, the term assimilation in Germany, Brubaker (2001) argues, ${ }^{3}$ has been "disqualified by its association with forcible Germanization" (p. 533). Additionally, integration rather than assimilation, is more common within the European academic and public discourse (Brubaker, 2001; Alencar \& Deuze, 2017, p. 152; see also Alba \& Foner, 2016).

Since this project closely investigated the lived experiences of immigrants, it explores how immigrants negotiate and carry out their identities within Germany. In so doing, it builds on similar studies undertaken by Berg (2011), Sperling (2013), and Çelik (2015) who explored immigrant identity and belonging in Spain and Germany, respectively. This project will also contribute to identity studies and build new ground by analyzing the identity politics of Cubans in Germany and evaluating if and how

\footnotetext{
${ }^{3}$ In his article, Brubaker (2001) tries to redefine and reconceptualize the term assimilation and its implication.
} 
the German ethnonational paradigm transforms Cuban identity. Lastly, because of the centrality of Cubans within this project, it also contributes to Cuban Diaspora Studies because it explores the lives of Cubans outside of Cuba who are integrating into a foreign society.

The following research questions guided this research:

1) Are Cuban immigrants integrating into Germany? If so, are they undergoing a similar process of integration in Germany as they have in the United States, in a framework of integration established by the Cold War, and in Spain, where historical and cultural roots run deep? I will measure this via the following criteria:

a) Are Cubans gaining German citizenship?

b) Are Cubans learning the German language?

c) Are they integrating into the labor market?

d) Are they culturally integrating via intermarriage, and/or religion?

2) How are Cubans negotiating their identities in Germany? Are Cubans seeing themselves as "German," or do they still feel like outsiders?

3) Do Cubans present an alternative narrative different from the largest and best-studied group of immigrants in Germany, such as Turkish immigrants, whom are thought to be integrating unsuccessfully?

\section{Overview of the Dissertation}

This dissertation is structured in the following ways. Chapter 1 has presented a brief background and laid out the focus of this study. Chapter 2 will explain the 
research methods utilized in this dissertation and will include my positionality within this study. Chapter 3 reviews the relevant literature focusing on German identity, integration and immigration policies, and will also give an overview of American Assimilation Theories. Chapter 4 examines the Cuban diaspora in the United States, Spain, and globally. Chapter 5 explores Cuban migration to Germany and presents the differing experiences of Cuban students, highly-skilled guest workers, and lowskilled guest workers in the German Democratic Republic. ${ }^{4}$ Chapter 6 will examine the integration measures used in this study. Chapter 7 will then present the ethnographic findings of the research and compare the two main waves of Cuban migration to Germany. The dissertation will conclude with Chapter 8 , presenting the main ethnographic findings, the implications of the study, and future research suggestions.

\footnotetext{
${ }^{4}$ This will be abbreviated as GDR.
} 


\section{METHODOLOGY}

After reviewing my site selection, I will catalog the qualitative methods used in this study, and the reasoning behind their utilization. These include ethnography, open-ended and semi-structured interviews, focus groups, and participant observation. I will then proceed to deconstruct the field experience and identify the main challenges and complications that presented themselves in the field, as well as address how I managed these obstacles. The chapter will conclude by addressing my own bias, positionality, and identity matrix through a self-ethnography. Together, all of this information will explicate the context of the study, providing insight into my research questions and the data presented in later chapters.

\section{Selection of Berlin, Germany as Field Site}

Berlin is a cosmopolitan city with a diversified immigrant population and rich with ethnographic possibilities. Countless future opportunities presented themselves through the presence of Cuban culture in Berlin through music, food, and people. My mother also served as primary inspiration as I realized that she, a Cuban professional who had lived in Berlin and worked in the former Cuban embassy in East Germany as a translator, could bring a wealth of knowledge and connections. A unique opportunity of a rich field, a trusted insider within the community, and my own unique positionality presented themselves. The field itself was limited to a single city for two main reasons. First, logic based on historical analysis and personal interaction dictated that Berlin would present greater chances of recruiting participants. Secondly, the Cuban community has no ethnic enclave in Germany or Berlin (Pérez 
Naranjo, 2014). By ethnic enclave, I utilize Portes and Bach's conceptualization where it is defined as "a distinctive economic formation, characterized by the spatial concentration of immigrants who organize a variety of enterprises to serve their own ethnic market and general population" (Portes \& Bach, 1985, p. 203; see also Grenier \& Pérez, 2003, p. 49). Using this definition of ethnic enclave, Cubans have neither a geographic concentration of co-ethnics nor do they have an ethnic sub-economy in Berlin. Therefore, Cubans are scattered across the city in an unpredictable pattern, from Charlottenburg to Pankow to even outside the city center in Potsdam. Thus, it would have proven extremely time-consuming and unproductive to expand the research to the rest of Germany because of the difficulty of locating and recruiting participants for this study.

\section{Qualitative Research}

This research is a qualitative study, centered on the lived experiences and perceptions of an immigrant group, that combines ethnography, twenty-five one-onone interviews, and three focus groups. I wanted to explore both the exceptional dimensions and the nuances of immigrant integration. This is why qualitative methods were chosen to explore Cuban integration in Germany; they allowed me to engage more intimately with the subject. It is also why I chose to conduct an ethnography. Reeves' (2010) describes the methodology as:

characterized by a naturalistic research approach which seeks to describe a human community or culture, built up of the subjective meanings and perspectives of those people participating in the culture ("introduction", para. 1). 
This is accomplished by spending long periods in the field; observing, recording, and in this case also participating. I took inspiration from several scholars who engaged in qualitative and ethnographic research to explore immigrant populations. Firstly, Berg (2011) used ethnography to tease out the complexities within the Cuban diaspora, specifically in Spain. Berg also engaged in fieldwork across Spain, Cuba, and Miami. Though this research is centered on a single city, Berg's ethnography inspired me to connect different narratives across spaces. Through this inspiration, three participants outside Berlin were recruited. One participant resides in Havana, Cuba, ${ }^{1}$ and the two others in Miami, Florida. They were key to reconstructing the conditions of arrival for Cubans in Germany preunification.

Secondly, García-Moreno (2015), used ethnographic methodology to investigate the paths through which Cuban women enter the labor market in Spain. Her usage of in-depth interviews encouraged the expansion of my semi-structured interviews. Beyond the use of ethnography and interviews, participant observation was also utilized in this research. Thirdly, Lohmeier and Pentzold (2014) used both participant observation and media ethnography. Through these methods, they explored how memories and the media interact and reproduce the collective within the Cuban community in Miami. Although media ethnography was not utilized in this research, it exemplified how to invoke and analyze memory through qualitative methods. Memories and the very action of remembering are essential to this study because they produce an ethno-historical account of Cuban immigration to Germany.

\footnotetext{
${ }^{1}$ This interview was conducted via phone conversation because I was unable to travel to Havana, Cuba.
} 
Additionally, memories and the meaning participants bestow upon them help create a more detailed picture of their paths toward integration. Kuhn (2010, p. 303, as quoted in Lohmeier \& Pentzold 2014, p. 778) argues that "memory work is an active practice of remembering that takes an inquiring attitude towards the past and the activity of its (re)construction through memory." This study thus allowed the theorization of ways to reveal and analyze participants' memories through qualitative methods.

Furthermore, I was also motivated by Sperling (2013), who studied the children of Latin American immigrants in Spain and their identity. I noted Sperling's advice when she urged:

These findings thus support the importance of examining identification at multiple geopolitical levels in migration and integration research, and indicate the need to consider supranational identity as a possible means of belonging (p.79).

It deeply inspired me to explore questions of national and supranational identities as they relate to integration. It also inspired me to analyze the importance of a hyphenated identity (Cheng, 2004). The most productive way to deconstruct the fluidity of transnational identity and integration is through an open conversation. An open conversation allows for "mind wandering" (Smallwood \& Schooler, 2006; 2015), encouraging participants to explore their complex thoughts and feelings regarding their own experiences.

Thus, to uncover the intimate feelings and perceptions of the participants, qualitative methodology was employed. The multifaceted answers the participants gave could only be encouraged and facilitated through qualitative methods such as interviews with open-ended questions. Quantitative methods, although not lacking their own merits and usefulness, would only constrict the flow of information within 
this ethnographic study. The only time quantitative methods were utilized in this research was when creating a visual representation of the participants' demographics to illustrate the sampling pool. Thus, quantitative methods were used to illustrate the data gathered rather than gathering the data through it. As Smallwood and Schooler (2015) argued, "mind wandering provides a clear paradigm in which to understand their psychological features" (p. 489); thus, methods such as closed-ended questions would only hinder the ethnographic process. From the language and terminology the participants used, to how they interacted with me, to even where they placed an emphasis in their stories, is a narrative in and of itself. A narrative that, without qualitative methods, I would not have been able to discover. The way a German-born and raised participant referred to Germans as "they/them" rather than "we/us" spoke louder than any quantitative data could.

\section{Recruitment}

For this research, I used snowball sampling, convenience sampling, and purposive sampling. The sampling criteria included being Cuban and Cuban-German of first, 1.5, and second-generation immigrants, and of adult age. First generation means the participant was not born in Germany and immigrated after adolescence. Generation 1.5 (Rumbaut, 2004) signifies that the participant was not born in Germany but immigrated before adolescence. Finally, second generation denotes children born in Germany of immigrant parents. Cubans began immigrating to Germany around the 1960s, with the second wave occurring during the 1990s (Pérez Naranjo, 2014), making third-generation Cuban immigrants minors. Minors are not only less easily accessible as research subjects but are also not the focus of this 
research. Instead, this research sought to explore the migratory trajectories and integration experiences of adults. I also selected individuals that resided in Berlin except for three participants. These three individuals, two living in Miami and one in Havana, were significant in gathering data on the process of migration during the Cuba-Soviet Union bilateral agreement. One participant lived in the former GDR while the other two lived in Poland but traveled often to the GDR and were closely involved with the guest worker selection process for the Soviet bloc and behind the scene politics. In total, 25 people were interviewed in this study, with 21 participants residing in Berlin. The next section will explore the sampling methods.

\section{Sampling}

The primary mode of sampling was in the form of snowball sampling that began with people I knew. As an insider in the community-a position I explain in more detail below - I had already established connections through friends and family. Regardless of whether they were viable participants themselves, I asked them to recommend and introduce me to other potential participants. Having a connection to the community facilitated my entrance and introduction into the field, as some scholars have suggested (Wilkes, 1999; Duke, 2002; Reeves, 2010). I relied on two primary gatekeepers who in turn started two nodes of snowball sampling. The first gatekeeper is a Cuban-German male college student who was born in Cuba but raised in Germany with a Cuban mother and a German father. He immigrated to Germany when he was less than a year old during the late 1980s and was raised within the German educational and cultural system. This made him a gatekeeper with access to 
the German, Cuban, and German-Cuban domains. Also, as a college student, he had access to students, the young, and low-skilled worker ${ }^{2}$ population. The second gatekeeper is a Cuban female in her mid-50s who arrived in the former East Germany in the 1980s. She was born and raised in Cuba but studied the German language at the university and was a highly-skilled worker during the guest worker era. She has a strong connection to Cuba, but after years of living in Germany and having its culture at the center of her extensive studies, she acted as a unique contact. She provided access to older professional Cubans, most of whom immigrated during the Soviet control of East Germany and was a vital historical point of reference. Through these two gatekeepers, connections were expanded and began several other nodes of sampling.

Convenience sampling and purposive sampling were also utilized. Through convenience sampling, I met potential participants through participant observation and daily interactions in Berlin. As I walked the city, potential productive spaces for this study were surveyed. At some serendipitous moments, I came across Cubans in my everyday life. There were moments when I was shopping in Kaiser's market $^{3}$ or dining in $\mathrm{KaDeWe}^{4}$ and I overheard someone speaking Spanish and decided to strike up a conversation. To my surprise, some of these individuals were Cuban, and I was able to introduce myself and have an informal conversation. A formal interview with the participant I met in KaDeWe was conducted and in turn she introduced me to

\footnotetext{
${ }^{2}$ For example, some of the low-skilled workers that he personally knows include bartender and fastfood employees.

${ }^{3}$ Grocery store chain.

${ }^{4}$ Multi-floor mall that has specialty stores and is often on the affluent side of indulgence.
} 
another Cuban who worked at the mall. Through convenience sampling, the sampling pool was diversified with completely unrelated third-party members. In terms of diversity, purposive sampling (Grossoehme, 2014) was additionally utilized to vary the sample pool of participants. At one point in the research, a considerable number of formally-educated, white individuals, aged 50 and older dominated the demographics of this sample. Logically, this was because the people the second gatekeeper associated with on a regular basis are of similar demographics as her. Also, at this point in the research, the second gatekeeper was most active in introducing me to potential participants. This created a skewed sample early in the research. To remedy this, I became selective to ensure I was representing the spectrum of Cubans in Berlin. I attempted to recruit participants via the Facebook group "Cubanos en Berlín." Although recruitment in the Facebook group did not generate participants, it made me aware of activities happening in Berlin by Cubans. Although this study was unable to equally represent all of the demographic variables (such as age, sex, or race), it still achieved a diverse sample. ${ }^{6}$

\section{Interviews}

Through participant observation, I noticed patterns of interaction that prompted me to add questions to the interviews about meaningful relationships in

\footnotetext{
${ }^{5}$ This group is made up of Cubans in Germany who want to stay connected and stay aware of different Cuban activities that are happening in Berlin.

${ }^{6}$ It is important to note that although I was mindful of demographics, I did not make them the center of this study. This is because this research is on immigrant integration primarily based on national origin which renders an in-depth look at gender, sex, race, and sexuality in terms of integration in Germany beyond the scope of this research.
} 
Berlin and the demographics of their peer groups. Then through the interview process, I allowed a natural progression of topics even if they veered from my questions. Additionally, inspired by grounded theory (Glaser \& Strauss, 1967; see also Grossoehme, 2014), I had the opportunity to seek out more interviews, but decided to stop at twenty-five one-on-one interviews and three focus groups (discussed below). This decision was partially because of time and financial constraints. Having limited funding and a timeline that I had already extended, more time in the field was unattainable. More importantly, as grounded theory suggested, the results became saturated as the information acquired reflected similar viewpoints, and nothing overtly new or innovative was recorded (Morse, 1995; 2015; see also Grossoehme, 2014).

I also conducted semi-structured interviews. This format gave participants the freedom to explore the questions and topics I presented them while providing a structure to rely on. I was able to build on my previous knowledge and acquire a new perspective on the situation by letting the participants explore their thoughts and introduce new topics of conversation. However, I introduced parameters within the conversations when I deemed they were veering into tangled and unproductive directions. As the interviewer, I aimed to tease out information but also to direct the conversation within the borders of the research. Using a semi-structured interview gave the participants both freedom and direction (Grossoehme, 2014). I began the semi-structured interviews by introducing myself and establishing rapport (Springwood \& King, 2001) with the participants. I supplied each participant with an 
IRB ${ }^{7}$-approved confidentiality agreement and an outline of the research and interview to be conducted. The forms were available for the participants in whichever language they chose. All interviews except one were conducted in Spanish, and thus each confidentiality agreement was distributed in the preferred language. Most preferred to speak in Spanish because it was their native tongue and/or they felt at ease speaking with me in Spanish. Some words or phrases were spoken directly in German. One of the participants preferred to conduct the interview mostly in English, with some words/phrase spoken in Spanish and German. Language is intimately connected to memory and emotions; thus, it was interesting to witness the change in language during certain points of the interview. None chose to conduct the interview in German.

After the formalities, I began asking the participants demographic questions to set up the interview process (see Appendix A). These questions were important because they gauged a wider picture of the sampling pool within this research. ${ }^{8}$ They also established a base of reference for the different paths of integration. I decided to design the questions on ethnicity and nationality as open-ended questions rather than as closed questions because I was more interested in how and why rather than the what. I then began asking semi-structured and open-ended questions (Kracl, 2012). They were intended to begin the conversation and establish a parameter to ensure exploration of the research questions. The participants were encouraged to explore these conversations in depth or move on to other topics of memory or sentiment that

\footnotetext{
${ }^{7}$ Institutional Review Board.

${ }^{8}$ See Appendix B for the demographic characteristics of the participants.
} 
were inspired. Nevertheless, I also used these questions as guidelines and script to steer the conversation within the bounds of the research and avoid unproductive tangents (see Appendix C).

\section{Focus Groups}

I developed the interview questions as mainly open-ended to tease out the complexities of integration, but I was now charged with the task of narrowing some of the wider broached topics and their meaning. Besides one-on-one interviews, I used three focus groups as inspired by Valdez, Padilla, and Valentine's study (2013). Within their investigation, they explored the collective perceptions of undocumented Mexican immigrant mothers concerning immigration policies. Within the focus groups, the participants were able to build on the synergy of others and add new elements to the discussion. I decided to engage in focus groups ultimately for that very reason. The duration of each focus group varied, but they lasted from two hours and 33 minutes to four hours and 15 minutes. The questions were similar to those asked in the one-on-one interviews except they were broader in context and were meant to clarify and expand on the answers given. Hence, instead of asking, "Are there areas or neighborhoods in Berlin where you feel unwelcome?" I now knew about the situation in Marzahn from answers given by earlier interviewees. I now questioned, "Tell me more about Marzahn. Have you ever had any discriminatory experiences there? Do you feel more or less comfortable talking in Spanish, for example, in Marzahn than in this neighborhood?" ${ }^{\prime 9}$ Additionally, having different

\footnotetext{
${ }^{9}$ The place where this sample question was conducted was a restaurant in Kurfürstendamm, most commonly known as Ku'damm in Charlottenburg-Wilmersdorf.
} 
perspectives on a subject allowed for greater expression of thought. I had a participant say, "Cubans here in Berlin don't like to get together," with a follow-up answer of "I'm not sure why" when asked to clarify. In the focus group, through group collaboration, explanation for the lack of camaraderie between Cubans in Berlin emerged. The two most prevalent causes were intragroup distrust and lack of community. Moreover, I initially intended to select participants at random for my focus groups. During my participant observation and interviews, I realized, however, that topics emerged among certain individuals that I felt could only be expanded if I placed them together in a focus group.

\section{Navigating the Interviews}

During the interviews, I also asked to clarify certain points and to expand on others. Originally, the interviews were scheduled to last an hour and a half to two hours. Practically, the time spent on the interviews was completely up to the participants, and they had exclusive rights as to when to start and end their interviews. When the interviews ran over the two-hour period, I asked the participants if they wanted to continue and reminded them the interview could end whenever they wished. I believe the success of these interviews was due to availability, atmosphere, and rapport. I will explore these three variables in greater detail later in this chapter.

\section{Participant Observations}

To supplement my interviews and focus groups, I utilized participant observation, motivated by Malinowski (2004) and Geertz (1973), as one of the 
qualitative methods used to investigate Cuban immigrant integration in Germany. Timseena (2009) defined participant observation as "a process and method of looking at other's cultures with native eyes. It is a process of long-term immersion in the daily lives of native peoples, which creates real and new information" (p. 75). I absorbed myself into the field as both an observer and a participant in the everyday lives of Cuban immigrants in Berlin. This helped not only create the groundwork for analysis and rapport for the interviews, but it also facilitated my navigation of the field. During participant observation, I recorded observations in written field notes that were both descriptive and reflective. The primary sites of participant observation involved bars, restaurants, and other public spaces frequented by Cubans, and public festivals.

Additional sites of participant observation involved everyday activities. I first became acquainted with Berlin's cultural landscape by walking around the city and taking note of any places of cultural significance. In Berlin, walking is a favored method of transportation, and it is a cultural marker for the residents of the city since "walking around is fundamental to the everyday practice of social life" (Lee \& Ingold, 2006, p. 67; Pink, 2008). I set out to establish a personal bond with the city and its residents. I trekked the city with both purposeful direction and without a due course in mind. Figure 1 shows an initial Google search of Cuban bars and restaurants in Berlin. Some of the establishments were within walking distance of my place of residence, but others were further away, requiring the use of the metro/taxi. I noted that some establishments were not particularly Cuban nor did they have any observable Spanish-speaking population; thus I moved on to the next place. 


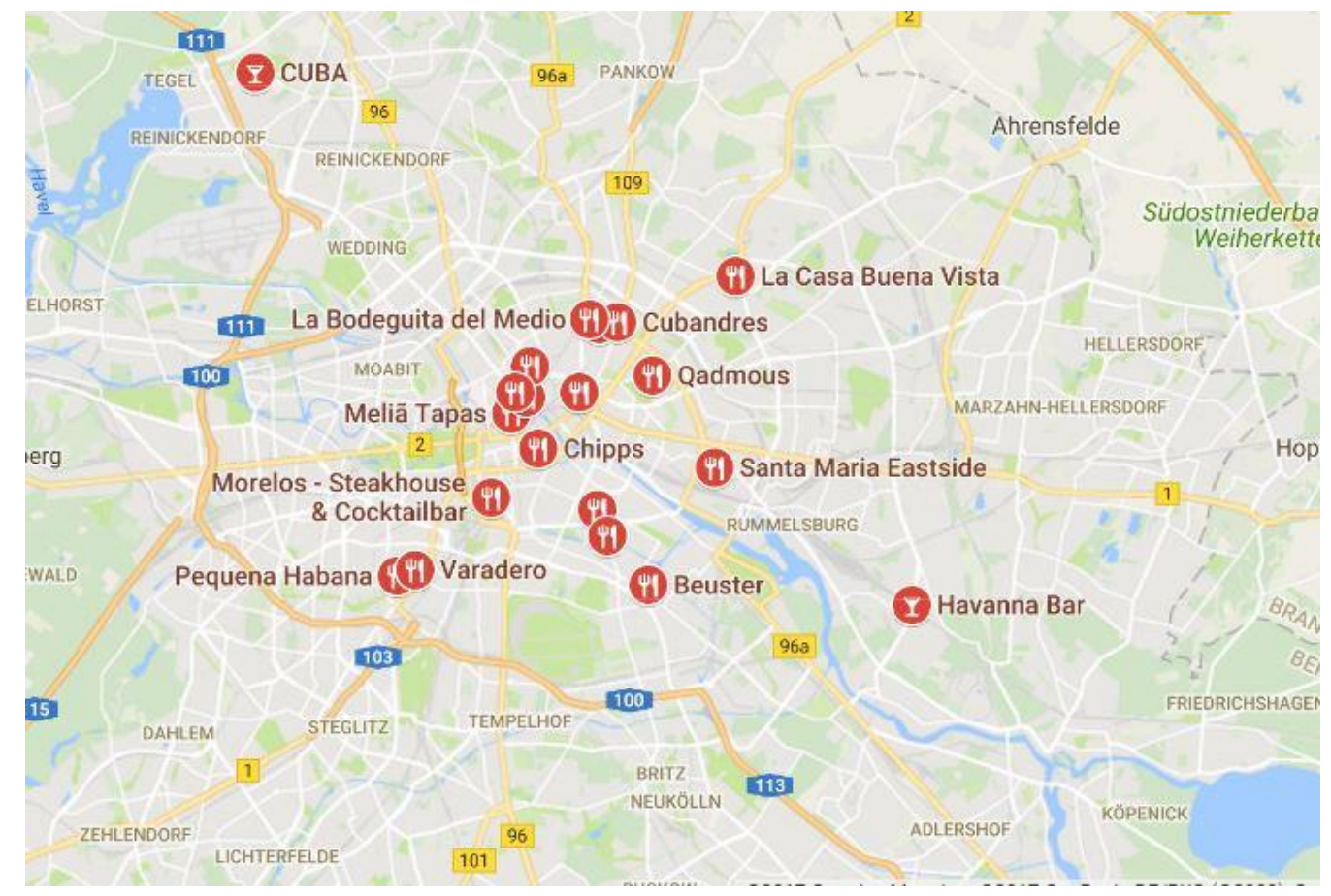

Figure 1: General Google Search Generated on Cuban Restaurants in Berlin

The bars and restaurants in which I chose to conduct participant observation were either owned by Cubans or employed Cubans. For example, Varadero is a Cuban restaurant that is both operated by and employs Cuban immigrants in Germany, while one of the QBA restaurants is operated by a non-Cuban individual ${ }^{10}$ but employs a mix of Cuban and Turkish workers. I visited and observed five Cuban restaurants in Berlin and two bars that were German/international ${ }^{11}$ but employed Cuban immigrants. I spent around two to three hours during each visit in each place, with one visit lasting over four hours.

\footnotetext{
${ }^{10}$ I was not clear on who owned this establishment. However, one participant did vaguely state that an Indian-German man owned it.

${ }^{11}$ Not shown on map.
} 
Besides places of business, I conducted participant observation in public spaces. Guided by insiders in the community and through my exploration of the city, I found a specific location of Cuban communal interaction. In Alexanderplatz near the World Clock, ${ }^{12}$ Cuban immigrants, predominantly male, are prone to gather and share stories and drink alcohol with one another. Pérez Naranjo (2014) explains that this space was popular among workers during the GDR and that Cubans now "meet there to exchange information concerning procedures to follow in Germany or to discuss about current Cuban affairs" (p. 142). Further participant observation also took place in festivals and outside markets, where I found stalls run by or employing Cubans. For instance, I attended an antique car festival where a Bacardi stall employed a Cuban bartender who had recently immigrated to Germany. The stall employees wore Hawaiian shirts and straw hats that tried to mimic "traditional" Cuban outfits, suggesting the German caricaturizing of Cuban culture. The stall also played Spanish salsa music playing and was popularly frequented. I was not able to formally interview the worker because he was working at the time and never called or emailed to meet with me after I introduced myself and gave him my business card. Regardless, it gave me a preliminary sense on the German perceptions of Cubans and how Cubans negotiated their identity within the German labor market.

I did avoid the Cuban Embassy in Berlin and any associations that might have had a political leaning because I wanted to distance myself from the Cuban government and Cuban politics. Otherwise, it would have created misguided feelings

\footnotetext{
${ }^{12}$ An aesthetic and cultural landmark in Berlin that shows the time across different countries in the world.
} 
and distrust among some of the participants. I actively navigated away from Cuban politics to avoid the response that Berg (2011) received when a participant thought she was "an agent of the Cuban government" (p. 35). In the end, I found that my efforts were successful partly because of my strategic avoidance of political associations and because Cubans in Germany tend to distance themselves from the politics of Cuba. $^{13}$

\section{Field Notes}

I kept track of the observations by taking copious field notes. ${ }^{14}$ I diligently wrote down a synthesis of the interactions and mental notes that I wished to further investigate. I registered any observations that seemed significant in my analysis, from actions, to language, even to restaurant decoration. Besides noting evident and significant details, I also noted obscure interactions and situations. Most of the ambiguous annotations did not produce any significant analysis for this investigation. On the other hand, some observations that did not seem significant at the time emerged as important after I coded the interviews. In one Cuban restaurant where a variety of immigrants from different national origins had gathered, I noticed the Cuban workers were speaking a mix of both German and Spanish. I highlighted this situation in my notes and labeled it simply as code-switching. ${ }^{15}$ As an insider in the

\footnotetext{
${ }^{13}$ Exceptions to this trend included a participant mentioning several Cuban political clubs and groups present in Germany, but they are not significant for most of my interviewees.

${ }^{14}$ I avoided the extensive use of a recorder as I found early on that it tainted the open conversations and participants started guarding their words.

${ }^{15}$ In which bilingual or multilingual speakers engage in the act of switching between languages in a conversation.
} 
community and because I was raised in a household in which multiple languages were regularly spoken, I was satisfied about its normalcy. At the time, I did not notice anything besides the fact that the Cuban immigrants in this restaurant were fluent in both German and Spanish. As Reershemius (2011), a sociolinguist, notes, "oral bilingual practices occur on a semi-conscious, intuitive level in interaction" (p. 386). The proclivity to fluctuate through the semi-conscious between both languages was noted as a positive marker of successful integration.

Nevertheless, after coding and reviewing all the interviews, I discovered that the switching between both languages in this situation was not usually semiconscious on the part of informants, but intentional. I noticed a correlation between the language being spoken and the social interaction between Cubans and other immigrants in Berlin. It appears that there is a sense of distrust and competition between Cubans and other immigrants, especially in the labor market. The Cuban waiters in the restaurant would speak German to both the patrons and fellow immigrant employees but would only speak in Spanish with each other. The conversations in Spanish, I noticed, were usually more private than the conversations in German, which were more professional. I also noted that when I was speaking with a Cuban waiter in Spanish she quickly switched to German or stopped talking when a non-Cuban worker approached us. I later correlated this to an earlier conversation where she acknowledged the tension with the non-Cuban employees and explained that "the cook es acomplejado." ${ }^{16}$ The decision to speak in either language was rooted in strategy and cultural paradigm rather than simply bilingual tendencies.

\footnotetext{
16 Translates to "complexed".
} 


\section{Safety within the Field}

I conducted the fieldwork, including participant observations and interviews, in public and semi-public spaces. These spaces included either a café or a restaurant for two main reasons. The first was my personal safety as the ethnographer (Sluka, 1990; Williams, Dunlap, Johnson, \& Hamid, 1992) within the field. As a young female ethnographer conducting these interviews in a foreign city, I took certain precautions to ensure a degree of safety (Easterday, Papademas, Schorr, \& Valentine, 1977). The ability to meet in a semi-public place that also had quiet atmosphere was conducive to feelings of safety, not only for myself but also for participants. As uneasy as I felt about meeting people I did not know, the feelings were likely mutual for the participants. Taking advice from Williams et al. (1992, p. 347), although I was not in a violent location, I created a "safety zone". I established these zones through several techniques. I first made sure to meet in neighborhoods I was familiar with and in cafés or restaurants near my residence. If they were too out of the way for the participants and they preferred another restaurant or café, I made sure to research the place and the area surrounding it beforehand. I also tried to let a family member or colleague know where I would be on that specific day if it was an unknown or distant location. The interviews conducted in someone's home were with participants I knew or close friends of people I know. Because of this previous contact and assurances about their character, I felt safe enough to interview them in their homes.

I heeded the advice given by Sluka (1990) and Williams et al. (1992) to ensure safety in the field. I re-familiarized myself with official emergency numbers, the U.S. Embassy, and German emergency procedures. I made sure to travel the city 
and become acquainted with the field on a personal level through everyday practices. As I ate breakfast or dinner, I extended my introduction by starting conversations with the waiters and locals whenever welcomed. Through this familiarization, not only did the local community became acquainted with me but also with the fact that I was a non-threatening graduate student, which allowed them to give me advice and help. Becoming familiar with the field and the local population allowed me to not only facilitate recruitment of participants but also created safety nets in a foreign city. Furthermore, these points of contact with the locals helped me map out the city, alerting me to dangerous spaces. Besides avoiding these spaces, I made sure that if I did find myself in one, I took precautions.

\section{Being Female in the Field}

Besides becoming well familiarized with the field, I also had to engage with my own gender identity within the field and how I negotiated my access. Inspired by female ethnographers who have critically assessed their own gender and sex within the field (Easterday et al., 1977; Warren \& Rasmussen, 1977; Bell, 1999; Lee, 1997; Perrone, 2010; Purdy \& Jones, 2011; Bucerius, 2013; Pante, 2014), I realized I had to address the position my gender placed me in. As a female in the field, "the threat of sexual assault or rape is a real concern for most female ethnographers" (Williams et al., 1992, p. 363; Perrone, 2010, p. 718; see also Lee, 1997). Besides conducting most interviews in semi-public spaces such as restaurants, I asserted and reinforced my position as an academic as the most prominent marker for my identity through my title and clothing as various scholars have brought up (Williams et al., 1992; Lee, 
1997; Perrone, 2010; Pante, 2014; see also Warren \& Rasmussen, 1977). If the participants did not know me, I introduced myself as "Professor Ana Rusch" or as “Doctoral student Ana Rusch,” only allowing my first name to be used informally when rapport had been established. I dressed not only professionally, but I also made sure to wear clothing with my university's insignia or name on it to reinforce my status as an academic. As Pante (2014, p. 70) mentioned, "Some men tend to foreground one's status as a 'female' rather than a 'researcher'." Therefore, a sweater, zip-up jacket, scarf, pin, or even a pen or notepad engraved with my university's logo was always present in the interviews. I also kept my long blonde hair, a performative and socially constructed feature of femininity, up in a bun or under a winter hat.

In terms of approachability, Perrone (2010) and Warren and Rasmussen (1977) suggest wearing a wedding ring to visibly attest to your unavailability. Although this is helpful advice, I did not do so because I was familiar with many of the participants and they knew I was not married. I feared that lying about being married might negatively impact our rapport if the participant had heard otherwise. I did, however, make it known that I was unavailable and, in a relationship, if I was asked. I also utilized Perrone's (2010) sense of space and intuition; she ceased interviewing certain participants and visiting certain spaces when she felt unsafe. I referred to her study when I encountered the area in Alexanderplatz frequented by Cubans. Since it was a social atmosphere fueled by alcohol and a space occupied by men primarily, I felt insecure there. Instead of using this site for recruitment, I merely engaged in non-participatory observation (Gold, 1958). 
I want to emphasize that my gender ${ }^{17}$ did not deter or interfere with my fieldwork or my role as ethnographer. Bucerius (2013), who engaged in an ethnography involving drugs and criminal activities among male immigrants in Germany, reported that being female did not impede her research. On the contrary, Bucerius (2013) noted that being female in the field can be beneficial. I was viewed as "non-threatening" (Pante, 2014, p. 71; see also Easterday et al., 1977; Warren \& Rasmussen, 1977, p. 361) partly because I was female. I utilized this to the benefit of the study because it provided me with greater access and rapport with participants. Moreover, although I am female, older participants at times desexualized me because I reminded them of their daughter or a niece. Just as Soyer (2014; see also Pante, 2014) used her position as a mother to establish rapport and instill a sense of trustworthiness and reassurance, I too utilized my participants' sense of familiarity. Being female in the field was something I had to be cautious and reflexive of, but it did not negatively affect my research. Instead, it benefited me because it facilitated my access into the field and the participants' lives.

\section{Controlling Interactions and Environment}

I developed my schedule entirely around the participants' schedules and allowed them to have control of the time and date they wished to meet with me for their interviews. The atmospheres I strategically picked were also highly conductive to the success of the interviews. Since they were mostly in cafés and restaurants, with some conducted at their residences, it created a sense of contentment. I found that

\footnotetext{
${ }^{17}$ I also did not find that being white made any significant difference conducting my fieldwork in this particular project. However, race, just as sex and gender, are important subjects to discuss when conducting fieldwork research in terms of self-reflexivity, access, and safety.
} 
spaces that revolved around food or comfort such as a home decreased a participant's exhaustion and increased comfort and familiarity between us. Germans hold leisure time in high regard; thus, social and calming places allowed for extended interviews. Spaces such as offices ${ }^{18}$ resulted in shorter interviews.

Besides the environment, I was careful to mold my rapport with the participants of this study because it would define the success of the interviews. I began by stating that I was a student and described my academic background. I was then careful to announce that I was in no way affiliated with the Cuban or German governments. I sensed early on that participants who had recently immigrated to Germany were hesitant toward me. As Purdy and Jones (2011) stated in their study, I reassured the participants that "I was not there to judge, just to record and try to understand" (p. 298). There is a collective memory or rather collective fear ingrained in the Cuban state of mind that creates suspicion of spies, or as one of my participant termed, "chivatos."19

The fact that researchers are confronted with these suspicions in the field is not new. In fact, Sluka (1990) argues that "perhaps the most common suspicion that subjects have about anthropologists is that they are spies of some sort" (p. 115). Pérez Naranjo (2014) also experienced it with Cubans in Germany (see also Berg, 2011). Besides emphasizing my status of an academic, I mentioned although I am CubanGerman, I am also an American graduate student. My identity as an American eased

\footnotetext{
${ }^{18}$ Offices that function as spaces in which to conduct work, either a home office or an office in a public employment setting.

${ }^{19}$ Translates as informer or sneak.
} 
the participants' fear that I had any affiliations with either the Cuban or German government. As Bucerius (2013) wrote, certain aspects of a researcher's identity will be more or less noticeable as the research evolves. At certain times, I was an insider because I was Cuban-German and at other times, I was also as an outsider as an American graduate student. I was either/or and both at the same time during my fieldwork, and I negotiated my access depending on which aspect of my identity put the participants more at ease. I could modify my status of insider, outsider, and "the space between" (Dwyer \& Buckle 2009, pp. 60-62) through the complexity of my own positionality.

\section{A Note on Positionality}

As a Cuban-German, I have a unique insider perspective that grants me a special rapport with Cubans in Germany since I am familiar with their linguistic markers and cultural symbols. I did not conduct any of the interviews in German (all but one in Spanish), often using common Cuban phrases and citing collective memories that forged a bond between myself and the participants. The participants were immediately put at ease when I introduced myself as a Cuban-German and a Ph.D. student from the United States. Being an insider provided me with many advantages beyond the initial trust with the participants. Bonner and Tolhurst (2002, pp.8-9) recognized that being an insider means "having a greater understanding of the culture being studied", "not altering the flow of social interaction unnaturally", and "having an established intimacy between the researcher and the participants which promotes the telling and judging of truth". Nevertheless, bias and difficulty being objective have been cited as disadvantages of being an insider (DeLyser, 2001). Bias 
and subjectivity are risks that any researcher, either an insider or an outsider, will encounter. As Grossoehme (2014) states, "Qualitative investigators are not disinterested outsiders who merely observe without interacting with participants, but affect and are affected by their data" (p. 110). Coming from both a Cuban and German background, I was able to thoroughly understand and differentiate between personal and impartial statements. Moreover, as someone raised in the United States, my American identity and positionality acted as buffers against bias. This is because, as an American, I am not fully engaged in the emotional and intimate politics of being a Cuban in Germany. Rather, being an American and an academic provided another aspect to my identity that nurtured an outsider perspective. This secondary perspective allowed me to take a step back and analyze the situation as impartially as possible.

In the following section, I will present my own self-narrative, not only to address any bias but to further explain my positionality. I present my own experiences and complex identity to provide transparency for my readers. Moreover, exploring the intimate experiences of the ethnographer as an insider and also an outsider will illuminate the correlation among integration, societal perception, and selfidentification.

\section{Identity, Integration, and Self-Perception}

My first languages were Spanish and German. However, when we moved to the United States, my family viewed learning English as a priority. I was only allowed to watch English language channels on television in order to facilitate 
English language acquisition. I jokingly credit The Simpsons and Star Trek Voyager as the programs from which I learned English. We always had Spanish-English dictionary next to the television and looked up words that we were unfamiliar with. I actively remember learning English as I translated what was happening on the episodes of Star Trek Voyager for my grandmother. I learned the English language primarily through American popular culture, reinforced through the school system and my peers. Before I knew it, English became my dominant language and though I integrated into the American mainstream successfully, I still considered myself Cuban.

The problem was that Cubans in Miami did not always see me as Cuban. My Spanish was slightly different from the regular Cuban-Spanish. This was not only due to my primary use of English, but because my maternal family's Spanish is influenced by my grandmother's Asturian ${ }^{20}$ dialect. Also, because I immigrated to the U.S. at such an early age, my integration into the American mainstream was almost seamless; thus, my mannerism and cultural traits were often different from other Cubans. Even when others my age had a quinceañera,${ }^{21}$ the idea was foreign to me. Instead, I chose to have a Sweet Sixteen ${ }^{22}$ birthday dinner-party. What was fascinating, though, was that instead of seeing me as American, Cubans in Miami saw me as German. One of my uncles even lovingly nicknamed me La Alemana, ${ }^{23}$ it

\footnotetext{
${ }^{20}$ My maternal grandmother's family is from Luarca, Asturias, while my maternal grandfather's paternal linage is from Spain and his maternal linage is from Cuba.

${ }^{21}$ A coming of age celebration held on a girl's $15^{\text {th }}$ birthday and celebrated across Latin America.

${ }^{22}$ A coming of age celebration held on a girl's $16^{\text {th }}$ birthday celebrated in the United States.

${ }^{23}$ Translate to "The German."
} 
caught on, and soon friends, family, and even neighbors began calling me that. Since I was born a redhead, my skin was pale, and I had a German last name, I embodied the common perceptions people had of Germans. It is also what made me feel different from other Cuban Americans. Every time I received a good grade, made the honor roll, or even arrived early for an appointment, I was presented with porque ella es alemana. ${ }^{24}$ I performed the stereotype that Germans are intelligent, polite, and punctual.

I remember a moment in high school when one of the Physical Education coaches was in her office with the door open; I knocked on the door frame and asked if I could come in. The coach looked stunned for a second, and asked me, "Why did you knock? The door is open." I responded that I did not want to be rude and enter her office without an invitation. She then abruptly asked, "Where are you from?" I told her I was from Cuba, but she looked at my school identification tag and asked, "Where does the 'Rusch' come from?” I responded that I was also German. "Ah, now I see," she said, as if the fact of me simply being German suddenly made sense in regard to my manners and upbringing. Similarly, one of my Cuban-German participants in this study articulated the stereotypes Cubans have toward Germans:

Cubans think Germans are more intelligent like if they were "una raza pura." 25 I was also told I was better because I was half German. They mean it as a compliment but it is so stupid and incorrect! If you say one side of me is better then you are saying the other side of me is worse.

\footnotetext{
${ }^{24}$ Translates to "because she is German." Some words or phrases are kept in the original language and not translated in the text but only in the footnote because they may lose the intended meaning or emphasis during translation.

${ }^{25}$ Translates to a pure race.
} 
He explained that Cubans tend to regard Germans in a positive light. This essentialism has produced feelings of frustration and confusion for Cuban-Germans. As explained by the above participant, a positive remark directed only toward our German side automatically insulted our Cuban side. I felt uncomfortable when the physical education coach relegated my manners to my German ethnicity and it was not until I engaged in this research that I realized why. In that statement, my mother, who is one of the most accomplished, independent, and intellectual women I have ever known, was deprived of her merits. Everything good about me is because of my mother and her family whom raised me, yet more often than not it was attributed to the perceived inherent characteristics of the German ethnicity. The participant's statement expressed a perception that relegated German ethnicity into a racial category, further enforcing an ethnonationalist inscription of the German identity.

At the same time, I was never German enough to be accepted as German by German standards. Even though I feel most German in Miami, I feel most Cuban when I am in Germany. I am not a native German speaker and I speak German with a thick American accent. I also have different mannerisms than native Germans and the way I perceive certain situations vary from my German peers. My Cuban identity was also a marker of difference in Germany. Both groups marginalized me as I was different from native Cubans and Germans. This sense of marginalization by both groups echoes the feelings of most Cuban-German respondents in Germany. Just as I could not seem to reconcile my Cuban and German identities, the Cuban-German participants of this study struggled with their dual identities. 
The greatest difference between myself and the Cuban-German participants of this research is that I identify strongly with a third identity. Just as I was different from Cuban Americans in Miami because of my German ethnicity, I was also different from Cuban-Germans in Germany because of my American nationality. Identity politics in Germany are also much more complex than in the U.S. The ability to subscribe to a national identity that supersedes your ethnic identity for immigrants in Germany is very complicated. ${ }^{26}$ Whereas the American identity for me has allowed me to embody both or neither of my ethnicities, being American was both inclusive and distinctive. I consider myself successfully integrated into the American mainstream. Structurally, I speak English, graduated from the American school system, and obtained my U.S citizenship. Culturally, I passionately celebrate the Fourth of July and consider Superbowl Sunday to be a holiday, just like the average American does. However, I also go home and speak Spanish as I eat schnitzel ${ }^{27}$ with arroz congri ${ }^{28}$ for dinner. I have always felt as if my ethnic differences are not only accepted but they are celebrated. ${ }^{29}$ Miami is the epicenter of Cuban culture in the

\footnotetext{
${ }^{26}$ This is not to say that identity politics in the U.S. is not also complicated. The U.S. has had a vast and infamous history of belonging, exclusion, and identity that too has seeped into modern-day identity politics. But in this particular study and through my own experience, I theorize Cubans in the U.S. have much more propensity to identify as "American" or "Cuban-American" than Cubans in Germany to identify as "German" or "Cuban-German". See Immerfall (2017, p. 6) and Rosenthal \& Kottig (2009) as their findings also supported this. See Berg (2011, p. 175) for similar findings in the Spanish context.

${ }^{27}$ Traditional German meal, breaded meat.

${ }^{28}$ Traditional Cuban meal, rice and beans cooked together.

${ }^{29}$ It is worth noting, that as a white, middle-class, documented immigrant of European ethnicity, I could negotiate and carry out my identities and still feel accepted into the mainstream. Moreover, I grew up in Miami and I am part of the Cuban ethnic enclave, which facilitated my family's economic and cultural integration. All three of my identities, all majorities in their own right, have shielded me from most of the prejudice and discrimination that prevents successful integration, belonging, and inclusion. I know this is not the same reality that other immigrants and even native-born minority Americans face.
} 
United States and when the fall season comes around, every major city, including Miami, celebrates Oktoberfest. I found my place within the Cuban-German binary through an American identity. Therefore, I consider myself both an insider and an outsider in this research. It is also why I can intimately understand the participants of this research while also holding an objective academic position.

\section{Conclusion}

In this study, I utilize qualitative methods, including ethnographic participant observation, non-participant observation, interviews, and focus groups to examine Cuban immigrant integration in Berlin. Because of time and economic constraints, I decided to limit myself to twenty-five interviews and three focus groups. But beyond these practical reasons, grounded theory indicates that one should stop the process when no new significant data are present. This is what guided the decision to conclude the study, since the data saturated. While gathering ethnographic data, I faced several challenges in the field such as safety, which I maneuvered using advice from earlier ethnographers and personal intuition. I also provided a self-ethnographic reflection that allowed for transparency as I described my feelings between the Cuban-German duality and how my American identity acted as a buffer between the two. I concluded that my Cuban-German ethnicity allows for an insider perspective while my American nationality allows for an outsider perspective also. 


\section{GERMAN IDENTITY, INTEGRATION, \& IMMIGRATION POLICIES \& AMERICAN ASSIMILATION THEORIES}

This chapter will present the main theoretical frameworks and historical background utilized to guide the research. First, the chapter will begin with an examination of German identity and German nationalism that gave birth to its ethnonationalist paradigm. As Sperling (2013) stated, "the social construction of identity is a key aspect of immigration and integration literature and of assimilation theories" (p.68; see also Alba \& Nee, 2003; Portes \& Zhou, 1993). It is necessary to understand the traditional concept of German identity to analyze its current effects on immigrant integration. This section will operationalize integration in Germany as it examines German nationalism and identity. Following, this chapter then presents a historical overview of German immigration/integration policies. Finally, this chapter concludes with an overview of the most relevant theories of assimilation as established by American academia to review the ways in which immigrant incorporation has been researched. This is necessary as understanding the concept of integration is the foundation needed to analyze if and how Cubans are integrating.

\section{The Evolution of German Identity and Nationalism}

This study examines both ethnonationalism and German identity while exploring how they interact with immigrant integration. Particularly how Cubans in Germany negotiate their identities within an ethnonationalist paradigm and how these negotiations are reflected in their integration. Therefore, this section presents a brief 
review of German identity and nationalism through a historical analysis to operationalize these concepts.

Germany has had a long, complex, and often contradictory relationship with identity and nation-building. Vick (2003) states that German ethnic exclusivity was propagated as far back as Roman times through Tacitus' Germania, where he admired "the tall blond Teutonic warriors of the North by contrast as indigenae, or as a people that had maintained its ancestral purity of both blood and culture in the lands it had always inhabited" (p. 242). Through this description, not only did anti-foreign politics and ethnic nationalism proliferate but it also articulated the image of German identity in terms of physical and biological features. In this sense, race and ethnicity were one and the same in the definition of a nation. Vick (2003) argues that Germany were more inclusive in the early $19^{\text {th }}$ century than is originally maintained. However, Vick (2003) also claims that during the late $19^{\text {th }}$ and $20^{\text {th }}$ centuries, because France had assimilationist policies, Germany reacted by adopting less inclusive policies towards immigrants and ethnic minorities (p. 249; see also Brubaker, 1992). The antiFrench fervor of the $19^{\text {th }}$ century fueled German's ethnically based identity and nationalism as “the question 'What is German?' was answered contrary to everything that France stood for" (Plonien, 2000, p. 85; see also Vick, 2003; Hagemann, 2004; see also Calhoun, 1993, pp. 396-397).

German ethnonationalism further developed when Germany became a unified nation in 1871 and adopted its citizenship law based on ethnicity (Brubaker, 1992, p. 52; Müller, 2001, p. 621; see also Brubaker 1990, p. 39; see also Kurthen, 1995). Germany's ethnically-based discourse evolved with the introduction of Social 
Darwinism in the late $19^{\text {th }}$ century as science added a biological component to ethnicity as a base for exclusion (Weikart, 2003; see also Macias, 1996). Science fused with German nationalism and identity as it progressed into a new spectrum of ethnic politics. For example, Friedrich Ratzel, a German political geographer, developed the theory of Lebensraum which justified German imperialism based on the notion of racial superiority (Weikart, 2003). The racialization of German politics gave rise to a radically violent form of identity and nationalism in Germany that erected the ideology of the Third Reich from 1933-1945. Echoing back to Tacitus' idolization of a "pure" ethnic German nation, the Third Reich's radical racial ideology was clear on classifying those who belonged within the German nation and those who did not belong. This led to the most extreme and destructive form of identity and nationalism in German history.

After WWII, as a reaction to the severity of the Nazi racial ideology, German identity was no longer expressed through a racial category. To separate itself from the Third Reich, Germany began to declare that race and racism no longer had a place in German national discourse (Müller, 2001, p. 622; see also Alba, 2005). Postwar, German discourse on identity and nationalism were no longer in relation to race but based on culture (Müller, 2001). Culture, which includes religious identity and language (Korteweg \& Yurdakul, 2009; Miller, 2012, pp.552- 553), has taken the forefront in the conversation regarding the German nation, identity, and belonging. Furthermore, "the exclusion of the Other was now legitimized by claiming that cultures are inherently incapable of communicating with each other" (Müller, 2001, p. 
622). Culture has now replaced race as a category of inclusion and exclusion and defines the German nation as explained in the followings sections of this chapter.

\section{German Ethnonationalism and Integration}

Germany has been traditionally a country of emigration that has transformed into one of immigration in the last half of the $20^{\text {th }}$ century (Kurthen, 1995). Germany was also slow in admitting its new role as a country of immigration (Seifert, 1997; Avci, 2006; Castles, 2006; Green, 2007; Boswell \& Hough, 2008; Silver, 2010; Williams, 2014; Çelik, 2015; Immerfall, 2017), which is why the notion of integration was all but ignored (Anil, 2005; Avci, 2006). As Germany's immigrant population began to grow at an accelerated rate after the 1960s, integration became an issue the government could no longer afford to ignore. Discussions of immigrant integration were now positioned at the center of political and social discourse in Germany. As Silver (2010) stated,

Germans devote an inordinate amount of attention to social integration not only because of their history of late national consolidation and the persistence of deep regional, religious, and class cleavages, but also because of a postwar taboo on addressing the content of nationhood (p. 166).

As Silver (2010) argued, Germany is now tasked with the undertaking of integration while simultaneously discounting issues of race, exclusion, and nationhood for fear of invoking its infamous past. Further causing ambiguity in its integration endeavors is that integration discourse is based primarily on its majority immigrant group. This majority, the Turkish migrants (Anil, 2007, p. 1365), has an intimate history with Germany through its guest worker initiatives of the 1960s (Anil, 2005; 2007; Faas 2007; 2008; Pütz, 2008; Ozuekren \& Ergoz-Karahan, 2010; Miller, 
2012; Oner, 2014; Çelik, 2015; Biedinger, Becker, \& Klein, 2015). Since these immigrants arrived and settled in Germany at a time when integration was not part of the discussion (Anil, 2005), they have faced several setbacks to successful integration. This has caused a sense of failed integration within the national discourse. This perception of failure is further propagated because of cultural and ethnoreligious differences between the Turkish population and mainstream German society.

Differences in identity create "bright boundaries" (Alba, 2005) that are “inherently relational" (Sperling, 2013, p. 68) and can either facilitate or hinder integration (Alba \& Nee, 2003; Alba, 2005). Consequently, the public discourse on Turkish migration to Germany has been generally negative as Turkish immigrants have been Othered (Said, 1978), spreading the sentiment across the social and political parameters of the nation (Korteweg \& Yurdakul, 2009; Verdugo \& Müller 2009; Miller, 2012; Çelik 2015; see also Müller, 2001; Alba, 2005; Oner 2014). Since the responsibility of integration is often solely placed on the immigrant (Immerfall, 2017), the perceived inability to integrate is blamed on cultural differences regarded as absolute. This creates a system of justification for prejudice, discrimination, and exclusion toward Germany's foreign population, based on the notion that immigrants not only cannot integrate but also do not want to integrate. Within the bounds of this absolutism, integration discourse and policy have become metanarratives. To explore how these metanarratives were constructed, the following two sections reviews modern Germany's immigration and integration policies 


\section{Overview of Germany's Immigration Policies}

Germany's immigration policies have been mostly static and controversial. The aim of its immigration policies has been to unify the German nation (Williams, 2014). The controversy stems from the fact that ethnicity has historically been the definition for this unity, which simultaneously also defined its exclusions (Brubaker, 1992; Kurthen, 1995; Macias, 1996 Williams, 2014). Since Germany has traditionally been a country of emigration (Kurthen, 1995), issues with its immigration policies were most emphasized after WWII due to the influx of immigration.

West Germany's ${ }^{1}$ immigration policies were based on the German 1913 Imperial Nationality Act that used jus sanguinis ${ }^{2}$ to determine citizenship (Brubaker, 1990; 1992, p. 169; Kurthen, 1995; Macias, 1996, p. 244; Williams, 2014, p. 56) as defined in terms of ethnicity (Macias, 1996, p. 244; Williams, 2013, p. 32; Williams, 2014, p. 56). This quickly became problematic considering the demographic changes that were underway. According to Bail (2008, p. 39), after WWII, Germany accepted most of the refugees from Eastern Europe (see also Castles, 1986; Brubaker, 1992). Moreover, guest workers also arrived under bilateral work agreements established by West Germany in the 1950s (Castles, 1986; Macias, 1996, pp. 241-242; Avci, 2006, p. 68; Pütz, 2008, p. 511; Drever \& Hoffmeister, 2008, p. 436). These guest worker agreements helped to remedy their employment and economic issues created by the war (Castles, 1986; Brubaker, 1992; Macias, 1996; Faas, 2008). The guest workers originated from “Italy .... Spain, Greece, Turkey, Morocco, Portugal, Tunisia, and

\footnotetext{
${ }^{1}$ This study will interchangeably use the terms West Germany and Federal Republic of Germany/FRG.

2 Translates to "right of blood."
} 
Yugoslavia" (Castles, 1986, p. 768; see also Brubaker, 1992, p. 171; Macias 1996, p. 242; Seifert, 1997, p. 443; Green, 2007, p.98; Kogan, 2004, p. 418; 2007, p. 492;

Faas, 2008, p. 109; Drever \& Hoffmeister, 2008, p. 436; Faas, 2016, p. 32). The economic oil crisis of the 1970s resulted in West Germany halting its guest worker program in 1973 (Castles, 1986; 2006; Brubaker, 1992; Faist, 1993; Kurthen, 1995; Seifert, 1997; Bail, 2008; Kogan 2004; 2007; Faas, 2007; 2008; Pütz, 2008, p. 512; Drever \& Hoffmeister, 2008, p. 436; Çelik, 2015; Faas, 2016, p. 34).

Regardless of the recruitment halt, immigration to West Germany continued through family reunification (Brubaker, 1992, p. 172; Castles, 1986; 2006; Kurthen, 1995; Faas, 2007; Green, 2007; Bail, 2008; Drever \& Hoffmeister, 2008, p. 436; Çelik, 2015; see also Pütz, 2008; see also Bauder, 2008, p. 56). West Germany's asylum policies (Anil 2005; Macias, 1996; Green, 2007) and ethnic migration laws (Green, 2007; Williams, 2004) were similarly generous (see also Kurthen, 1995). Anil (2005) describes West Germany’s asylum policy as “granting virtually unlimited right of asylum" (p. 459), to which Green (2007) adds that "West Germany has also been the destination for one of the world's largest ethnic migrations" (p. 98). The 1953 Refugees and Expellees' Law facilitated the remigration and citizenship acquisition of displaced ethnic Germans (Anil, 2005; Green, 2007; see also Kurthen, 1995). Anil (2005) explains that this law defined ethnic German as " 'resettlers' returning to their country of origin from the East European countries such as Poland, Romania, the former Czechoslovakia, and Hungary, and the former Soviet Union" (p. 456; see also Brubaker, 1992, p.170; Kurthen, 1995). Therefore, this liberal immigration law directed at ethnic Germans acted as a unifying force for the German 
nation, despite geopolitical displacement imposed after WWII (Brubaker, 1992; Williams, 2014). With the influx of immigration, including ethnic immigration, a quota system was introduced for ethnic migration as integration issues became increasingly evident (Williams, 2014, p. 56).

In 2000, the Nationality $\mathrm{Act}^{3}$ was instituted, adding jus soli ${ }^{4}$ to Germany's immigration policies "for the first time in modern German history" (Williams, 2013, p. 33; see also Brubaker, 2001; Anil, 2005; Auernheimer, 2005; Avci, 2006; Ersanilli \& Koopmans, 2010; Kaya \& Kayaoglu, 2014; Çelik, 2015). This act lessened the strict naturalization requirements such as "by reducing the residence requirement for naturalization from 15 to eight years" (Williams, 2014, p. 59; see also Anil, 2005; 2007; Williams, 2013, p. 33). A caveat in this new law, termed Optionsmodell ${ }^{5}$, denied dual citizenship and required children applying for jus soli to renounce their foreign citizenship when they became adults (Anil, 2005; 2007; Ersanilli \& Koopmans, 2010; Williams, 2014; Çelik, 2015; see also Brubaker, 2001). The exception to the denial of dual citizenship was made for some EU nationals (Williams, 2014). This change also affected those claiming citizenship per ethnicity as "the quota was reduced, and a language test was required of claimants to prove their ethnic heritage" (Williams, 2014, pp. 56-57). As the new immigration law took measures to start the incorporation of its foreign population, it also began to actively restrict its flow of ethnic migration (Williams, 2014).

\footnotetext{
${ }^{3}$ Approved in 1999, enacted in 2000. See Williams (2014).

4 Translates to "right of the soil."

5 Translates to "option model."
} 
Another change was introduced in $2005,{ }^{6}$ with the Immigration Act. It securitized immigration (Korteweg \& Yurdakul, 2009; Kaya \& Kayaoglu, 2014; see also Çelik, 2015) as it articulated national security concerns as a basis for the denial of citizenship (Williams, 2014, p. 61; see also Boswell \& Hough, 2008). It also further dealt with ethnic migrants as it extended the language tests to their families who wished to migrate with them (Williams, 2014, p. 61). In 2007, another dimension to naturalization was added through the EU-Directives Implementation Act, ${ }^{7}$ which now required a naturalization test and opened dual citizenship for all EU nationals (Williams, 2014, pp. 69-71). For non-EU citizens, dual citizenship is possible since 2014, according to Çelik (2015), if they meet certain civic and residential requirements. $^{8}$

In conclusion, the changing demographics of Germany initiated after WWII spoke to the need of reevaluating Germany's exclusionary immigration policies that dated back to 1913 . West Germany experienced mass migration of post-war refugees, guest workers and subsequent family reunification migration, and ethnic migration. Yet, Germany was slow in reformulating its immigration policies based on German ethnicity, even after reunification. The Nationality Act of 2000 introduced a historic change as it added jus soli to its immigration policies. The 2005 Immigration Act and the 2007 EU-Directives Implementation Act also brought further changes to German

\footnotetext{
${ }^{6}$ Approved in 2004, enacted in 2005. See Williams (2014).

${ }^{7}$ Approved in 2007, enacted in 2008. See Williams (2014).

${ }^{8}$ See "Notes" in Çelik (2015).
} 
immigration policies such as the addition of a naturalization test to the requirements for citizenship acquisition.

\section{Overview of Germany's Integration Policies}

While immigration laws allow for the legal inclusion of non-Germans into Germany's population, the laws encouraging integration have always been more conflicted. Guest workers in West Germany were never expected to stay and settle in Germany and were only seen as a temporary solution to an employment problem (Castles, 1986; 2006; Kurthen, 1995, p. 923; Williams, 2014; Çelik, 2015, p. 1647). Guest workers were not seen as migrants since "Germany, like other Western European states, was trying to import labor but not people" (Castle, 2006, p. 742; see also Brubaker, 1992, p. 171). Therefore, integration was never part of the equation and immigrant incorporation did not form part of the dominant discourse during the guest worker era (Brubaker, 1992; Green, 2007). With increasing number of foreigners, West Germany had to face demographic shifts in society. There was talk about integration under the Ausländerpolitik ${ }^{9}$ in 1982 (Avci 2006, p.69). Instead of instituting an integration policy, however, it instituted "the 1983 law for the 'Promotion of Readiness to Return"” where "every 'guest worker' who voluntarily left Germany received an incentive of 10,500 deutschmark" (Faas, 2008, p. 110; see also Seifert, 1997, p. 453; Avci 2006, p.69; Faas, 2016, p. 34). Instead of incorporating Germany's foreign population, policies were put in place to return them to their home countries (Macias, 1996; Avci, 2006; Boswell \& Hough, 2008). Even

\footnotetext{
${ }^{9}$ Translates to "foreign/foreigner policy."
} 
with the new policies instituted in 1991, Avci (2006) argued that there was still the "options for the re-immigration of children and assistance for return and reintegration to the country of origin" (p. 69).

Part of this hesitation to create integration policies was that the German government refused to see itself as a country of immigrants (Brubaker, 1992; Auernheimer, 2005; Avci, 2006; Green, 2007; Boswell \& Hough, 2008; Silver, 2010; Williams, 2014; Çelik, 2015; Immerfall, 2017; see also Kurthen, 1995). Before the 1990s, Germany had not engaged with any form of integration strategy (Anil, 2005, p. 453; Avci, 2006, p. 69), except for educational policies involving the children of foreigners ${ }^{10}$ (Faas, 2008, p. 109). The growing foreign population coupled with the lack of integration strategies was becoming increasingly problematic. It was problematic enough that state governments tried to institute local integration policies. Some German states attempted to grant residents of foreign descent the right to vote in local matters but the policy was ultimately struck down by the Constitutional Court (Williams, 2014, p. 58; Anil, 2005, p. 458). Germany’s sizeable ethnic migration reopened the discourse for "a re-evaluation of what being German meant" (Williams, 2014, p. 57). Ethnicity had historically acted as the thread that stitched the Germany community together, which now had begun to unravel.

It was in 2004 when integration policies were fully developed as "integration measures were centralized and standardized" (Williams, 2014, p.61) and integration courses were promoted (Williams, 2014; Anil, 2007). During the 2000s, Germany also instituted policies that recruited highly-skilled migrants; however, it was not

${ }^{10}$ See also "Notes" in (Anil 2005) 
successful (Green, 2007, pp. 104-105; Boswell \& Hough, 2008; Williams, 2014, p. 62; see also Bauder, 2008). Integration policies and discourse have been contentious in Germany, which is why some scholars see Germany's integration policies as a failure. Çelik (2015) argues that Turkish guest workers were "ethicized" (p. 1647), which is supported by Castles (2006) who claims that "[w]estern European societies did not integrate immigrants as equals, but as economically disadvantaged and racially discriminated minorities" (p. 743). Other scholars, however, praise the progress Germany has undertaken in terms of immigrant incorporation and acceptance. Williams (2014) argues that Germany is trying to distance itself from its ethnonationalist roots, as some politicians have attempted to define its identity in terms of "adherence to political institutions instead of ethnic heritage" (p. 64). Immerfall (2017) suggests that, even with issues concerning German identity, immigrants in his study felt they belong to German society and "migrants are predominantly at ease with their life in Germany" (p. 10).

Despite these continuing debates, Germany has experienced great progress with its integration policies and inclusivity, evident through its promotion of integration and attempt to distance itself from an ethnic self-definition. At the same time, Germany still has major integration issues, both historically derivative and modernly induced, that needs to be addressed. 


\section{American Assimilation Theories}

The United States ${ }^{11}$ has been at the forefront of assimilation theories utilized in Integration Studies. Unlike Germany, the United States has always been a country of immigrants. Also, dissimilar to Germany, the United State has traditionally seen and described itself as such. Thus, the U.S. has had a much longer history of engaging with immigration and integration than Germany, which is reflected in its extensive development of assimilation theories. Moreover, the 1960s proved to be a defining era for the U.S as it began to receive massive waves of migration (Brubaker, 2001; Kurthen \& Heisler, 2009). This era also marked the change in mass migration from European countries to non-European countries in the U.S (Massey, 1995; see also Portes \& Zhou 1993; Kurthen \& Heisler, 2009). Therefore, after 1965 when the quota system ended in the U.S (Massey, 1995), U.S. academia was tasked with reimagining its assimilation theories. This reimagining, built on previous theories, has been highly productive in understanding contemporary integration issues in Germany and thus why this section reviews them.

To begin with, sociologist Robert Park is "generally considered by critics and advocates of the concept alike as the key name associated with the articulation of assimilation's canonical formulation” (Kivisto, 2004, p. 149; see also Alba \& Nee, 1997). He examined race relations in the U.S. and discussed how assimilation interacts with race. Park (1914) argued that seamless assimilation can be achieved through subsequent processes. However, race acts as an obstacle to this seamless assimilation as a racialized and ethnicized person "cannot become a mere individual,

\footnotetext{
${ }^{11}$ Will be abbreviated as the U.S.
} 
indistinguishable in the cosmopolitan mass of the population" (Parks, 1914, p. 611; see also Kivisto, 2004). This marker of difference also leads to negative receptivity and prejudice (Parks, 1914; see also Kivisto, 2004) by the mainstream. Furthermore, Parks introduced the "race-relations cycle", where assimilation is assumed to be a uniform process with four steps. This theory has been criticized as monolithic; however, both Kivisto (2004) and Alba and Nee (1997) have argued that Parks himself rarely used this theory.

Milton Gordon, however, did argue for three major steps that functioned as a straight-path towards assimilation. The first step is acculturation, in which Gordon (1964) defines as "cultural or behavioral assimilation" (pp.70-71); the next step is structural assimilation, and the third was intermarriage (Gordon, 1964; Haller, Portes, \& Lynch, 2011, p. 735; see also Zhou 1993; Alba \& Nee 1997; 2003). For Gordon, similar to Parks, cultural uniformity was the end goal of assimilation. Assimilation meant that immigrants became indistinguishable from the mainstream and "prejudice and discrimination will decline (if not disappear), intermarriage will be common, and the minority's separate identity will wane" (Alba \& Nee 1997, p. 830).

Several scholars have criticized this theory of assimilation. The first major problem is that it views assimilation as an apolitical, "uniform" (Haller et al., 2011, p. 735) process. It theorizes that assimilation follows these three successive steps; however, Portes and Zhou (1993, pp. 81-82) reasoned that acculturation is not always the first step towards assimilation. Gordon's theory also speculated that immigrants would eventually assimilate into all aspects of the mainstream society. Portes and Zhou (1993) argued instead that immigrants could assimilate into selective parts of 
American society. Furthermore, Portes and Bach (1985) and Portes and Rumbaut (2001) maintained that immigrants, without having to assimilate in other aspects of the mainstream, can still assimilate into the American economy. Portes and colleagues claim that this is achieved through ethnic sub-economies and not necessarily through mainstream American society.

Scholars such as Glazer and Moynihan (1970) have contested this theory by arguing that some immigrants actively stay in their ethnic communities as "ethnic groups ... are continually recreated by new experiences in America" (p.17; see also Haller et al., 2011, p. 735). Furthermore, this theory has been seen as incompatible with recent waves of post-1965 immigration (Portes \& Zhou, 1993). Portes and Zhou (1993) further argue that modern American immigrants face more barriers in assimilation than early European migrants, such as racialization ${ }^{12}$ (see also Neckerman, Carter, \& Lee, 1999; Portes \& Fernández-Kelly, 2008).

Alba and Nee (2003) and their New Assimilation Theory has rethought the classical view of assimilation. The aim of their theory was to step away from Gordon's assimilation theory's most controversial aspects. However, Alba and Nee (2003) have been criticized because "their definition of assimilation so inclusive that it is difficult to see what is left out" (Portes \& Fernández-Kelly, 2008, p.15; see also Haller et al., 2011). Building from, and as a reaction to, Classical Assimilation and New Assimilation Theory, Portes and Zhou (1993) developed Segmented Assimilation Theory. This theory explores how post-1965 second-generation immigrants are incorporated into society. Deviating from Gordon and Alba and Nee,

\footnotetext{
${ }^{12}$ Presently, racialization also involved the securitization of immigrants.
} 
Portes and Zhou argued for different paths towards assimilation and that some immigrants might not assimilate into the mainstream at all. According to Portes and Zhou (1993), assimilation can take three main paths; mainstream assimilation, downward path assimilation, and selective acculturation (see also Zhou 1997, p. 984). Mainstream assimilation denotes assimilation into the "white middle-class" (Portes \& Zhou, 1993, p. 82; see also Neckerman et al., 1999, p. 947). Downward assimilation, however, is a path where the children of immigrants go downwards in terms of economic and social status (Portes \& Zhou, 1993; see also Neckerman et al., 1999). Lastly, selective acculturation is when immigrants steadily become acculturated to the American mainstream while at the same time keeping ethnic ties (Portes \& Zhou, 1993; see also Neckerman et al., 1999.

In sum, U.S. academia has had a longer history in the furthering of assimilation theories due to the United States' traditional identity as a nation of immigrations. Especially after 1965, with the changing context of immigration in the U.S.,American scholars were driven to rethink assimilation theories. Building from Parks and Gordon, new prominent theories and scholars such as such New Assimilation Theory created by Alba and Nee (2003) and Segmented Assimilation Theory created by Portes and Zhou (1993) have emerged. These new theories have transformed the way assimilation—or integration in the European context- is studied. 


\section{Conclusion}

German identity has historically been defined in ethnonationalist terms. These terms have evolved from rigid categories based on race to more fluid categories based on culture. Especially after the severity of the Third Reich and its transition from a country of emigration to a country of immigration (Kurthen et al., 2006), Germany redefined its identity and nationalism. However, this redefinition has been slow and controversial, especially concerning immigration and integration. The Nationality Act of 2000 was the first big step towards an inclusionary practice of nationhood as it added jus soli to it citizenship laws. Integration was also furthered in 2005 through the Immigration Act that promoted integration. Nevertheless, immigration and integration are still contested in Germany. Immigration and integration have also been and currently still is controversial in the United States as well. However, unlike Germany, the United States has traditionally seen itself as a country of immigrants. Therefore, the United States has had a longer and more involved process with integration, leading to the development of several leading theories of assimilation, which emphasize the complexity and variability of integration. As we will see in Chapter 4, which explores the Cuban diaspora, integration varies even within the same group. 


\section{THE CUBAN DIASPORA}

This research, which deals with Cuban immigrants, will contribute to Cuban Diaspora Studies. This interdisciplinary field has flourished into a multifaceted area of study which emphasizes the diversity of the diaspora from Cuba. The Cuban diaspora is present across the world in which contemporary studies are now reflecting the vast presence of Cubans globally. These studies have contributed and reworked notions of Cuban identity, integration, and acculturation as they explore the different trajectories and experiences of their migrants' journeys. This chapter will explore the diaspora in the two main places of destination, the United States and Spain, in addition to reviewing work on less frequent destinations. The section on the Cuban diaspora in the United States reviews the four main waves of Cuban migration, specifically to Miami, and its changing context. Followed by an examination of some of the ways the diaspora has been studied in Spain. To further demonstrate the versatility and expansiveness of the Cuban diaspora, this chapter concludes with studies conducted in Puerto Rico, Canada, Australia, and Germany.

\section{The Cuban Diaspora in the United States}

Geographically, Cuba and the United States share an extreme proximity, as the distance between the two countries is a mere 90 miles (Grenier \& Pérez, 2003, p. 18). More important than the geographical relationship between the two countries are the political and social connections, built over time, since the first Cubans began arriving in the U.S. 
Cuban migration to the U.S. did not begin with the "Golden Exiles" wave of migration after the triumph of the Cuban Revolution in 1959. Cubans have been migrating to the U.S. as early as 1823 with the arrival of the Cuban Catholic priest, Félix Varela (Grenier \& Pérez, 2003, p. 15), as the Spanish colonial rule drove an exile movement to the U.S. (Grenier \& Pérez, 2003, p. 17; see also Cobas \& Duany, 1997). Those who emigrated opposing Spanish rule found their way to the U.S. as “almost every prominent Cuban Separatist found himself in New York" until Cuba's independence in 1898 (Grenier \& Pérez, 2003, p.17). Miami, however, replaced New York as the center of Cuban migration after the 1959 Cuban Revolution (Grenier \& Pérez, 2003).

Miami is considered the "Capital of the Caribbean" (Grenier \& Pérez, 2003, p. 47; see also Portes 1987, p. 340; Mchugh, Miyares, \& Skop, 1997, p. 504; Woltman \& Newbold, 2009, p. 70). It is also considered the epicenter of the Cuban diaspora as situated by the four post-1959 Cuban migration waves (McHugh, Miyares, \& Skop, 1997; Grenier \& Pérez, 2003; Woltman \& Newbold, 2009) as examined in the following sections. Therefore, most Cuban diaspora scholarship based on the U.S. is centered on Miami. Portes and colleagues ${ }^{1}$ transformed the field through their conceptualization of on the Cuban enclave in Miami. They argued that the Cubans in Miami, created ethnic sub-economies. Cubans in Miami were incorporated into these sub-economies without having to assimilate into the wider American mainstream. Nevertheless, Grenier and Pérez (2003, p. 49) argue that even with magnitude of the

\footnotetext{
${ }^{1}$ See Wilson and Portes (1980), Portes and Bach (1985). See also Portes (1987), and Portes and Rumbaut (2001).
} 
Cuban ethnic enclave, "almost all Cubans interact extensively with mainstream American institutions" (p. 49). Because the enclave has penetrated the structures and institutions in Miami, Cubans have found success operating either inside or outside of the mainstream (Grenier \& Pérez 2003, pp. 48-55). Socially and economically, the Cuban diaspora in Miami has largely been defined by the ethnic enclave, which is defined politically through its members' collective memories and group identity as exiles (Grenier 2006; Girard \& Grenier, 2008).

\section{First Wave: Golden Exiles}

The first large wave of Cuban migration to the United States, particularly to Miami, was termed the "Golden Exiles" (Portes, 1969, p. 508; Grenier \& Pérez, 2003, p.23). It was sparked by the Cuban Revolution when Fidel Castro seized power in 1959. It gained momentum in 1960 as the regime took control of private property (Pedraza-Bailey, 1985, p.9). The term, "Golden Exiles", denotes that the wealthiest and most privileged members of the Cuban population began fleeing the communist regime (Portes 1969; Pedraza-Bailey, 1985; Cobas \& Duany, 1997; Grenier \& Pérez, 2003). These people were the most threatened by Castro's regime in its initial stages due to the "nationalization of American industry, agrarian reform laws, and the United States' severance of diplomatic and economic ties" (Pedraza-Bailey, 1985, p. 10). They also had the financial means to relocate to another country amid political upheaval.

This wave of migration included those who were primarily white and of similar social class (Skop, 2001, p. 450). The United States government responded 
with an assistance program targeted specifically for Cuban migrants, who were given the title of "refugees" (Pedraza-Bailey, 1985; Grenier \& Pérez, 2003, p. 23; see also Pérez, 1986, p. 129). Nackerud, Springer, Larrison, and Issac (1999, p. 177) argue that the "anti-communist political agenda" of the United States gave Cubans preferential treatment (see also Pérez, 1986, p. 129). The U.S. government gave Cubans in this wave political and economic support as the geopolitics of the Cold War aligned advantageously with the Cuban exodus. Furthermore, the socioeconomic and racial composition of this wave created a skewed archetype of Cuban immigrants in the United States. Many of these Cubans blended into the American mainstream. Therefore, scholars argue that the success of this wave shaped the American perspective on Cuban immigrants and set the stage for future waves (Grenier \& Pérez, 2003). The economic and entrepreneurial success of this wave molded Miami into the multicultural city it is today (Grenier \& Pérez, 2003) as it opened the doors for future waves of migration.

\section{Second Wave: Freedom Flights}

The next wave of immigration was called "Freedom Flights" (Pérez, 1986, p. 130; Cobas \& Duany, 1997, pp. 27-28; Grenier \& Pérez, 2003, p.23). This wave lasted from 1965-1973 and allowed Cubans from the U.S. to claim and retrieve family from Cuba (Grenier \& Pérez, 2003, pp. 23-24; see also Pérez, 1986, p. 129; Cobas \& Duany, 1997, p. 28). There were slight demographic deviations included in this wave from that of the Golden Exiles. Those in this wave were primarily older and more women than men since the Cuban government restricted military-eligible men 
from this agreement (Grenier \& Pérez, 2003, p. 24). Another change in the demographic, is that more of Cuba's middle class and paraprofessionals were part of this emigration (Cobas \& Duany, 1997, p. 28; Grenier \& Pérez, 2003, p. 24). Most of these emigrants were related to the emigrants of the first wave (Cobas \& Duany, 1997, p. 28) and thus still belonged to a relatively privileged class. Hence, they were an extension of the first wave and still fit neatly into the American image of what it meant to be a Cuban political exile. It was not until the next wave of migration that the boundaries of that image were stretched and new archetypes, and consequently also new policies, were introduced.

\section{Third Wave: Mariel}

After the Freedom Flights ended, it became increasingly difficult to directly immigrate to the United States. In 1980, a group of frustrated individuals stormed the Peruvian embassy, with 10,000 people later joining them and demanding asylum (Grenier \& Pérez, 2003, p. 24). The Peruvian embassy refused to let Cuban militia in and granted protection to the Cubans already inside. The situation became even more complicated because there were not enough supplies to feed the thousands of Cubans inside the embassy and many fainted from hunger. ${ }^{2}$ The Cuban government responded by opening the port of Mariel, whence 125,000 Cubans emigrated to the United States within a few months (Pedraza-Bailey, 1985, p. 22; Grenier \& Pérez, 2003, p. 24; see also Portes 1984. P. 394; Charon-Cardona, 2004, p. 42).

\footnotetext{
${ }^{2}$ Firsthand accounts reported by Cubans that were in the Embassy at the time.
} 
This wave of migration contrasted sharply with the previous two because it was primarily made up of the lower class and racial minorities (Pedraza-Bailey, 1985, p. 23; Skop, 2001, p. 450; Grenier \& Pérez, 2003, p. 24). This thrusted the imagined homogeneity of Cuban migrants into chaos. Castro sent individuals in the exodus that he believed were a danger to the revolutionary cause, including criminals, mental health patients, homosexuals, and prostitutes (Pedraza-Bailey, 1985, p. 22; Cobas \& Duany, 1997, p. 29; see also Portes, 1984, p. 394; Grenier \& Pérez, 2003, p.24). However, "there were also writers, artists, professionals, and even government officials" (Grenier \& Pérez, 2003, p. 24; see also Pedraza-Bailey, 1985). Nevertheless, the stigma of this wave of migration as a group of criminals (Portes, 1984; Pedraza-Bailey, 1985; Martinez, Lee, \& Nielsen, 2001; Portes \& Puhrmann, 2015) created dramatic tones around Cuban immigrants. A caricature of Mariel immigrants was both created and reinforced by popular culture and the news media as it sensationalized the criminal background of some individuals in this wave (Cobas \& Duany, 1997; Martinez, Lee, \& Nielsen, 2001). The Mariel stereotype became so widespread that it even gave birth to the world-famous movie, Scarface, about a Cuban immigrant from Mariel becoming a violent and corrupt gangster in $\mathrm{Miami}^{3}$ (Cobas \& Duany, 1997; Martinez, Lee, \& Nielsen, 2001). As Portes \& Puhrmann (2015) argued, the term "Marielito" (p. 41) became synonymous with criminals or undesirables and was perpetuated in the American mainstream and within the Cuban community.

\footnotetext{
${ }^{3}$ See Martinez, Lee, and Nielsen (2001) for in-depth analysis of the Mariel imagery and the Scarface phenomenon.
} 


\section{Fourth Wave: Rafter/Balsero Crisis and Beyond}

This fourth wave was perhaps the most heartbreaking, tragic, and desperate wave of migration from Cuba thus far. During the Rafter Crisis, Cubans used small boats or homemade rafts to escape Cuba. These extremely dangerous small vessels threw them into the mouth of a perpetually ravenous ocean. Many tragically died, including children and pregnant women. The majority were detained in the Guantánamo U.S naval base as the U.S. refused to let them enter the country (Grenier \& Pérez, 2003, p. 25). After Mariel, President Clinton’s administration was hesitant to allow Cuban migrants to enter the U.S. without restriction (Grenier \& Pérez, 2003, pp. 25; see also Cobas \& Duany 1997; Nackerud et al., 1999). Eventually, Clinton came to a bilateral agreement with Castro (Grenier \& Pérez, 2003, p. 225; see also Nackerud et al., 1999) which allowed the legal entrance of 20,000 Cubans into the U.S. through traditional visa channels (Cobas \& Duany 1997, p. 30; Grenier \& Pérez, 2003, p. 25). Additionally, it stipulated that any Cuban captured by the U.S. Coast Guard at sea would be sent back to Cuba (Grenier \& Pérez, 2003, p. 25). Due to the "wet-foot/dry-foot policy", ${ }_{4}$ any Cuban who reached U.S. territorial land would be allowed to stay in the U.S. With this caveat in mind, although not in mass numbers, occasional individuals still risked their lives and bravely tried to emigrate using a raft. As of January 2017, President Obama revoked the "wet-foot/dry-root policy".

\footnotetext{
${ }^{4}$ Common name for the 1995 revision of the Cuban Adjustment Act of 1966.
} 


\section{Beyond the United States}

The four main waves of Cuban migration to the U.S., particularly to Miami, have encompassed their own unique characteristics. Not only have the characteristics of each migration wave been different but so has the subsequent receptivity of the U.S. Most notably, the Mariel migration wave was the most diverse in both internal characteristics and receptivity by both the U.S government and popular culture. The declining favorability, both in terms of policies, towards Cuban migration accumulated in the ending of the "wet-foot/dry-foot policy". This change in policy carries repercussions that alter the course of Cuban migration to the U.S. Moreover, Cuban Diaspora Studies will also change as they will reflect the potential decrease of Cuban migration to the U.S. and the increase migration to other countries. The following sections will discuss how Cuban Diaspora Studies have already begun to evolve into a more geographically diverse discipline.

\section{The Cuban Diaspora in Spain}

In the last decade, more research on the Cuban diaspora outside of the United States has begun to emerge, particularly on Cubans in Spain. This is an important development for the field considering the intimate relationship between Cuba and Spain. Due to Cuba being a colonial territory of Spain, Cuban migration to Spain extends back to the $19^{\text {th }}$ century (Eckstein \& Berg, 2009, p. 160; Berg, 2011, p. 12; see also Cobas \& Duany, 1997; Grenier \& Pérez, 2003). It is also the second most common destination for Cuban migration (Eckstein \& Berg, 2009, p. 161). Moreover, 
the Cuban diaspora in Spain presents an interesting case study as compared to the much better documented experiences of Cubans in the U.S.

Abad and García-Moreno (2016, p.129) argue that the prevalent reason behind immigration has been given in terms of economic factors. This is true for both Cubans in the U.S. and Cubans in Spain, where "a shift from a political to an economically driven migration following the 1990's crisis"5 has taken place (Simoni, 2016, p. 459; see also Berg, 2011). Although economic factors are central to Cuban migration; diverse motivations, including political and social motivations, are still active, as Abad and García-Moreno (2016) found to be true for some Cuban women in Spain. Berg (2011) also supported this view because she too found diverse motivations for Cuban migration to Spain. Using a historical and generational approach, Berg (2011) addressed the nostalgia and complex identity politics among Cubans in Spain. She discovered that Cuban identity, collective memories, and notions of belonging differed across generations as historical moments defined them (see also Eckstein \& Berg, 2009).

The characteristics of the migration waves between those who arrived in the U.S. and those who arrived in Spain, show several similarities and differences. The exiles who immigrated to Spain were overwhelmingly of the same upper and middle class and usually saw themselves as "political exiles as opposed to economic migrants" (Berg, 2011, p. 41). The same could be said of the same migration wave to the United States (Skop, 2001; Grenier \& Pérez, 2003, 23). This group of migrants in both countries was largely anti-Castro and anti-Communist (Grenier \& Pérez, 2003,

\footnotetext{
${ }^{5}$ The 1990s Crisis referenced in this quote is termed El Periodio Especial translated to The Special Period.
} 
p. 86; Eckstein \& Berg, 2009, p. 164; Berg, 2011, p. 40). One distinguishable characteristic of this wave between the U.S. and Spain is that those who migrated to Spain were often considered "returnees" (Eckstein \& Berg, 2009, p.163; Berg, 2011, p. 41). As explained by Eckstein and Berg (2009), while the Golden Exiles in the U.S. did not have extensive family or connections, those who migrated to Spain, frequently traced their linage and background back there (see also Berg, 2011). Another similarity stems from later migration waves such as Mariel and those who immigrated during and after the Periodo Especial. Both in the U.S. and in Spain, these later Cuban migrants were more racially and socioeconomically diverse than their predecessors (Skop 2001, p. 450; Grenier \& Pérez, p. 24; Berg 2011, p. 41). This group of migrants also identified more as economic migrants than political exiles, as they became "disillusioned with politics" (Eckstein \& Berg 2009, p. 165).

The Cuban diaspora experienced greater opportunities in the U.S. than in Spain due to Miami's ethnic enclave and the U.S.' "preferential treatment" (Eckstein $\&$ Berg, 2009, p.169). Considering that Spain still had economic ties with Cuba, whereas the U.S. instituted an embargo, Spain "never dedicated resources on the scale of Washington's generously funded Cuban Refugee Program" (Eckstein \& Berg, 2009, p. 169). Along these same lines, Cubans in Spain lacked the political influence that Cubans in the U.S. had concerning policy towards Cuba (Eckstein \& Berg, 2009, p. 172). Furthermore, in terms of integration, the distance between Cubans and the mainstream is further in the U.S. than in Spain, considering shared cultural factors (Eckstein \& Berg, 2009, pp. 160; 173-175). 


\section{The Cuban Diaspora in a Global Context}

Although Cuban migration is concentrated in the U.S. and in Spain (Eckstein \& Berg, 2009), the diaspora is spread globally, with noteworthy scholarship now reflecting this. For example, Cuban migration to Puerto Rico presents a noteworthy case study as "more than thirty-six thousand exiles" fled to Puerto Rico "between 1959 and 2014" (Duany, 2017, p. 82). The connection between Cuba and Puerto Rico stems from their shared colonial history under Spain (Cobas \& Duany, 1997, p. 42). Because of their shared colonial past, they also share cultural similarities such as a common language (Cobas \& Duany, 1997). Cobas and Duany (1997) argue that the Cuban diaspora in Puerto Rico "retain a strong sense of solidarity and ethnic identity" (p. 59) but still shows a proclivity towards intermarriage with the local population. Canada also presents an interesting view of the Cuban diaspora. Gutiérrez (2013, p. 56) states that Canada is a top receiving nation for Cubans. In terms of the demographics, a defining characteristic of Cuban immigrants in Canada is that the majority has some sort of formal education (Gutiérrez, 2013). As in Spain, Cubans have not been given preferential treatment compared to the U.S., and the two countries have a normalized relationship (Gutiérrez, 2013). The current prime minister of Canada, Justin Trudeau, even gave a heartfelt statement on the passing of Fidel Castro, symbolizing the friendly relationship between the two nations.

On the other side of the world, the Cuban diaspora in Australia had two primary migration waves, similar to the U.S. context. The first wave in the 1970s was composed of those like the exiles, while the second wave in the 1980s was a more diverse group like those of Mariel (Charon-Cardona, 2004, p. 41-42). Charon- 
Cardona (2004) found that the diaspora in Australia works to preserve its ethnic identity primarily through food. The Cuban diaspora in Germany is also unique, as Pérez Naranjo (2014) has shown. To begin with, Cuba and East Germany commonly worked together during the Cold War, even instituting a formal bilateral agreement to bring Cuban workers and students to East Germany before reunification (Mac con Uladh, 2005, p. 9; Pérez Naranjo 2014, p. 74; see also, Ireland, 1997, p. 546; Holtz 2014, p. 468). Currently, Germany and Cuba still have a diplomatic relationship. As with Australia, due to its smaller size compared to the U.S., the primary methods by which the diaspora retains its ethnic identity are through food and music. Also, unlike the U.S. context, the diaspora does not seem to encompass the exile ideology as fervently as in the U.S. The participants of this study expressed an aversion to the politics of the island in general, citing that "Germany is like a vacation from Cuban politics. ${ }^{\prime 6}$ When visiting a Cuban restaurant in Berlin, adorned by pictures of Fidel Castro and Che Guevara, ${ }^{7}$ one participant stated that though some Cubans are offended, "most did not care." These are just a few examples of contemporary scholarship conducted on the Cuban diaspora that represent the fields' evolution towards a geographically dispersed network of communities.

\section{Conclusion}

The Cuban diaspora is extremely diverse as Cubans have settled into different countries at different times and have integrated in different ways to their host

\footnotetext{
${ }^{6}$ Data from my own interviews. This statement was uttered by a participant.

${ }^{7}$ It should be noted that this restaurant was not owned by a Cuban migrant.
} 
societies. Cuban migration to the United States has been continuous through four main migration waves, each with its own political and socioeconomic characteristics. These migration waves have transformed Miami into an epicenter of Cuban culture. This contrasts sharply with Cuban migration to Germany, even as Berlin is the epicenter of a smaller and more dispersed Cuban population in Germany. The U.S has had a restrictive and ambivalent relationship with Cuba, reminiscent of Cold War politics, whereas Germany has had a relatively cordial relationship with Cuba. Cuban migration to the U.S, however, far exceeds Cuban migration to Germany, and any other country. Because of the geographic proximity of the U.S and favorable immigration policies such as the Cuban Adjustment Act, the U.S. has been the preferred migration center for Cubans. Germany is not geographically close to Cuba and lacks the favorable immigration policies towards the island. Miami, because of its ethnic enclave, shares cultural similarities to Cuba and provides economic and social co-ethnic opportunities for immigrants from Cuba. Contrastingly, Germany lacks a Cuban enclave and cultural similarities with the island. These are reference points for varying integration paths as they change the dynamics of language attainment, labor market entrance, intermarriage, and identity between the Cuban diaspora in the U.S. and Germany. 


\section{CUBAN MIGRATION TO GERMANY}

In this chapter, I will explore the conditions of the initial Cuban migrant arrival in Germany. This chapter will also address the issues faced by those who returned to Cuba after reunification. Just as Cuban migration was driven by Cold War politics in the United States, so was Cuban migration in Germany. Most of the immigration from Cuba to pre-reunified Germany was to the GDR (Pérez Naranjo, 2014; Holtz, 2014). Throughout this chapter, the analysis will focus on the migration pattern to the GDR as opposed to the Federal Republic of German (FRG). ${ }^{1}$ Considering the geopolitical tensions of the Cold War, ${ }^{2}$ there was no significant presence of Cuban migrants in the FRG (Pérez Naranjo, 2014, p. 63; Holtz, 2014). This contrasts with Germany's majority immigrant group, as the FRG signed agreements with Turkey to recruit guest workers to fill the temporary void in the German workforce during the 1960's (Anil, 2005; 2007; Faas 2007; 2008; Pütz, 2008; Ozuekren \& Ergoz-Karahan, 2010; Miller, 2012; Oner, 2014; Çelik, 2015; Biedinger, Becker, \& Klein, 2015). For Cubans, migration was directed to the GDR during the Cold War because of Cuba's geopolitical and ideological relationship with the Soviet Union and its Eastern European allies (Ireland, 1997, p. 546).

While Cuban migration to the U.S and Turkish migration to Germany are comprised of several migration waves, Cuban migration to Germany is roughly divided into two main waves. I will explore the two main waves of Cuban

\footnotetext{
${ }^{1}$ This will be abbreviated as FRG.

${ }^{2}$ See the FRG's Hallstein Doctrine.
} 
immigration, pre- and post- German reunification, and the conditions of arrival using information from various sources, including my own interviews and ethnography. Moving forward, I also will explore in greater detail the living conditions and trajectories of Cuban students and highly-skilled works, ${ }^{3}$ and low skilled workers ${ }^{4}$ who arrived in the GDR through the bilateral agreement with Cuba. Next, I will describe the complications for Cubans who stayed in Germany and for those who returned to Cuba after German reunification. I will conclude with a brief summary of current methods for migrating to Germany.

\section{The Post-Revolutionary First Migration Wave: Post-Cuban Revolution and Pre- German Reunification: Early 1960s to Mid-1990s}

While many countries refused to recognize the GDR (Berger \& Lilleker 2002; Low, 2015), "up to 1972, revolutionary Cuba was the only Latin American country to give the GDR diplomatic recognition" (Holtz, 2014, p. 472). Once the revolutionary government of Cuba took control in 1959, the exchange of goods, services, and people increased between the two ideologically akin states. Due to East Germany's postwar labor shortage (Adams, 1989), guest workers from allied nations began immigrating to the GDR, with Cuban migration to the GDR starting around the 1960’s (Pérez Naranjo, 2014, p. 66). An estimated 30,000 Cuban migrants, including students, arrived in the GDR before the fall of the Berlin Wall in 1989 and Germany's reunification in 1990 (Holtz, 2014, p. 468; Pérez Naranjo, 2014, p. 64). Cuban

\footnotetext{
${ }^{3}$ I also categorize government, military, and political officials as skilled workers.

${ }^{4}$ Low-skilled workers also include semi-skilled workers.
} 
students were sent to study in universities across East Germany while highly-skilled workers were sent to work in political institutions such as the Cuban Embassy in East Berlin, or to act as translators and sociopolitical liaisons. Cuban low-skilled workers were usually sent to work in factories.

\section{Students and Highly-Skilled Workers}

In the early 1960s, the first Cuban students who had arrived in the GDR were part of the initial stages of the developing Cuban-GDR relationship. Most Cuban students were not trained in the German language, were unfamiliar with German culture, and faced difficulties with the GDR's educational system (Mac con Uladh, 2005; Pérez Naranjo, 2014). To remedy this situation, students were sent upon arrival to the Leipzig's Herder Institute where they attended rigorous language lessons and were exposed to a Marxist-Lenist educational doctrine (Pérez Naranjo, 2014, p.67). Afterwards, students and highly-skilled workers began German languages courses in Cuba before immigrating, with the exception of those already fluent in German (Pérez Naranjo, 2014). Students identified as candidates to study in the GDR had to "have good grades and prove their allegiance to Cuba. Usually the students had to be part of the Communist Youth (UJC), but not exclusively, or they had to prove that their attitude toward the country was in favor of the socialist model" (Pérez Naranjo, 2014, p. 68).

The students and highly-skilled workers who had already attained the fluency in the German language were given priority in the selection process. Those who had graduated with a degree in the German language and qualified as translators were 
immediately placed at the top of the list, as noted by a study participant who worked as a translator in the Cuban embassy in East Berlin.

I have always loved learning new languages, but I already knew English, and I did not like Russian too much, which at the time everyone was studying. So, when I entered La Facultad de Lengua y Literatura Extranjera ${ }^{5}$ in Havana, I decided to study German. It was such a beautiful language, and I enjoyed education, so I thought I would study to be a German language professor one day or maybe a translator. Never did I think I would end up going to Germany. But after graduating from my studies, since I was fluent in German, I was presented with the offer to move to the GDR and work at the German embassy. All I had to do was fill out an application and provide my qualification as a translator. I was called right away, like two weeks later, there was so much need for German translators that I was immediately told I was leaving to the GDR. ${ }^{6}$

Some students who were sent to study abroad in specific universities or specific educational tracks saw that those options were no longer available upon their arrival in East Germany (Pérez Naranjo, 2014). These students had a sudden change of study and upon their return to Cuba, were at times faced with inexistent career paths (Pérez Naranjo, 2014). As for living arrangements, some students shared their dormitories with German roommates, while others shared their rooms with other Cuban students (Pérez Naranjo, 2014). Most highly-skilled workers, such as embassy officials, had to either share an apartment with a colleague or were given their own apartments. As one translator from the Economic and Commercial Department of the Cuban Embassy in East Berlin mentioned:

I was given all different types of apartments. At first, I shared an apartment with another translator that also worked in the embassy but then I was given my own apartment. Once I was given a beautiful one-bedroom apartment whose balcony faced the gardens, that one was my favorite! Another time I

\footnotetext{
${ }^{5}$ Translates to The School of Foreign Language and Literature.

${ }^{6}$ My own translation from Spanish. All interview translations are my own. Names are either not included or changed to protect participant identity.
} 
was even given a three-bedroom apartment, I hated that one, because I lived there alone, and it often felt scary and lonely, so I would leave all the lights on at night just in case.

The highly-skilled workers ${ }^{7}$ who lived on their own still had to ask for permission to travel as they had their passports taken away upon arrival in Germany. For example, one participant had to ask the Cuban embassy for permission to drive to Poland to visit her sister. Students living in dormitories also had to request permission if they wanted to sleep elsewhere, since intimate relationships were not encouraged, and marriages were difficult to get approved (Pérez Naranjo, 2014). Marriage between Germans and Cubans was heavily restricted, and even marriages between Cuban students were controlled (Pérez Naranjo, 2014). The students' primary focus was supposed to be their studies, so they could actively contribute to the Cuban nation once they returned. Marriage and relationships were not only seen as obstacles and distractions but also as a dangerous incentive for them not return to Cuba. This ultimately proved true of those who married Germans because they were given a legal avenue to emigrate after reunification.

Besides control of their romantic relationships, Cuban students faced other restrictions. They were not allowed to have outside work or earn extra income, had restrictions on items they were allowed to purchase, and if their grades fell, they were sent back to Cuba (Pérez Naranjo, 2014). On the positive side, all Cubans under contract in the GDR were given paid vacations to visit Cuba every two years, which they could accept or decline (Pérez Naranjo, 2014). Some students and their colleagues traveled back to Cuba to visit their families and bring back goods, but

\footnotetext{
${ }^{7}$ Cuban students who had already graduate in Cuba and were hired as highly-skilled workers.
} 
others decided to stay and travel in Germany. A highly-skilled worker who traveled

back to Cuba on her vacations recounted the gifts she brought back:

I went back to Cuba every two years because I really missed my family and I had no particular reason to stay in Germany during my vacations. I would bring back many different types of goods, especially for my niece who is like a daughter to me. I would bring her a suitcase full of shoes since they were of high quality and you couldn't find those in Cuba. I once even brought her back a stuffed tiger toy animal that was bigger than her. You could clearly tell they were foreign products.... Of course, not everyone traveled back to Cuba, some of my friends preferred to stay. But they either had their spouse or kids in Germany already so they had no real reason to go back like I did. My best friend in Berlin had her son, husband, and even mother with her so it didn't make sense for her to visit Cuba.

Once students finished their studies or the highly-skilled workers' contracts

were up, they had to return to Cuba or apply for an extension of their contracts. Those

who returned to Cuba were held in high regard and received beneficial employment

even if they were not placed specifically in their chosen fields (Pérez Naranjo 2014,

p. 73). As explained by one translator,

Before I even arrived back in Cuba, I already had a position waiting for me. The director of Cubaequipos ${ }^{8}$ already had a position waiting for me as a translator. Later, I was offered different positions of employment, the one I picked was as a translator in La Isla de Juventud in the Hotel Colony, for which I was paid the same as in the Cubaequipos office but in a much more comfortable position where I enjoyed the freedom and intellectual independence I had back in Germany and did not have to sit in an office all day. Later, I was hired as a translator in the Hotel La Habana Libre and in the Hotel Riviera in the reception desk for German tourists. I missed being back in Germany and working there, but once back in Cuba, I was given great employment opportunities that I enjoyed.

${ }^{8}$ Office of Exterior Commercial: The office that signed and approved the purchases and contracts of equipment and their parts. 


\section{Low-Skilled Guest Workers}

Cubans of adult age, typically who did not attend school past secondary education, were recruited as guest workers to be sent anywhere in the Soviet bloc after Cuba entered The Council for Mutual Economic Assistance in 1972 (Fagen, 1978, p. 73; Pérez Naranjo 2014, p. 88). A bilateral agreement was signed with the GDR in 1978 (Mac con Uladh, 2005, p. 9; Pérez Naranjo 2014, p. 74; see also Ireland, 1997, p. 546). Besides the educational divide, Pérez Naranjo (2014) also notes a racial divide between students and workers because "workers there were more persons with dark skin compared to students" (p. 88). When recruited, they were required to attend a training course to prepare them in the language, culture, and technical skills of the receiving nation. The Cuban government placed the workers where there was the greatest need. The potential guest workers had the right to either accept or reject the contract, as one participant explained,

When I finished $10^{\text {th }}$ grade, since I had to repeat seventh grade and did not have the best grades, I couldn't move on to pre-university. Instead, I applied to the Oceanologia Technico ${ }^{9}$ in the Soviet Union because they needed workers in that industry. I had no idea what that was or what I would be doing, but it was a chance to leave Cuba. Before going over there, though, I first had to attend a one-year long training course that taught me the Russian language, math, physics, and chemistry. All my teachers were Soviets and none were Cuban. They taught me how to eat and how to conduct myself too. When I finished that course, they vaccinated me, and I was ready to go to the Soviet Union. But I decided not to go at the last minute and they became angry that I wasted revolutionary money and resources, but they couldn't make me go so I renounced my position and gave back the suitcase full of clothes they had given me for travel to the Soviet Union.

The Cuban workers who agreed to go abroad and later retracted their applications were informed that this decision would affect their future opportunities.

9 Translates to Oceanology Technical. 
They also had to return any items given to them for travel and were forced to formally renounce their position in a government office. They were labeled an embarrassment to the nationalist effort in Cuba and were pressured to honor their contracts. The participant from the above story continued to explain:

So, I couldn't study anywhere else and I was worried that I wouldn't be able to find a job after resigning. During that time lapse, my mom became friends with a government official who had connections and encouraged me to apply for East Germany as a factory worker, since they needed factory workers. So, I did, and they told me that in a couple of weeks I would leave. This time, they didn't make me go through the training I first did when I thought about going to the Soviet Union. I don't know why but I am guessing they either needed more workers immediately or I was exempt since I already had attended training. But when they came to take me, I hid under my bed because I began to realize how hard working in a factory would be and became scared. I asked my mother to come with me to renounce the position because I was so embarrassed and I knew they would be angry. So again, I was forced to officially renounce my application and again they were very angry but they couldn't force me to go.

If the potential guest worker did accept the proposed position and completed the training, travel expenses were paid, and the worker was sent to the receiving country. The selection processing times varied depending on whether the worker had political connections, as seen with my participant's experience. Because she did not have any connections, it took her more than a year to have her travel approved, but once her mother became friends with an official, the process took mere weeks. The selection process for the GDR could either be extensive or instantaneous, depending on whether the worker had previously served in the military or, as mentioned, had connections (Pérez Naranjo, 2014). These guest workers were mostly employed in the following industries "In the tire production, chemical, textile, and tool industry assembly processes of the construction of vehicles ... they were also employed in the 
transportation sector, as well as in the frozen and food industry" (Gruner-Domi, 1997, p. 7 as quoted in Pérez Naranjo, 2014, p. 75). ${ }^{10}$

The work in these production industries was arduous, demanding, and restrictive. Additionally, just as the professional Cuban migrants were not allowed to have relationships, romantic entanglements were also forbidden for the workers. If a female worker, or student, became pregnant, it did not matter if the father was East German or Cuban, her contract would be revoked, and she would be sent back to Cuba (Pérez Naranjo, 2014, p. 230; Ireland 1997, p. 548). Hence, workers had to tread carefully regarding romantic and sexual entanglements. According to my own participants, factory workers did engage in romantic relationships with not only other Cuban workers, but also East Germans. They felt a sense of fear of not only having their contracts revoked due to these romances, but also because of racial discrimination. For example, I was told of one Afro-Cuban man who had a child with an East German woman but he never reported that he was the father and was not allowed to marry the mother of his child. Because of these circumstances some preferred not to be involved with East Germans. Pérez Naranjo (2014) adds that other Cubans also judged harshly workers who became involved in Cuban-German relationships.

Another restriction that workers faced was their inability to travel freely in either the GDR or the Soviet Union. Upon arrival, all Cuban migrants had to leave their passports with the Cuban embassy "with the exception of some doctoral

\footnotetext{
${ }^{10}$ My own translation: the actual quote is "Sie Wurden vorwiegend als Produktionsabeiter in der Reifenproduktion, Chemiefaser, Textil, und werkzeugindustrie sowi bei Montageprozessen des fahrzeugbau eingesetzt...Daruber hinaus wurden sie auch im Verkehrswesen sowie in der Frost und Nahrungsmittelwirtschaft beschaftigt".
} 
students, who enjoyed a greater level of self-determination and more agreeable living conditions in general" (Holtz, 2014, p. 472). Moreover, factory workers were often sequestered to their area of work with only nearby attractions ${ }^{11}$ as their source of recreation and occasional cultural trips arranged by factory leaders (Pérez Naranjo, 2014, p. 87). Additionally, $60 \%$ of the workers' salaries was not paid out to the workers but instead was sent to Cuba for them to use upon their return (Pérez Naranjo, 2014, p. 80; see also Mac con Uladh, 2005). This was another veiled enforcement for them to return to Cuba and deterred them from staying in the GDR.

Conversely, one main incentive for the workers to go to the GDR in the first place was that the Cuban government would allow each worker to purchase European-made motorcycles (Pérez Naranjo, 2014). If the worker's contract was revoked, he or she did not finish its entirely or was subject to discipline, his or her claim of the motorcycle would be forfeited. The conditions required the contracts had to be completed successfully and without incident. Pérez Naranjo (2014) articulated that the contracts were usually a four-year contract, while some of my participants stated their contracts were for only two years. ${ }^{12}$ When administrative supervisors saw a decline in work ethic of the Cuban factory workers, some factories threatened them with the possibility of losing their motorcycle incentive (Mac con Uladh, 2005; Pérez Naranjo, 2014). These motorcycles were expensive, luxurious, and inaccessible in Cuba. This made the possibility of obtaining one from overseas a desirable incentive that helped with not only recruitment to the GDR but with maintaining a certain

\footnotetext{
${ }^{11}$ Such as bars and night clubs.

${ }^{12}$ Some were also given the opportunity to extend their contracts.
} 
quality of work once in the GDR. One participant described the importance of the motorcycle:

Those motorcycles were famous, everyone dreamed of having one. If you completed your contract, then you were able to purchase one and take it back to Cuba with you. Back in Cuba, some people used them as their means of transportation and people in the neighborhood would look at you in amazement. But there were some who sold them for money or traded them for better apartments. This was not allowed and was pretty dangerous to do, but they were such good bikes that you could get a lot for them if you traded or sold them. People would go to the GDR blindly just for the promise of getting one of those motorcycles.

Cubatecnica $^{13}$ is a Cuban governmental agency designed to facilitate the exchange of labor between Cuba and other countries, which currently still exists. For the GDR, it created the groundwork for importing Cuban labor (Pérez Naranjo, 2014). This agency was not only in charge of recruitment, but also appointed "leadership of Cubans groups in the different factories" (Pérez Naranjo, 2014, p. 77). Besides group leaders, factory workers were also given a translator who would act as a liaison between them and the German administrators and the wider population. Cubatecnica also appointed these translators who were the voices of these workers because, regardless of the language training they received in Cuba, speaking the language was still difficult for most Cubans (Pérez Naranjo, 2014, p. 78). These translators were professionals who had graduated with a degree in the German language or from another discipline and happened to be fluent in German. Regardless, as my participants explained, they had to provide evidence of their qualifications and a translator's certificate. Factory translators did not enjoy the same luxuries as other translators, such as the one employed in the Cuban embassy in Berlin. When

\footnotetext{
${ }^{13}$ Empresa de Contratación de Asistencia Técnica.
} 
explaining her trajectory as a translator, a participant confirmed the differences in the employment environment:

I was going to be sent as a translator in a factory that specialized in spare parts in the GDR. I was a little nervous because working in a factory was something I was not used to. But one of the translators in the Berlin Embassy finished her contract and did not opt to extend it so they needed someone to fill her position. My brother-in-law was an important official in the Polish embassy and had many connections so he was able to place me in the embassy instead. I was very comfortable there. Everyone was polite and disciplined and I was treated with the upmost respect. I worked until around 5 p.m. and was never asked to stay overtime. I had to go once a week to different provinces in the GDR to verify contracts, mediate agreements, and attend meetings with different officials. It was the best job I have ever had.

This narration is a contrast to the translators who were sent to the factories.

As Pérez Naranjo (2014) and Mac con Uladh (2005) argue, working in a factory setting was arduous. However, factory translators still had significantly better conditions and greater freedom than factory workers. Cuban low-skilled factory workers had grueling and at times violent experiences (Ireland, 1997; Mac con Uladh, 2005; Pérez Naranjo, 2014). Not only did Cuban factory workers at times do the most "physically-demanding and dirty jobs" (Mac con Uladh, 2005, p. 95), but their lives were riddled with hardship.

After a strike by Cuban workers in a synthetics factory in Wittenberge, an investigation into conditions uncovered the widespread abuse of contract workers. Not only had management transgressed a number of labour regulations regarding working hours, sick pay and holiday leave, but East German workers had made Cubans clean up after them and referred to them as 'Neger' (Mac con Uladh, 2005, p. 82).

Racial discrimination and prejudice were rampant in these factories. Many incidences of violence and mistreatment were directed at Cuban workers by East Germans. If migrant workers were involved in a conflict, the reports by East German officials were at times fabricated to place the blame on the migrant workers (Mac con 
Uladh, 2005). Thus, the Cuban workers involved in a conflict would be punished, even if they were not at fault. One participant, a former worker in the Cuban embassy in Poland, commented on the inequality of treatment in some situations in Poland as well as in East Germany.

There were these two Cuban workers who got in trouble at a bar and we made sure to quickly send them back to Cuba right away. I believed them when they said they didn't start the fight and I knew they were not at fault because the story did not make any sense. But if I let them stay in Poland, I knew the local police would mistreat them and something worse than just being sent back to Cuba would happen. Instead of having them be subjected to una entrada de palos, ${ }^{14}$ we just sent them home. This wasn't a unique situation, this happened in the GDR too.

Besides their minority status as factory workers and immigrants, Afro-Cuban workers were unfortunately further targeted by racial discrimination in the GDR. Mac con Uladh (2005) explained that:

Of the 774 contract workers deported for disciplinary transgressions in 1989 for example, 369 were from Mozambique, 303 from Cuba ... This must not be taken as evidence of greater wrongdoing on the part of the Mozambican and Cuban workers, however, but as a consequence of the prevalent racist attitudes in the GDR which were primarily directed at black contract workers (p. 99).

These acts of discrimination were not only carried out by East German administrators but also by local police and people intolerant of foreigners in the GDR. The media was forbidden to report any anti-foreigner incidents that occurred in the GDR (Ireland 1997, p. 549), which made these incidents invisible to the wider public. One instance, as Mac con Uladh (2005, pp. 146-150) recounts through police transcripts, highlights the tension between Cuban workers and East Germans. In Merseburg, a Cuban worker and an East German were involved in a conflict at a

${ }^{14} \mathrm{~A}$ Cuban colloquialism denoting a beating or a severe beating. 
nightclub. Testimony by other East Germans in the club that night suggests that the Cuban workers did not instigate the incident. Though they did not get into a physical altercation that night, it motivated the East German individual to round up a group of friends and target Cubans around town and assault them. The assaults sent three Cubans to the hospital and provoked a group of 23 Cubans to seek revenge for the attack. The conflict escalated, and violence ensued between the two groups. When a chase began, two Cubans were forced to jump into the river, where they drowned. One of the young Cuban men drowned because he could not swim and the other died when he was forcefully hit in the head by an East German. When the police arrived on the scene, no one alerted them to the two drowned individuals, and their bodies were found days after the incident. No one was charged, and the incident was deliberately overlooked (Mac con Uladh, 2005, pp. 146-150). ${ }^{15}$

\section{Differing Integration Experiences}

As can be appreciated from the above narratives and supported by several scholars (Mac con Uladh, 2005; Pérez Naranjo, 2014; Holtz, 2014), the living and working conditions of Cuban students, highly-skilled workers, and low-skilled workers varied considerably. Their contrasting experiences in the GDR invoke diverging paths of integration based on structural obstacles. For example, low-skilled workers had more boundaries imposed on them which reinforced their identities as workers rather than as members of their host society. One participant who migrated as a professional commented on the difference of life situations in the GDR:

\footnotetext{
${ }^{15}$ See Mac con Uladh (p. 147-150) for specific details involving this incident and related incidents.
} 
Life was hard for factory workers, they had to learn to use machineries that did not exist back in Cuba .... they also had so many restrictions and were not allowed to move around the city like we did. They were also under the constant threat of being sent back to Cuba if they misbehaved. Berlin treated me so well that I often reminisce about those times, but I realize that this was not the same for others.

For this participant, a sense of nostalgia was invoked with the memory of Germany. Nostalgia comprises memories and feelings strong enough to be longingly remembered even as time has passed. This participant created a life in Germany. This was harder for the low-skilled workers as structural obstacles hindered this process. Their place in Germany was situated as temporary through the threat of forced return to Cuba. Temporal situations discourage integration. The harsh working conditions and substandard living conditions also hindered their positive affective connection to Germany, cutting the threads of belonging and community. The regulation of their physical space and movement reinforced their place as contracted workers rather than free members of society. The language barriers further limited them through the ethnic insulation of their working and living situations and divided them from native Germans. The lack of attention to language acquisition coupled with the discouraging of inter-ethnic relationships strengthened the division between Cuban workers and the German mainstream.

Low-skilled migrants and professional migrants also occupied different statuses in the socioeconomic structure of the GDR. As Holtz (2014) argued, academic migration does not only benefit the receiving country, instead, skills and knowledge gained in the receiving country can then be brought back to the home country. As Holtz (2014) maintains that, "The single academic migrant is considered more important than the low-skilled worker who can be more easily replaced. Cuban 
academics migrants had a political and economic mission, as well as an academic one" (p. 469).

Cuban highly-skilled workers and students arrived in the GDR with an institutionalized form of social and symbolic capital (Bourdieu, 1987; see also Pérez Naranjo, 2014) through their educational qualifications and status as highly-skilled, which the low-skilled worker did not possess. This form of capital was enough to purchase a better standard of living and easier modes of integration within the GDR. The low-skilled workers were seen "as mere producers, contract workers were not seen as future propagators of a positive image of the GDR abroad and as such never enjoyed the same levels of immunity as international students" (Mac Con Uladh, 2005, p. 67).

Their living conditions helped shape and determine Cuban immigrants' paths to integration in the GDR in various ways. The way that Cuban immigrants became familiar with the German culture and its people influenced their path for integration. For example, Cuban students had opportunities to become intimately acquainted with East German culture through formal higher education and daily interaction with German peers and professors. In contrast, the low-skilled workers who primarily worked in factories were sequestered in migrant living quarters, and their interactions with East German peers were seldom amicable (Mac Con Uladh, 2005; Pérez Naranjo, 2014). These conditions also affected German language acquisition, which further stratified the integration experiences between Cuban students, highly-skilled workers, and low skilled workers and (Pérez Naranjo, 2014). The ability to speak the receiving country's language provided greater occasions for positive relationships 
between Cuban immigrants and the East German native population. Positive social interaction facilitated through language attainment is key for integration because, as contact theory states, the more contact with diversity in harmonious situations, the less prejudice there is (Allport, 1954). The highly-skilled workers in this study reported having good relationships with East Germans, which allowed them to feel accepted. One participant in my study sentimentally recounted how her Cuban and East German coworkers at the Cuban Embassy in Berlin often traveled to the Leipzig Fairs, where they would smoke menthols and drink Gluhwein together. ${ }^{16}$ She finished her interview with this sentence: "I must have been born German in another life because my time in Germany was the best in my life."

\section{Cuban Returnees: Maybe More Integrated Than They Thought}

Cubans who returned to Cuba faced several issues. Participant interviews frequently found a reverse culture shock for the Cubans re-integrating into Cuban society. The difference in the quality of living and customs they had adapted to in the GDR presented a barrier to re-adaptation. One participant described her adverse reaction when she first arrived in Cuba and noticed the difference in terms of lack of resources and infrastructure:

When I first arrived in Cuba after four years overseas and saw the dilapidated buildings, people walking in the streets without shoes, and the poverty ... I wanted to die. I couldn't believe that this was my life. The cold water, no electricity, barely any food. I would often have nightmares about it.

\footnotetext{
${ }^{16}$ A warm spiced wine served during winter in Germany.
} 
Another participant said the shock of being back in Cuba did not present itself immediately but only when a clash of cultural traits, rather than material necessities, occurred:

At first, I wasn't so shocked to be back in Cuba because I was happy and excited to see my family. I brought a bunch of gifts for my niece and I couldn't wait for her to see them. I traveled back to Cuba on my every vacation so coming back here felt like another vacation. Then a couple weeks later my mom had guests over in the house and everyone began talking so loud and all at the same time. I started sobbing in front of everyone and my body began shaking. My mom asked me what was wrong and everyone looked worried but I couldn't get a word out from how much I was crying. Back in the GDR I had my own private quiet apartment and my friends, both Cuban and German, interacted differently. I was used to the reserved German way of life. When I finally found my voice, I told my mom's friends that I was just not used to such loud noises, one of my mom's friends laughed and said I had become muy fina ${ }^{17}$ in Germany. I suffered so much because not only was everything different but my family did not understand why I as so bothered by things like loud talking.

Although a small difference such as the loud speaking by an animated group

of friends, it drove my participant to tears. For her, one marker of German identity in her experience was the formality and quiet composure of interaction among peers.

When presented with the opposite upon her arrival, it brought her identity into

question. The above participant interestingly added:

I didn't feel completely Cuban anymore. After so many years in the extranjero ${ }^{18} \mathrm{I}$ became una extranjera ${ }^{19}$ in my own home. I didn't want to date Cuban men anymore because of the way they interacted with me and the way they spoke. German men were so much reserved and calm .... for example, a good German friend of mine liked me but he was so reserved he never asked me out on a date even after years of knowing me! I only found out he liked me after a mutual friend told me years later.

\footnotetext{
${ }^{17}$ Directly translates to "too fine" which is a Cuban colloquialism that roughly denotes a person that is very elegant or delicate.

${ }^{18}$ Translates to a foreign place.

${ }^{19}$ Translates to a foreigner.
} 
The confusion and frustration my participant felt stem from the different cultural environments between Cuba and Germany. My participant felt like a foreigner because she felt in-between the society she grew up in and society she had become accustomed to. She negotiated her place within both cultural structures through a meso-level ${ }^{20}$ participation. She began working at a hotel, which allowed her to socialize with other Cubans who had formerly worked in the GDR and with German workers and visitors. ${ }^{21}$ There she was able to continue speaking German and partaking in an environment that resembled her former life in the GDR. Her space of employment became a mediating place of identity.

Besides the reverse culture shock and re-integration, some guest workers faced professional difficulties as well. Workers sent to the GDR to train in new technology found themselves unable to apply those skills in Cuba because the technology from the GDR was not always available in Cuba (Pérez Naranjo, 2014). These workers found themselves in the unique position of having skills and qualifications that Cuba could not accommodate.

\section{Fall of the Berlin Wall and the Second Migration Wave: Post-German Reunification: Mid-1990s until the Present}

After German reunification in 1989, Castro ordered Cubans to return to Cuba, and guest worker agreements ended (Ireland, 1997; Mac Con Uhladh, 2005; Pérez Naranjo, 2014). Some Cubans ignored the decree and stayed in Germany (Holtz,

\footnotetext{
${ }^{20}$ Meso-level is in-between micro and macro levels of society such as communities or social groups.

${ }^{21}$ Cubans were mostly not allowed to stay in the hotel with the only exception of Cubans married to foreigners and were subjected to verification.
} 
2014, p. 471; Pérez Naranjo, 2014). Those who decided to challenge Castro's order and stay, encountered several issues in the new Germany. After Germany's reunification, factories under the GDR regime were closed and universities changed their operations (Pérez Naranjo, 2014). Additionally, those who decided to stay in Germany were branded exiles. This was a precarious situation because it meant that they would sacrifice relationships with their families that were still in Cuba. As defectors, they had to sever ties with Cuba. They also faced great uncertainty and fear due to the changing political and social climate in reunified Germany. No longer residing under a socialist regime, Cuban immigrants did not know exactly where they stood in the newly reunified host country.

Unfortunately, German reunification increased racial discrimination and tension (Coester, 2010; Mushaben, 2010, p. 79; Boswell \& Hough, 2008; Faas, 2012). As one participant recalled, racial and ethnic tensions in the GDR were not just secluded to preindustrial areas. A group of Cubans who worked in the accounting office of the Cuban embassy in Poland and who were traveling in the GDR wanted to buy shoes in a popular store. The German cashier threw the shoes to the ground and refused to wait on them because they did not speak German and were foreigners. This ethnic, racial, and nationalist tension was only intensified after reunification, ${ }^{22}$ as data from the Federal Criminal Police Office ${ }^{23}$ in Coester's study (2010, p. 57) suggest. This rise in discrimination brought new challenges where "the hatred of foreigners,

\footnotetext{
${ }^{22}$ See Ireland (1997) for an in-depth look into the ethnic tension of East Germany.

${ }^{23}$ Figure 4 in Coester (2010, p. 57) study summarizes data from the German Federal Police and notes that there is a spike of "Right-wing extreme criminal offenses" in the immediate years after Reunification.
} 
mainly asylum seekers, spread through the whole of Germany and peaked in 1993 with 34 murders and attempted murders" (Coester, 2010, p. 52). Integration into the GDR brought its challenges, but now a double integration into a reunified Germany brought a unique twist to national identity and belonging. The German nation has been subjected to constant ideological chaos since World War I, and with reunification, it was once again thrust into disarray (Silver, 2010). The East and the West of the country, which had created separate national identities, were now suddenly brought together. Although East and West Germany have been politically reunified, its identities have not entirely been meshed together (Gruning, 2010; see also Zazilska-Florczuk \& Ciechanowicz, 2011; Faas, 2016, p. 42).

Take the neighborhood of Marzahn, for example, as it was explained to me by a participant $\mathrm{t}^{24}$ who regarded it as an exclusionary space since "that neighborhood is East Berlin and a lot of Neo-Nazis live there. Even though nothing has ever happened to me the times I've been there, I try to stay away and you should too." Instead of referring to the neighborhood as former East Berlin, it was still currently East Berlin in the participant's imagination. The quest for a unified German identity is still in flux, making immigrants' incorporation a complex and contradictory process. Cuban immigrants were now tasked with integrating into a country that is still trying to create a unified German identity. This presented another dimension of difficulties for the Cuban migrants who decided to stay in Germany.

Pérez Naranjo (2014) claims that the majority of Cubans did not stay in Germany but rather returned to Cuba (see also Hotlz, 2014, p. 471). There were 4,317

\footnotetext{
${ }^{24}$ My participant is an Afro-Cuban female and regards Marzahn as a distasteful place for the only foreigners but for Germans as well.
} 
Cubans in Germany in 1990 (Pérez Naranjo, 2014, p. 101) these numbers dropped to 3,362 in 1991 (Pérez Naranjo, 2014, p. 101). These statistics suggest that the majority of immigrants did not return to Cuba but rather stayed in Germany after the fall of the Berlin Wall. Pérez Naranjo (2014), however, suggests that rather than Cubans staying, a new migration of Cubans occurred after 1990. Some of my participants support this assertion. One participant married a German in Cuba and moved to Germany in the early 1990s. Another began his studies in Germany but went back to Cuba and years later finished his studies in Germany. During the 1990s, Cuba experienced the Periodo Especial, described as "the greatest crisis that the Revolution has had to confront in its history" (Lara, 1999, p. 232 as quoted in Cunha \& e. Cunha, 2008, p. 210). At this time, Cubans were faced with extraordinary hardship, hunger, and destitution (Berg, 2011, pp. 63-64). According to some accounts, some people were forced to season and fry pieces of rags to have something to eat. ${ }^{25}$ This economic crisis initiated a period of large-scale emigration (Berg, 2011, p. 64; Holtz, 2014, p. 471). Although most went to the U.S. and Spain, Cubans also emigrated to Germany (Pérez Naranjo, 2014). Connections to people in Germany and marriage to Germans made emigration possible, leading to a count of $8,383^{26}$ Cubans in 2004 (Pérez Naranjo, 2014, p. 102). It stands to reason that the majority of Cubans did return to Cuba after reunification and that many re-migrated to Germany following reunification.

\footnotetext{
${ }^{25}$ Accounts noted by friends and relatives who lived during that time in Cuba.

${ }^{26}$ I urge readers to take these statistics lightly due to the variability of German Census data concerning the foreign population.
} 
After the fall of the Berlin Wall and the dismantled Soviet Union, the official guest worker agreement between Cuba and Germany ended (Pérez Naranjo, 2014). Currently, Cubans who migrate to Germany do so through marriage and family reunification (Pérez Naranjo, 2014; Holtz 2014). Because of the longstanding GDRCuba relationship, Germans became familiar with Cuba. Cuba is also a popular tourist destination because of the tropical climate and its famous beaches in Varadero. Cuba is also romanticized in German imagery, as my participants noted the favorable sentiments Germans had for Cubans. One participant even said that her place of employment in a popular Berlin upscale mall would be hosting a Cuban-themed party in the upcoming weeks. In turn, Cubans also hold Germans in high regard. CubanGerman marriages became one of the primary paths for post-reunification immigration. Cubans who wanted to marry Germans ${ }^{27}$ had to pay a fee for permission and be married by a notary specifically for foreigner-Cuban marriages. Cubans married to foreigners were also not allowed to work in Cuba any longer. The Cuban government also investigated relationships with marriages to foreigners. A participant remembered an instance right after her marriage to a German:

After I got married, the comite ${ }^{28}$ of the neighborhood reported that a German was living in one of the households in the neighborhood. A car full of officers from the State Security arrived at my house to verify what was going because a house with a foreigner meant there were American dollars circulating in that household and possible illegal businesses. They started asking me questions about his presence in the household and when told them that I was married to him, they looked at me in shock. They kept asking "What do you mean married to a German? You are not allowed." I explained that I legally married him and I showed him our marriage certificate and our receipt of the fee we

\footnotetext{
${ }^{27}$ Or any foreigner.

${ }^{28}$ All neighborhoods in Cuba have a Revolutionary Defense Committee that oversees the neighborhoods' activities.
} 
paid, which was almost $800 \$$, to be married. They then took my husband to their office to further ask him questions and to verify the notary because the notary was part of a Foreign-Cuban company in Havana that married Cubans with foreigners.

All my participants who married Germans in Cuba eventually emigrated. One participant whose grandmother is German and grandfather is Cuban ${ }^{29}$ stayed in Cuba for decades. When she, her mother, and uncle moved to Germany, her grandparents decided to join them there. The spouse of the German is granted the right to apply for a German visa. Before migrating to Germany, the Cuban must visit the German embassy and apply for a visa. Once positioned as "documented" 30 immigrants, Cubans enter Germany in a comparably better socio-political position compared to undocumented immigrants. This facilitates the path toward integration since the very act of being labeled "documented" carries advantages. Moreover, scholars argue that migrant networks (Palloni, Massey, \& Ceballos 2001; see also Elrick \& Ciobanu, 2009, p. 102) such as family and friends in Germany help Cubans migrant to Germany and simplifies the process of immigration and integration.

Besides marriage and family reunification, some Cubans migrate to Germany through academic and professional methods. For example, one man and his wife were granted a visa to visit Spain to attend a literary conference. The man was warned by a friend that Cuban officials were becoming concerned about his books and revolutionary status, so he and his wife decided to stay in Spain. His two children

\footnotetext{
${ }^{29}$ My participants' grandparents were not interviewed because they were unavailable at the time of my fieldwork.

${ }^{30}$ In this research, I use the term "undocumented" rather than "illegal" because the latter carries derogatory implications.
} 
were not granted visas to join them overseas and had to wait for years before they reunited. The man was later offered an employment opportunity in Germany, where he applied for asylum and currently lives there with his family. Another example is a musician who was granted permission to go to Europe to play with his band and now divides his time between Spain and Germany. Germany has a growing fascination with salsa music. Berlin hosts several salsa music festivals, and Cuban bands are often invited to play in restaurants and nightclubs. The second wave of Cuban migration to Germany can be characterized as mostly legal migration in terms of marriage and family reunification. Professional and academic methods of migration have also been employed such the two examples mentioned above.

\section{Conclusion}

The first wave of Cuban migration to Germany started taking place after the Cuban Triumph of the Revolution in 1959. Those who migrated before the fall of the Berlin Wall went to the GDR under bilateral agreements between the Soviet Union and Cuba. These agreements allowed Cuban students, highly-skilled workers, and low-skilled workers to migrate to the GDR under academic and employment contracts. The conditions of arrival and integration during their time in the GDR between these two groups varied considerably. Cuban highly-skilled workers and students, arrived with a more fortunate socio-political position. Consequently, they enjoyed greater freedoms, privileges, and positive intergroup interactions. Lowskilled workers were mainly sent to work in factories that usually resided outside of 
city centers (Pérez Naranjo, 2014). They also often faced with greater restrictions, discrimination, and negative intergroup interactions.

After German reunification, those who stayed in Germany, regardless of sociopolitical status, faced issues related to the sudden change of government and society. Those who returned to Cuba, reportedly the majority, encountered issues as well. They found it difficult to re-integrate into a society they no longer were accustomed to. Some workers and students found they had acquired skills in the GDR that Cuba could not accommodate. During Cuba's Periodo Especial, Cubans migrated en masses, seeking better economic, social, and political opportunities elsewhere. Those who returned to reunified Germany did so primarily through marriage and family reunification, aside from those who used academic and professional opportunities to travel and then defect. Thus, Cuban migration to Germany can be categorized into two main waves, each with its defining characteristics. 


\section{MEASURES OF INTEGRATION}

This chapter examines the measures used to analyze Cuban immigrant integration in Germany, as seen in Figure 2. It also introduces the significance of each integration measure and thus why they are used in this research. Furthermore, as Goodman (2010; see also Green, 2007, pp. 106-108) have argued, there has been a refocusing of integration that emphasizes the importance of social-civic commitment to the receiving host country. Goodman (2010) describes civic integration as:

the idea that successful incorporation into a host society rests not only on employment (economic integration) and civic engagement (political integration), but also on individual commitments to characteristics typifying national citizenship, specifically country knowledge, language proficiency and liberal and social values (p. 754).

Taking inspiration from Goodman's (2010) definition and the fact that she describes integration as a "performance" (p. 755), besides using integration measures such as citizenship acquisition and the labor market, this study also investigates measures of belonging and identity. This chapter begins by presenting the importance of citizenship acquisition for immigrant integration, followed by an examination of language attainment and the labor market as integration measures that drive immigrant incorporation in Germany. These three measures reinforce the discussion on one another as the legal, economic, and social are interrelated spheres of integration. To further investigate the social aspects of integration, this chapter also explores intermarriage, religion and religious identity, and identity, belonging, and receptivity. These last three integration measures are used to discuss the personal and lived experiences of integration. 
Therefore, this chapter not only analyzes how Cubans integrate into legal and economic structures but also how they negotiate their identities, formulate belonging, and reflect on their experiences in Germany. Together, these six integration measures, as represented in Figure 3, engage in a relationship where they interact and affect one another. Each individual integration measure narrates a specific aspect of Cuban integration in Germany and produces an alternative narrative to integration in Germany.

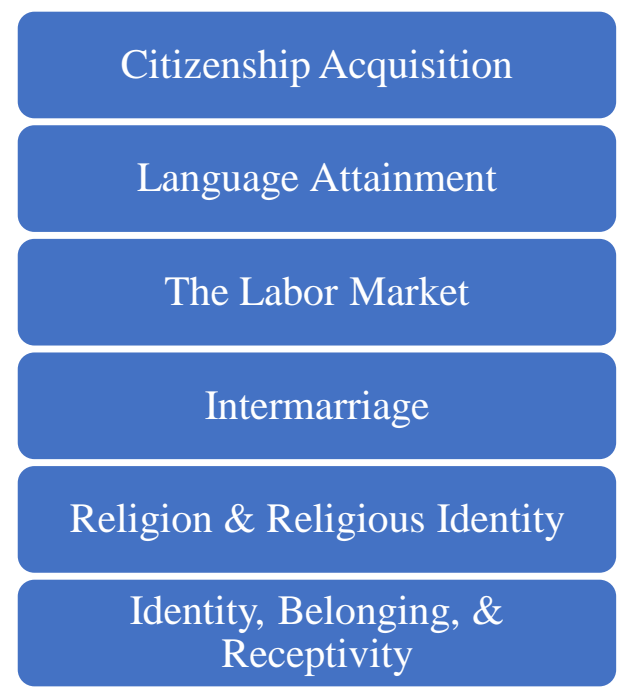

Figure 2: Integration Measures 


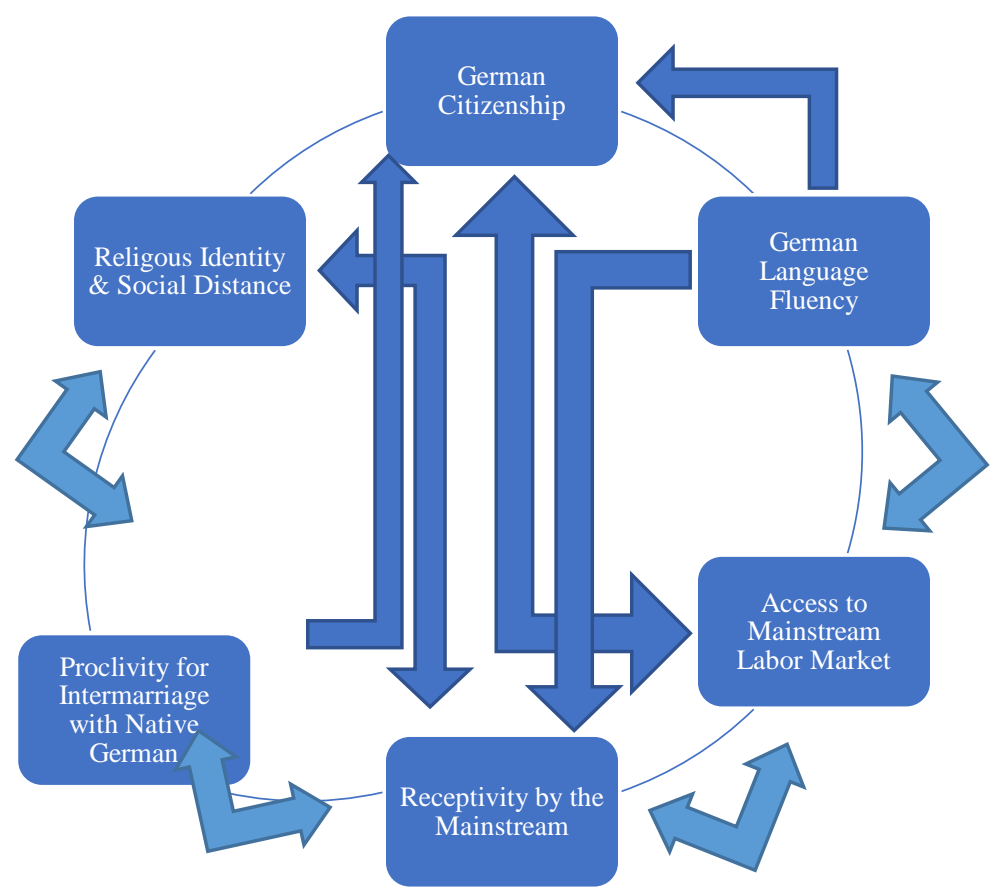

Figure 3: Relationship Between Integration Measures

\section{Citizenship Acquisition}

Acquiring the citizenship of the receiving nation is an important marker of integration for immigrants. It is not just a legal acceptance (Brubaker, 1992; Alba, 2005; see also Bloemraad, Korteweg, \& Yurdakul., 2008; Goodman, 2010), but it initiates an emotional connection to the host country, as "citizenship is not only about the enjoyment of rights and the performance of duties as a full member of a political community; it also confers an identity and a feeling of solidarity with other citizens" (Kaya \& Kayaoglu, 2014, p. 114; see also Alba, 2005; Diehl \& Schnell, 2003; Bloemraad et al., 2008; Goodman, 2010) Moreover, obtaining citizenship can be a safeguard against injustice or abuse (Moynihan, Gaboury, \& Onken, 2008). As 
Moynihan at al. (2008) argued, "abusers use their power and control to influence the victim's immigration status and often use threats of deportation to prevent their victims from seeking help" (p. 124). One participant who arrived in Germany through marriage suggested that her citizenship facilitated a path out of an abusive marriage:

My husband turned emotionally abusive as the years went on, I had to seek a lot of professional help to undo the damage that he did to me. I still have a lot to work through, but I am better now, I am a lot happier now ... I was so in love with him that I left everything in Cuba and followed him to Germany blindly. But while I was with him I felt worthless .... now I am a German citizen and I have a part-time job and a nice apartment. I made my own life here in Germany that I love ... I work my part-time job and then go home to my son and during my time off I go to QBA, ${ }^{1}$ which gets wilds sometimes, and dance and drink with my friends until late. I am very happy now.

Arriving in a foreign country with no friends and family and on a temporary visa/residency did not allow her much independence from her German husband, especially since her citizenship was contingent upon being married to him for a certain length of time. Being awarded citizenship opened a new pathway toward integration into German society that included self-sustainability and independence. Citizenship is also important for integration because to enter the labor market in equal terms as the native population, one must obtain it. The German labor market gives preference to German citizens (Kogan, 2007; 2011), and without citizenship, it can be difficult to find employment. In my own experience, when I was applying for a consulting position in Munich, I not only had to prove I was "highly qualified," but my prospective employer also had to prove that the work I was applying for could not be done by a German citizen. Obtaining German citizenship opens a wide channel of

\footnotetext{
${ }^{1}$ A Cuban restaurant/bar in Berlin that hosts salsa nights.
} 
economic opportunities that are otherwise legally closed. German citizenship defines one's position within politics, society, and the labor market.

Traditionally, to be considered part of the German nation and subsequently gain citizenship, one had to be ethnically German (Brubaker, 1990;1992; Alba, 2005; Bloemraad et al., 2008; Williams, 2014). Although this changed in 2000 (Anil 2005; Avci, 2006; Williams, 2013) when Germany's immigration laws were revised, the ethno-nationalist sentiment still seeps into the rhetoric and discourse of citizenship and integration. As Piller (2001) stated, "it is not uncommon to speak of 'Auslaender in der dritten Generation,' 'foreigners of the third generation', and where many migrants and their descendants have not been able to obtain the citizenship" (p. 260). Partly to blame for the lack of citizenship attainment is that public officials in Germany tend to see citizenship as a reward for integration rather than a pathway toward integration (Ersanilli \& Koopmans, 2010; Williams, 2014). The acquisition of German citizenship is a narrative in of itself. Not only does it carry sociopolitical and symbolic significance, but it also stands as a testament to the integration process. It is also likely that once awarded German citizenship, the naturalized immigrant is relatively integrated. Citizenship acquisition means that the person has learned enough German to pass the language requirement, since he or she must achieve at a least B1 level² (Pochon-Berger \& Lenz, 2014, p. 9; see also Anil, 2005, p. 455; Williams, 2014, p. 70). The person must either directly pass the language exam or provide a certificate to attest to his or her language capabilities. It also means that the

\footnotetext{
${ }^{2}$ For a detailed explanation of each German language fluency level, see the Goethe Institute website at https://www.goethe.de/ins/us/en/spr/kon/stu.html.
} 
person or family is financially self-sufficient as demonstrated by the fact that they are not reliant on government welfare (Anil, 2005, p. 455). ${ }^{3}$ This requirement shows the interconnectedness of the legal, economic, and social processes of all six integration measures.

\section{The Importance of Language Attainment}

The acquisition of the receiving country's national language is a fundamental indicator of successful integration (Pochon-Berger \& Lenz, 2014, p. 14; see also Shohamy, 2006). Flubacher and Yeung (2016) state that the European model argues for language attainment as a necessity when integrating into immigrants' host because it "enables all other forms of (employment, educational, and cultural) inclusion" (p. 600). This makes sense especially when considering that unlike the United States, European states have one or more official national languages that are both ingrained in every aspect of the nation and define the nation itself (Piller, 2001). Take the German case, for example. Stepping aside from the issue of immigration to dissect the discourse of difference, tension can arise even from intragroup dynamics. This intragroup conflict stems from cultural and socioeconomic regional differences that are deemed contradictory. For example, East and West Germany, although no longer having a wall as a barrier between the two, still have cultural and social barriers (Silver, 2010; Gruning, 2010; see also Zazilska-Florczuk \& Ciechanowicz, 2011). Not only have the feelings of Otherness (Said, 1978) shaped through the geopolitical

\footnotetext{
${ }^{3}$ For a complete list of citizenship requirements, see The Federal Minister of the Interior, Building and Community website at

https://www.bmi.bund.de/SharedDocs/faqs/EN/themen/migration/staatsang/Erwerb_der_deutschen_St aatsbuergerschaft_durch_Eingbuergerung_en.html
} 
conflict of the Cold War era been internalized by the two regions, but distinct cultural ideologies have also emerged. The political and social structures of the socialist and democratic systems have seeped into the feelings of identity and belonging. ZazilskaFlorczuk and Ciechanowicz (2011) showcase statistics indicating there are people that still view East and West Germans as distinctively different (p. 17). Some scholars go so far as to say that East and West Germany are parallel societies, with language acting as the unifying force (Zazilska-Florczuk \& Ciechanowicz, 2011, p. 19).

The slogan "One Language, One Nation" (Piller, 2001, p. 261; Blackledge, 2009, p. 7), often heard within integration and nationalistic discourse, suggests that the strongest unifying force between the native and immigrant population is language. As Shohamy (2006) argued, "language continues to be used as a symbol of integration and belonging to the nation" (p. 2). Thus, language can either facilitate inclusion or produce exclusion (Blackledge, 2000; 2009; Piller, 2001; Shohamy 2006; Biedinger et al., 2015). It is also a marker that produces "justifiable" discrimination within Germany because it is neither an ascribed status, nor is it contingent upon socioeconomic class. ${ }^{4}$ Discrimination toward attributes such as race, ethnicity, religion, and even social class is deemed immoral. Discrimination based on language is not just accepted but is legally inscribed into society and institutionalized via citizenship requirements (Shohamy, 2006) and labor market opportunities (PochonBerger \& Lenz, 2014; see also Pütz 2008; Drever \& Hoffmeister, 2008; Biedinger et al., 2015; Alba \& Foner, 2016). Specifically, discriminatory policies based on

\footnotetext{
${ }^{4}$ However, it should be noted that socioeconomic class can factor into language acquisition in terms of access to language courses.
} 
language are structuralized within the labor market in Germany. To enter the labor force,,$^{5}$ a non-citizen must give proof of his or her language qualifications. Without these documents attesting to one's fluency, "you basically can't find work," as one participant stated. Huschke (2014), whose ethnography focuses on undocumented Latin Americans in Berlin, explained that those who cannot enter the labor market legally are employed in low-skilled occupations such as "cleaners, babysitters, servants" (pp. 2014-2015). Those who enter the German labor market by nontraditional methods are not just undocumented individuals, but also those who lack German fluency (Pérez Naranjo, 2014). One participant who has been in Germany since she was 21 years old and who is now 39 , helped her brother immigrate to Germany recently. Although he is documented, he cannot speak German and found it difficult to obtain a job until a friend was able to help him. Without the help of already established points of contacts, my participant's brother would have been unable to find adequate work.

Through this institutionalized discrimination, failure to acquire the receiving nation's language is negatively viewed and seen as a failure on the immigrant's part (Pochon-Berger \& Lenz, 2014, p. 14). In countries such as Germany, which strongly defines identity through sociolinguistic markers, not learning German is perceived as offensive and even threatening (Pochon-Berger \& Lenz, 2014; see also Wright 2011). The discourse surrounding the failed integration of immigrants in Germany often points at the immigrants' perceived rejection of the German language. This is both emotionally and discursively translated to the rejection of Germany itself by

\footnotetext{
${ }^{5}$ Exceptions are sometimes made if the job is primarily conducted in another language other than German and/or is based on highly-skilled work.
} 
immigration opponents. Consequently, it incites xenophobia and discrimination among native Germans because rejection leads to aggressive tendencies, as Leary, Twenge, and Quinlivan's (2016) psychological study on aggression has shown. A demand for the acquisition of the host country's native language is also a demand toward integration. Unfortunately, when an immigrant does not acquire the native language and is deemed not integrated, a stereotype arises. Such stereotypes tend to be focused on the Turkish immigrant group because not only are they the majority immigrant group, but "the share of Turkish immigrants with a good command of German is lower than in other labor migrant groups"6 (Becker, 2011, p. 430; see also Pütz, 2008; Verdugo \& Müller, 2009). This stereotype is then projected toward all immigrants and foreigners and is at the center of exclusionary discourse, creating a metanarrative that affects the trajectory of integration.

\section{The Labor Market}

Entering the labor market in a receiving country is an important indicator of integration because it provides self-sufficiency and economic integration within the receiving nation. Obtaining employment also means a pathway toward German citizenship because applicants cannot be dependent on welfare. Entering the labor market not only means integrating economically but is also a push forward social and cultural integration. Based on the capitalist and neoliberal model that shapes both the economic and the social ideologies of Western nations, the labor market is a

\footnotetext{
${ }^{6}$ There are several socioeconomic and sociopolitical reasons behind this statistic; see Becker (2011) for an overview on some.
} 
monumental and necessary aspect of the immigrant experience. However, entering the labor market is a complicated task. Immigrants, especially those from nonWestern nations, when entering the labor market of a Western nation, face several obstacles. Compared to native citizens, immigrants face a much more demanding process of navigating the labor market overall (Chiswick, 1978; Kogan, 2007; Ballarino \& Panichella, 2015; 2018). To begin with, one important struggle pertains to acquiring the language of the receiving country. Without German language abilities, access to the labor market is limited because one must provide language fluency documentation when applying for employment (Pochon-Berger \& Lenz, 2014; see also Alba \& Foner, 2016). Additionally, in Germany, "lack of language competency is thus often the cause of career discrimination" (Pütz 2008, p.519; see also Biedinger et al., 2015).

Immigrants are often faced with ethnic discrimination, both individualized and institutionalized, within the labor market (Kogan 2004, p. 421; Silver, 2010; Kesler, 2006; Constant et al., 2011; Kaas \& Manger, 2011; Ballarino \& Panichella, 2015; see also Bürgin \& Bürgin, 2013; Alba \& Foner, 2016). In the United States, ${ }^{7}$ employers will at times provide a guideline that will clearly advise the applicant against submitting a picture within their resume. In Germany, it is commonplace and considered professional to provide a photo along with a resume. Moreover, there tends to be discrimination towards the applicant's name depending on its ethnic background. For example, Kaas and Manger (2011) sent out a series of job

\footnotetext{
7 This is not to suggest the lack of discrimination in the U.S. labor market, but rather there are certain methods taken to address and reduce it. It should also be noted that name-based discrimination is also present in the U.S, see Bertrand and Mullainathan (2004).
} 
applications in Germany. Half of the applicants had a German-sounding name, and the other half had a Turkish-sounding name. Even though there were no other discernable differences between resumes, the German-sounding name produced less rejection and a higher success rate (see also Bürgin \& Bürgin, 2013, p. 465; Çelik, 2015, p.1649). This is the main reason why some of my participants who married Germans opted to change their last names to their spouses' last name: "In Cuba no se $u s a^{8}$ changing your last name to your husband's last name. But here in Germany, Cubans that marry Germans tend to change their last name to their German spouses' last name"

Constant et al. (2011) identify two categories of ethnicity, the inescapable ascribed status ${ }^{9}$ and the fluid and achieved status ${ }^{10}$ (p. 755; see also Wright, 2011, p. 839). The participants who chose to change their last names to a normative Germansounding name tended to be less ethnically indistinguishable. Consequently, they could strategically navigate the ethnic characteristics of the native population. Their ethnic fluidity granted them "blurred boundaries" (Alba, 2005), in which the lines of difference between them and the native population were distorted. This distortion of noticeable differentiation facilitates integration because it lowers the chances for discrimination. As a white middle-class participant who immigrated before 1990 stated, "Cubans here blend in, they don't really standout." Another participant of mixed race conversely said, "If by any chance you forget that you are not German,

\footnotetext{
${ }^{8}$ Translates to "Not used" but denotes more along the lines that it is not popular or not in fashion.

${ }^{9}$ A sociological term denoting a status that one is assigned to at birth and that one cannot change.

${ }^{10}$ A sociological term denoting a status that one can change throughout life and that is "chosen."
} 
they [Germans] will remind you." Those who could ethnically "blend" into the native society enter the labor market through a more privileged position (Constant et al., 2011; see also Badwi, Ablo, \& Overå, 2018, pp. 28-29). This position is not available to all immigrants, not even to all immigrants within the same nationality, as seen by the different responses given by these two participants. Furthermore, the unemployment rates are high among immigrants in Germany (Worbs, 2003; Kesler, 2006; Kogan, 2004; 2007; 2011; Constant et al., 2011; see also Faist, 1993; Drever \& Hoffmeister, 2008). Bürgin and Bürgin (2013) add that "the poor integration of persons with immigration background is shown by the unemployment rates for noncitizens" (p. 464). Beyond unemployment, immigrants tend to take lower paying jobs or positions that are not popular with the native population (Seifert, 1996; Kogan, 2004, 2007, 2011; Kesler, 2006; Constant et al., 2011; Ballarino \& Panichella, 2015; see also Faist, 1993). The uneven access to labor market opportunities is still true even in the second generation (Luthra, 2013). Moreover, as Riphahn, Sander, and Wunder (2013) found, immigrants are also more likely to be dependent on state welfare than the native population, which further decreases their chances of gaining citizenship and overall successful integration.

One noticeable cause of the discrepancies in entrance and opportunities within the labor market between immigrants and the native population is education. One difficulty brought up by participants in regard to their struggle within the labor market is recognition of their educational qualifications by the receiving country (Pütz, 2008, p. 518; Drever \& Hoffmeister, 2008, p. 432; Pérez Naranjo, 2014, p.277; Ballarino \& Panichella, 2015, p. 341). Recognition of foreign educational or technical 
degrees can be a challenging and complicated process. The opportunity cost of this venture is also not always beneficial, especially considering that applicants run the risk of having the recognition denied and having the dedicated fee, time, and resources unreimbursed. The very act of being able to apply, having the capital, resources, and physical documents to navigate this process, is an act of privilege. One participant who was a writer and scholar in Cuba expressed his immense disappointment when he was not allowed to teach at a German university:

I wanted to be a German university professor. I have the qualifications and have published several books in both Cuba and here in Germany too. I have the respect of my peers, connections, and I am regularly invited to give presentations at the university. However, they told me I could not be a professor. They sent me a list of the things they needed, some of which were documents still in Cuba that I could not physically get.

Despite having the qualifications, my participant could not feasibly apply for recognition because it would be logistically impossible. Countries such as Cuba lag behind in technology and lack the resources to offer digital documents. Even if they were made available digitally, there is concern about whether or not the Cuban government would willingly provide them. Beyond the logistical intricacies of the recognition process, is that even if recognition is granted, it does not guarantee a job. Furthermore, if the person is not a German citizen, he or she is tasked with finding an employer who will testify he or she is taking a job no German can do. Germany is legally bound to give preference to its citizens within the labor market, which further limits access to non-citizens (Kogan, 2007; 2011). Beyond that, as Kogan (2011) confirmed, "highly qualified immigrants seem to face serious obstacles in the German Labour market, which is known for its pronounced segmentation along professional lines” (pp. 95-96; see also Faist, 1993; Bürgin \& Bürgin, 2013). Considering these 
factors, for an immigrant to enter the German mainstream labor market and seek equal opportunities, he or she must meet three minimum requirements: recognition of qualification and/or educational/technical degrees, German language fluency (Kogan, 2011, p. 95), and German citizenship.

\section{Education and the Labor Market}

Educational attainment is also a fundamental aspect of the labor market in Germany (Mayer, Müller, \& Pollak, 2007; Kogan, 2011; Ballarino \& Panichella, 2015; see also Drever \& Hoffmeister, 2008; Bürgin \& Bürgin, 2013). Access to education or a specific track in education funnels immigrants into specific segments of the labor market (Drever \& Hoffmeister, 2008). This segmentation is often unequal between immigrants and the native population due to the structure of the educational system. Especially since it has been argued that "class differences in educational participation and class differences in levels of education achieved are higher in Germany than in many other advanced societies" (Mayer et al., 2007, p. 247; see also Alba \& Foner, 2016). The German educational system is divided into two different routes. All students follow the same educational track until they are around ten years old (Crul \& Schneider, 2010, p.1259; Worbs 2013, p. 1019). From that point onward, the child must go into one of the three educational institutions (Worbs 2013, p. 1019; see also Faist, 1993; Alba \& Foner, 2016). The Hauptschule is the lowest educational track; the Realschule is similar but with more intensive technical training; and the Gymnasium is the pre-university level of education (Worbs, 2010, p. 1019; see also Faist, 1993; Faas, 2016). 
To attend university, students must obtain the Abitur certification in which Mayer et al (2007) reason that students who attend Gymnasium have a higher chance of passing this certification (p. 248). Children of immigrants have a tendency to attend Hauptschule and Realschule more than children of native parents (Worbs, 2010, p. 1019-1021; Bürgin \& Bürgin, 2013, p. 464; see also Drever \& Hoffmeister, 2008, pp. 430-431; Mushaben 2010, p. 81; Foner \& Alba, 2008, p. 731; Luthra, 2013, p.1096; Alba \& Foner, 2016, p. 9; see also Faist, 1993, p. 313). Auernheimer (2005) goes so far as to say, "the Hauptschule is often called a 'school for leftovers' In urban regions it has become the "school for foreigners or migrants"” (p. 80). Some scholars such as Constant et al. (2011, p. 761) have found that in some instances, immigrants perform better than native Germans in education. Other scholars such as Luthra (2013, p. 1096) have argued that immigrants' better educational performance has to do with their socioeconomic status. This means that an immigrant does as well, if not better, than the native German if they have a certain socioeconomic level (Luthra, 2013, p. 1096). If the immigrant arrives in Germany with capital and an equivalent level of education, this limit, if not eliminates, bias in their entrance and position within the educational system.

\section{Intermarriage}

Marriage between an immigrant and a native citizen is not only considered a significant indicator of integration, but it might be the most important indicator 
(Gordon, 1964; Kalmijn, 1998; Pagnini \& Morgan, 1990; Klein, 2001; Alba \& Nee, 2003; Lee \& Bean, 2004; Dribe \& Lundh, 2008; Song, 2016). Its significance lies in the notion that it is a pathway toward social integration and multicultural cohesion since "intergroup contact has a positive effect on structural integration" (Carol, 2013, p. 67; see also Allport, 1954). The blending of ethnic and national groups is of interest to integration scholarship because people tend to marry within their own groups (Kalmijn, 1998; Lucassen \& Laarman, 2009; Carol, 2013). When those normative lines of marriage cross over ethnic and national boundaries, barriers of difference are eroded, as argued by Gordon (1964). Education, neighborhood integration, availability of ethnic community and viable partners, socioeconomic status, religiosity, cultural ideologies, and reason for immigration influence the propensity towards intermarriage (Pagnini \& Morgan, 1990; Kalmijn, 1998, 2012; Klein, 2001; O’Leary \& Finnäs, 2002; Song, 2009, 2010; Lucassen \& Laarman, 2009; Furtado \& Theodoropoulos, 2009; Carol, 2013; Dribe \& Lundh, 2008; Schacter, 2016).

Levels of education have long been deemed a variable behind intermarriage ${ }^{11}$ for several reasons (O’Leary \& Finnäs, 2002; Dribe \& Lundh, 2008; Song, 2010; see also Kalminjn, 1998; Furtado \& Theodoropoulos, 2008). Individuals with higher levels of education tend to have more "liberal attitudes in terms of greater tolerance for partners of other groups and lower in-group marriage preferences"(O’Leary \& Finnäs, 2002, p. 236) Additionally, education encourages and facilitates residential mobility, as Dribe and Lundh (2009, p. 331) and O'Leary and Finnäs (2002, p. 236)

${ }^{11}$ See Song (2010) for a comprehensive argument on the connection between education and marriage. 
have argued. In terms of residential mobility, those who live in a mixed neighborhood and not in an ethnic neighborhood have a higher propensity toward intermarriage (Song, 2009; Dribe \& Lundh, 2008; Klein, 2001; Carol, 2013; Schacter, 2016).

Heterogeneous neighborhoods allow individuals to meet and interact with individuals of different ethnic and national origins daily, whereas in ethnic neighborhoods, an individual's daily interactions are mostly with same-group individuals.

Besides the physical geographic parameters, intermarriage relies on the actual size of both the ethnic and native groups (Klein, 2001; O’Leary \& Finnäs, 2002; Dribe \& Lundh, 2008; Song, 2009). The larger the in-group, the more chances of endogamy occurring, whereas the smaller the in-group, the greater the chances to intermarry. Klein (2001, pp.326- 327) takes this further when he takes the "sex ratio" (p. 327) of the groups into account. He gives the examples of guest workers in Germany and how the sex composition of this group is skewed toward males. Klein argues that because of this, male foreigners in Germany have a propensity to marry female Germans.

The socioeconomic status of the individual also affects the proclivity of intermarriage. Since people tend to marry along the same lines of class (Lucassen \& Laarman, 2009; see also Kalmijn, 1994), ethnic, racial, and religious lines might be crossed in marriage if the socioeconomic status of both individuals is similar. For some groups, religion tends to be a defining factor within the marriage decision process (Klein, 2001; Song, 2009; Lucassen \& Laarman, 2009; Carol, 2013; Kalmijn, 1998). Some groups tend to marry within the in-group because of their religiosity (Lucassen \& Laarman, 2009, 54) especially if the receiving country's receptivity is 
negative (Carol, 2013, p. 69; Schacter, 2016). Besides religion, another factor that influences intermarriage are the cultural ideologies of both the in-group and outgroup. For example, some groups that have "highly familistic cultures" (Dribe \& Lundh, 2008, p. 331) tend to marry within in-groups because of the cultural propensity toward in-group cohesion. Moreover, how different the in-group and outgroup are culturally will also influence intermarriage (Klein, 2001; See also Pagnini \& Morgan, 1990).

Another factor that significantly influences intermarriage is the reason behind their migration. Take Lucassen and Laarman's (2009, p. 54) example when they explained the lack of intermarriage between the Spanish immigrant community and the native Dutch. Lucassen and Laarman (2009) explain that the Spanish immigrants had the intent of returning to Spain rather than making the Netherlands their permanent home. In addition, the reason for the marriage itself should also be noted. Klein (2001) brings up social exchange theory, stipulating that intermarriages are influenced by benefits such as "economical security, an attractive partner, the attainment of the residence permit" (p. 328). Furtado and Theodoropoulos (2009) argued that one benefit of an immigrant marrying a native is that it facilitates access into the labor market because the native spouse acts as a "teacher" (p. 125) of the receiving nation. Therefore, noting the proclivity of intermarriage between Cubans and native Germans and which variables are important in partner selection, will explore the relationship between integration and intermarriage. Consequently, it will also further illustrate the interaction between the six measures of integration. 


\section{Religion and Religious Identity}

Germany is a secular nation, and Europe overall has seen a decline in religious institutions and religiosity (Pollack, 2002; Elff \& Rossteutscher, 2011). Moreover, more Germans are becoming non-denominational, non-practicing, and even atheists (Pollack, 2002; see also Foner \& Alba, 2008, p. 374). Still, the dominant Christian paradigm of European ideology (Xuereb, 2009, p. 36; see also Foner \& Alba, 2008, p. 374; Faas, 2016, p. 32) is deeply rooted in the German identity. In fact, Pollack (2002, p. 374) argues that the decline of religiosity "does not mean religion is generally losing significance." To which Daiber (1996, p. 415) adds, "having left the Protestant or Catholic Church, one can still describe oneself as Protestant or Catholic." Implying that institutionalized religion is transforming into individualized religiosity in modern times. Furthermore, statistics on the religiosity of Germans is not as important as the fact that Christianity has been institutionalized into the everyday structures of German society and politics. The institutionalization of Christianity turned Christian principles and ideologies into an invisible matter of fact of daily life in Germany. Besides the discursive and political significance of Christianity in Germany, religion, mostly Judeo-Christian, is taught in primary schools (Auernheimer, 2005; Alba, 2005). It is also ingrained in the public identity of Germany as Judeo-Christian holidays that are celebrated statewide, with Christmas market taking center stage every year (Alba, 2005, p. 33).

Those who "belong" are not aware of the effects religion has on integration measures, such as intermarriage, because it does not negatively impact them. I operationalize religious belonging as those who are members of a denomination of 
Christianity, non-denominational, or non-practicing. I do so because their identity is not negatively impacted by the Judeo-Christian religious structure. Whereas nonJudeo-Christian and non-western religious minorities have their ethnic and religious identity pulled into a dichotomous boundary of inclusion and exclusion (Zolberg \& Woon 1999, p. 7; Foner \& Alba, 2008, p. 374; Faas, 2016, p. 32; see also Statham, 2016). For immigrants, their religious identity in Germany can either facilitate or hinder their integration since "religion is seen in Europe as the marker of a fundamental social divide" (Foner \& Alba, 2008, p. 361; see also Alba, 2005). Furthermore, Miller (2012) goes as far to argue that "political officials have begun conflating religion with other cultural traits used to classify groups as 'worthy' or 'incapable' of integration” (p. 553). Therefore, where the immigrant's religious identity falls within the ideological boundaries of the receiving nation will factor into his or her integration experience.

\section{Identity, Belonging, and Receptivity}

Identity is a complex and multifaceted concept (Stryker \& Bourke, 2000; Wright, 2011; Maxwell, 2017;). Philosophers such as Descartes and Hegel, modern scholars such as Cooley and Mead, and even more recent scholars such as Derrida, Foucault, and Butler have all attempted to dissect identity. This fascination with identity thrives not only within the realms of academia, but also within national politics. Germany has been identified as an ethnonational state, which has developed through its historical fixation on common identity. German identity has taken on many forms through the ages, institutionalized through ethnic, racial, and 
ethnoreligious politics (Brubaker, 1990; 1992; Müller, 2001; Weil, 2002; Vick, 2003; Castles, 2006; Macias, 2009). Today, the German nation tries to distance itself from its discriminatory past (Müller, 2001) as it endeavors to transition to a more inclusive and multicultural definition (Williams, 2014). Thus, it is important to explore Cuban immigrant identity and belonging in Germany as it will further examine the changing context of German identity.

Furthermore, exploring my participants' identity thought their own interpretation was vital because as Binaisa (2012) explained, "self-reflexive articulations highlight migrants' negotiations of the socially constructed nature of their experiences" (p. 886). Articulating my participants' identity through their own perception thus allows for a greater exploration of the correlation between identity and integration. This study will also examine how they define "German" and how they narrate exclusion and inclusion in Germany. Therefore, exploring Cuban identity and belonging will examine how the Cuban diaspora is situating itself in Germany, how feelings of belonging and exclusion is interrelated to integration, and how identity fundamentally interacts with other measures of integration.

\section{Conclusion}

Acquiring citizenship is an important integration measure because as an immigrant becomes a citizen, they become part of the nation (Brubaker, 1992) and form an affective belonging to that nation (Kaya \& Kayaoglu, 2014). Language, as argued by Pochon-Berger and Lenz (2014, p. 14) is a fundamental measure of integration. Especially in the European context where language interacts with various 
other integration measures (Piller, 2001; Flubacher \& Yeung, 2016). For example, both citizenship acquisition and entrance to the mainstream labor market is contingent upon German language attainment. When discussing the labor market, it is important to point out that entering the mainstream labor market not only measures economic integration, but also social integration. For example, Verdugo and Müller (2009) argued that one of the reasons Turkish migrants are considered a parallel society is partly due to the isolation caused by the ethnic labor market.

Another important integration measure is intermarriage which has been considered one of the most important integration measures (Gordon, 1964; Kalmijn, 1998; Pagnini \& Morgan, 1990; Klein, 2001; Alba \& Nee, 2003; Lee \& Bean, 2004; Kalmijn, 1998; Song, 2016; Dribe \& Lundh, 2008). Intermarriage is the social and the legal manifestation of the blending of different groups. This blending erodes differences (Gordon 1964) and facilitates access to the labor market (Furtado \& Theodoropoulos, 2009). Additionally, religion and religious identity, though not an obvious or even prevalent integration measure, was necessary to address in this study. Religious identity is used as an abstract integration measure because religion is seen as a distinct boundary between inclusion and exclusion in Europe (Alba, 2005; Foner \& Alba, 2008). The last integration measure are three concepts. This study operationalized identity, belonging, and receptivity as a singular integration measure because they are intimately relational and dependent to one another. This measure examines integration through the participants' own identity, perceptions, and placemaking. In conclusions, this chapter examined the importance of each individual integration measures and demonstrated how interrelated all six measures were. 


\section{FINDINGS: CUBAN INTEGRATION}

This chapter will present the remaining findings of this study. It begins by examining Cuban immigrant citizenship acquisition and then moves to examine Cuban language attainment in Germany. The following section explores Cubans within the German labor market and provides a subsection addressing CubanGermans in the educational system. This chapter then continues by analyzing intermarriage with an accompanying subcategory of dating/inter-marrying a nonnative German member. The following section addresses Cuban identity, including religious identity, in Germany with an additional analysis on supranational identity and the Cuban perception of German identity. Along the same lines, this chapter presents how Cuban immigrants feel regarding discrimination, receptivity, transnationalism, and spaces of inclusion and exclusion in Germany. This chapter concludes by answering if Cubans are integrating and then addressing the difference in the degree of integration between the two main migration waves. By exploring these topics, the diversity of the Cuban diaspora, the relativity of integration, and the complexity of identity becomes clear.

\section{Cuban Citizenship Acquisition}

All of my participants were documented immigrants in Germany. Eighteen of the twenty-two participants who reside in Germany ${ }^{1}$ were German citizens. The four

\footnotetext{
${ }^{1}$ Three of my 25 participants did not live in Germany at the time of the interviews. These three participants were integral to the sociohistorical analysis during Cuba's bilateral agreement with the GDR as one participant was an official from the Cuban government, one applied as a guest worker twice and ended up in Poland but would often visit the GDR, and the third participant lived and worked in the GDR.
} 
who did not have German citizenship either had Spanish citizenship, a residency permit, or a temporary worker visa. All except the Spanish citizen announced their intention of one day obtaining their German citizenship. Not only were they all documented immigrants, but some had even acquired the Permiso de Residencia en el Extranjero from Cuba, which secured their right to their property back home and to freely travel back to Cuba (Berg, 2011, p. 15; Pérez Naranjo, 2014, p. 192). This visa nurtures transnational networks.

However, a participant narrated the unfortunate circumstance one of her friends was currently in because of retaining this transnational network without German citizenship. This is a second-hand account of the person's situation because the original person was unavailable to be interviewed. It appears that her friend's son stayed too long in his visit to Cuba past his visa allowance and has not been able to legally return to Germany. As my participant stated, "if he were a German citizen, this wouldn't be happening... but because of his permit, there are so many things you have to pay attention to." Obtaining German citizenship allows for another layer of autonomy and self-determination regarding transnational visits. It was noted, however, that the longer a Cuban migrant has lived in Germany, the less frequent these visits to Cuba were regardless of citizenship. In this study, the recently immigrated tended to visit Cuba more often more than who have spent longer periods of time in Germany, who often have limited or altogether stopped traveling to Cuba. Regardless, being a German citizen gave them the freedom to travel where they pleased, as Alba (2005, p.27) noted when discussing citizenship as a boundary. As a participant concluded, "with a German 'reisepass'... the same with an American 
passport like yours ... you can go wherever you want". In her perception, holding German citizenship equated to autonomy of choice.

The post-1990s wave of Cuban immigration to Germany consisted primarily of marriage or family reunification cases. It can then be stipulated that the migrant networks (Palloni et al., 2001; Elrick \& Ciobanu, 2009, p. 102) provided by the conditions of arrival via marriage or family reunification facilitate citizenship acquisition and integration. Cuban immigrants who migrate through marriage or invitation visas ${ }^{2}$ already have a point of contact, usually people who are either fully or relatively integrated already. These points of contact help navigate the receiving country and its legal processes toward citizenship. Furthermore, migrating legally to Germany gave them greater access to resources. With legal documents, immigrants have the right to services such as government assistance or access to health care. Without any documentation, one cannot even apply for an insurance card (Huschke, 2014). To be undocumented is to virtually not exist in Germany. As one participant said, "If you do not have papers here in Germany, you have no work, you have no help. You are on your own.” All my participants were legally residing in Germany.

\section{Cuban Language Attainment}

Most of my participants residing in Germany, ${ }^{3}$ except five, are either fluent or conversational in German. All the participants who immigrated before the 1990s migration wave were fluent German speakers. The language attainment levels of

\footnotetext{
${ }^{2}$ Known as "carta de invitacíon" in Cuba.

${ }^{3}$ One participant that worked in the GDR and now lives in Miami is also fluent in German.
} 
Cuban immigrants in Germany began to shift in the post-1990s migration wave. Most of my participants mentioned learning German as a marker of an integrated individual when asked, "What does integration mean to you?"

Those who lacked German fluency, however, still integrate across other measures. For example, one participant is an Afro-Cuban musician ${ }^{4}$ who immigrated to Spain in 1996 but has been dividing his time between Seville and Berlin since 2014 because "Berlin is very active; I can easily play many gigs every weekend." He also considers Berlin "the center of Europe" and says it "opened up many opportunities for me." We began our introductions, and he was fascinated by my status as a CubanAmerican academic. When he heard me order the food in German, his eyes lit up. "You know German?!" he enthusiastically asked. I answered that I was half German and that I can converse in the language but not as well as I would like to. He replied:

That's good that you know German! If you can, you should always practice your German so you can become better at it. If I lived here all the time, I would learn it completamente. ${ }^{5}$ It's a falta de respeto ${ }^{6}$ if I lived here and didn't know German. Besides, my German friends speak very good Spanish so how can I not to the same with their language? ... I've been considering taking German language courses.

I was fascinated by two main aspects of his answer. The first is that even though he does not live in Germany full time, he is still willing to learn the language and considered it a sign of respect to do so. Second, he brought up his German friends and their knowledge of Spanish, even regarding it as an integration of sorts. $\mathrm{He}$

\footnotetext{
${ }^{4} \mathrm{He}$ describes his music as trans-Caribbean.

5 Translates to "completely".

${ }^{6}$ Translates to "lack of respect".
} 
considered his German musician friends to have integrated into Cuban culture. Another participant who does not speak German is also an Afro-Cuban who works at a Cuban restaurant as a cook and immigrated to Germany in 2004. He was softspoken and rather shy. His answers, although brief, were instructive. I began by asking about his mother language and the languages he prefers to speak. He answered, "I speak Spanish, mostly." I then asked if he felt pressured to learn German. He responded, "No, I get around with Spanish fine and I do speak a little German. My wife is German and she helps translate for me. I came to Germany too old to learn it"

He explained that because he immigrated later in life, ${ }^{7}$ he was not able to pick up the language as easily as others. "I am also a very private person and do not like to go out too much," he continued. "I go to work and then home. Sometimes I play soccer during the weekend." These details apparently insulated him within a controlled environment in which the German language was not dominant. The circumstances of his life led him to integrate economically by working in a Cuban restaurant and through intermarriage but did not integrate linguistically. The same could be said of another who speaks very little German and immigrated in 2005. She is an introvert and does not like to go out often or socialize. Her husband is a Cuban who is fluent in German but appeared to be a much more extroverted and socially active individual. She also socializes mainly with other Spanish-speaking individuals, usually from her church. Another participant who did not speak German is married to

\footnotetext{
${ }^{7}$ See Diehl and Schnell (2006, p. 802) as they argue that age can factor into the language attainment process.
} 
a Cuban of German ancestry who was raised in Cuba but had traveled to Germany before. Both husband and wife immigrated to Germany in 2014. The wife's mother, a Cuban-German, immigrated in 2015 to live with them and is fluent in German. The wife, also fluent, speaks German for work but prefers to speak Spanish. The husband, however, does not speak German. He stated that because he did not speak German, he found it difficult to find a job, so he stays mostly at home and socializes primarily with his wife's family, who are all bilingual. Although he was not integrated linguistically, socially, or in the labor market, he remarked:

When we visit Cuba, I miss Germany more than [Barbara] ${ }^{8}$ I found myself thinking, ya tengo ganas de irme a mi casa or extraño mi casa. ${ }^{10}$ I realized that though I was raised in Cuba my whole life and my entire family is there, I thought of Germany as my home now. I love seeing my family in Cuba but into the second day of being there I begin feeling homesick. It is a strange thing when I think about it.

This participant and his feeling of belonging stood out because regardless of his lack of German fluency, lack of employment, and lack of inter-group socialization, he considered Germany home. This conflicts with the binary notion that a rejection of German language and a lack of overall successful integration mean a rejection of Germany itself. This participant stated the contrary. As Immerfall (2017, p. 2) argued, "scholarly attention to the affective dimension of integration has been nevertheless sparse" (see also Antonsich \& Matejskova, 2015). This participant account adds an emotional dimension to integration. For his sense of belonging is not

\footnotetext{
${ }^{8}$ I changed the name of the participants to protect their identity.

9 Translates to "I want to go to my house."

10 Translates to "I miss my home."
} 
through language or citizenship, but through the notion of home and his affective connection to it. He related his nostalgia to the fact that while he was away in Cuba, he missed his couch, his Yorkie dog, his favorite TV show The Vikings, and waking up in his own bed; objects and sentiments of comfort that created a place ${ }^{11}$ within the German space. The notion that Germany is home, an emotional and personal place of belonging, was expressed in several interviews. There were exceptions, however, such as his mother-in-law who is fluent in German and is Cuban-German. She does not view Germany as home and prefers to speak Spanish. All three prefer to speak Spanish. Surprisingly, her brother who is also in Germany and has lived there on and off, until permanently settling there in the 1980s, prefers to speak German and considers Germany to be his home.

This brings me to one of the differences between the two distinctive migration waves of Cuban migration to Germany. Since all the pre-1990s Cuban migrants were fluent in German, I highlighted a few of the interviews from the post-1990 migrants. These migrants from the second wave showed a spectrum of language attainment from not-fluent, to conversational, to fluent. The second wave showed diversity in level of fluency, and its members were more open to using their native Spanish at home as opposed to the first migration wave. In the first migration wave, all the participants answered that they spoke German or a mixture of both German and Spanish at home, particularly so their children could acquire both languages. While at work and with friends, they mostly prefer to speak German unless their friends spoke Spanish. In contrast, the participants who had immigrated after 1990 answered that

\footnotetext{
${ }^{11}$ Place denotes an emotional connection, while space denotes a geographic area.
} 
even if they speak German at work, ${ }^{12}$ they still prefer to speak completely in Spanish at home and with friends who speak Spanish. The first migration wave is comprised of people with a partiality to speak either German or a mixture of German and Spanish, while the second wave, even if fluent in German, prefers to speak Spanish. One participant who immigrated in 2001 commented on the mutability of language through integration. She speaks fluent German at work but mostly Spanish at home and with friends. She recounted an instance when she traveled back to Cuba after being in Germany for several years. She recalled that one day while she was eating dinner with her family:

I was talking with my family and eating and I began saying "Pasame el"13 but then I stopped and I kept saying "el... el" because I completely forgot how to say bottle in Spanish! I could only remember the German word for it. This kept happening to me throughout the whole trip. I started pointing at certain things or grabbing them and just saying "esta cosa"14 because I couldn't remember how to say it in Spanish. It was ridiculous! I spent my whole life in Cuba and suddenly I couldn't even say azúcar. ${ }^{15}$

Another participant related a similar experience regarding the German language when he did not realize that through intensive language training, he was slowly gaining fluency. This participant immigrated in 2005 and is a celebrated writer whose books are primarily in Spanish. When he immigrated, he went through an

\footnotetext{
${ }^{12}$ Or English. A few of my participants are employed in companies that required them to speak English.

${ }^{13}$ Translates to "Pass me the."

${ }^{14}$ Translate to "This thing."

${ }^{15}$ Translates to "Sugar."
} 
integration course. Germany offers courses on integration that teach the German

language along with German politics and culture. This participant said:

Before I went through the integration course I would go to the U-Bahn and when the speakers came on I would only understand "blah, blah, blah, bitte"16 but then one day after I had been attending the integration course, I woke up and I realized that I had a dream not in Spanish nor in English but in German. I was so mystified. Then later on randomly one day, I went into an office and spoke German for the first fifteen minutes without realizing it, it was astonishing.

He related the story with pride because he explained that knowing German is not only important in Germany but was important to him. He wanted to be able to communicate freely with the local population and to expand his future possibilities.

\section{Cubans in the Labor Market}

The educational and employment background of my participants varied widely. Those who immigrated in the pre-1990s migration wave have all finished their formal education either at the university level or through a vocational or technical school. For example, one participant studied in East Berlin in the 1980s and received his Ph.D. in biology at a German university. He is now the head of a research unit at a major company. Another Cuban participant studied both in Cuba and in Germany and permanently immigrated to Germany in the 1980s to work. He is employed also at a major company within the production assemblage unit. Other Cuban participants from the pre-1990s migration wave are employed in occupational fields such as higher education, real estate, finance, literacy, and business entrepreneurship. The educational and employment composition of this group

\footnotetext{
${ }^{16}$ Translates to "You're welcome" but it can also be used as "Please" or as a request, plea, or even an interjection.
} 
followed similar patterns. All are currently employed, and none reported any welfare benefits, signifying successful labor market integration. In fact, one participant, an Afro-Cuban female, emphasized she was "doing better than even most Germans. I have a brand-new BMW, the latest model.”

The variation becomes more apparent with Cubans who immigrated post1990. The range of educational background of this group ranges from no education past basic secondary education in Cuba to a Ph.D. earned in Germany. The occupations of this group also range from unemployment, part-time employment, temporary work contracts, self-employed, to full-time employment. Within this group, two participants were unemployed, and one works part-time; all three receive welfare from the state. The musicians, artists, and writer of this group also work with temporary and sporadic work contracts; it was unclear whether they were on welfare. One of the unemployed participants had an educational background in Cuba in engineering, but he could not figure out a way to enter the mainstream labor market. He has been in Germany for almost two years:

I don't speak German. It is hard to find work here in Germany. It is not like in Cuba where you if have amistades $^{17}$ you can find a good job or in Miami. I don't know the language, I don't have my citizenship yet, and I don't really know other people here yet besides my wife's family so it's really hard.

One of my participants did mention that her newly arrived brother had found a job through a friend, but she did not provide details about what type of job it was. I speculate it was a non-traditional job or temporary job that a non-fluent and noncitizen can take. Such jobs include positions as a Discotek DJ, which was explained

17 Translates to "friendships" but also suggests having professional connections. 
to me that some young and unmarried Cuban men take when recently arrived.

Another participant who arrived during the first wave of migration explained:

I was a DJ here in Berlin when I was young. Imagine, you are young and full of life coming from a place like Cuba and coming to live in Berlin which is the capital of nightlife. It was drinking and dancing every night! The German women loved me because I was Cuban and you know, look exotic. I took home a new woman every night. It was fun but it was a bad life too. It is very easy to get in trouble when you're in that environment. But that is all behind me now. I am married and have two beautiful children.

The idea that being Cuban is advantageous in Germany was pervasive in many interviews. Although this participant related it to romantic relationships, it was also related to success within the labor market in other interviews. When navigating the labor market, some participants mentioned the benefit of being Cuban, as one woman exemplified. She studied economics and finance in Germany during the 1980s, went back to Cuba once her contract in the GDR ended, and immigrated back in 1988 through marriage. She worked at a pharmaceutical company for eleven years and attributed the chance to work there because she was Cuban:

When I first came to Germany I went to the employment office and I began asking how to file paperwork to begin working. When the man at the office found out I was Cuban he went crazy with excitement and loved the fact that I was Cuban. He began telling me stories about his vacations to Cuba and how much he loved it there. He found me a job at [the pharmaceutical company]! ${ }^{18}$ On my first day of work at [the pharmaceutical company] they had flowers, a welcome sign, and wine waiting for me at my desk. I felt so welcomed!

Besides citing that Germans had favorable perceptions of Cubans as an advantage when entering the labor market, several participants stated that Cubans possessed inherent qualities that made them successful. Four interviewees saw those inherent qualities as granting them better opportunities than native Germans in the

\footnotetext{
${ }^{18}$ The name of the company is not given to further protect the identities of the participants.
} 
labor market. The first participant referred to his son, who immigrated to Germany at

18. The father argued that even though his son did not attend an educational

institution in Germany, he matched those that did because he was Cuban:

My son came here at 18 years old and now works in a computer firm where there are so many highly educated people all around the place. He started out in the most basic entry position and now is practically the manager. You see, Germans function systemically with order and logic to everything. Which is great but the total opposite of Cubans. Germans go through step one to get to two to get to three while Cubans already skipped all the steps! My son was working one day when the person configuring the systems did not show up for work. The entire department became worried that they would have to shut down because the designated person was not there. My son came into the room and said, "Hey, I can do his job until he comes back." And everyone looked at him in shock. They were hesitant but let him take over the position....my son made such an impression that they gave him the job. If you tell a German, "your job is to hit the head of this nail," that is what they will do and will not think of going outside that job description. This is why Cubans tend to take over wherever they go.

Another participant echoed that being Cuban and embodying its cultural

characteristics allow him to navigate the labor market more inventively than native

\section{Germans:}

When I was first given my unit to run I wanted to change everything about the way things were! I wanted my unit to have an edge that no one else had. But it was hard getting these Germans to approve anything that was even slightly different. Like when I wanted to add a ping-pong table to our breakroom and it took months of back-and-forth to approve it or when I wanted to change the colors of the walls in my office, that took just as long! But the edge I bring into this unit has made me successful because I have a view of things that no one else does and if they do, they won't dare say it. Meanwhile, I'll scream it out. I became successful here because of that. The way we Cubans are is special.

Another participant also brought up how being Cuban gave her an advantage not only over Germans but over other immigrants as well. She held the strong belief that Cubans were completely different from any other immigrants, including Latin 
Americans, in Germany, because of their values. She explained through her

experience in her job:

The moment my feet touched the ground here in Germany, I knew I had to find a job pa salir adelante. ${ }^{19}$ I finally found a job at a children's recreational center where parents can rent the rooms out for parties and such. It is owned by a rich Russian woman, but there are different types of workers there, from Germans to Turks to Latin Americans. I liked to arrive early and leave late to make sure everything was cleaned up and that all the toys were in place ... I always asked for more responsibilities and made sure that the owner knew that I am capable of more. Within only six months of working there, I got promoted. The other workers began to resent me. When I first came to Germany, I lived with my uncle but in less than a year, I moved into my own apartment, and I promise you I will soon own a house.

Beyond the perceived advantages of being a Cuban in Germany, an empirical disadvantage is also present. The lack of social networks does not facilitate the entrance and navigation of the labor market for Cubans in Germany. As Badwi et al., (2018, p. 28) asserts, social networks are an important gateway in which immigrants enter the labor market (see also Drever and Hoffmeister, 2008). Some scholars also suggest that cooperation with the native society is vital for upward social mobility and economic integration into the mainstream (Gordon, 1964; Granovetter, 1973; Wilson \& Portes, 1980; Alba \& Nee, 1997; Drever \& Hoffmeister, 2008, pp. 427428). In Germany, relationships with natives are difficult to establish if the immigrant is not familiar with the local language and culture. Since Cubans and Germans do not share a similar language, those who are newly arrived find themselves unable to communicate effectively to network. Cuban and German cultures also contrast regarding involving informal relationships. In Cuban culture, individuals tend to initiate informal relationships readily, while in German culture, relationships have a

\footnotetext{
19 Translates as "go forward," which denotes personal advancement and success.
} 
more involved progress that takes time. One participant described the process of establishing his relationships with Germans:

It takes a long time to gain a friendship with a German, not like with Cubans. With Cubans * ping-pang*20 and there you go you are compadres, ${ }^{21}$ even if that friendship can sometimes be superficial. But it's more complicated with Germans, it's definitely a longer process. The amazing thing is that once you do gain a German's trust and friendship, you have it for life.

The clash of cultures involving friendship networks (Silver, 2010, p. 178) can sometimes translate into the notion that Germans are unwelcoming or standoffish. Participants who have been in Germany over a decade commented on the common misrepresentation of Germans. They argued that, at first, they perceived Germans as unfriendly, but after time, they came to realize that "Germans are the most helpful people you will ever meet." This feeling of amity and understanding of differences in cultures took time, and it was a process that developed through interpersonal relationships with Germans. For newly arrived Cubans, this process has yet to be initiated because of lack of language skills and familiarity with the host culture.

Social networks are further limited because of the lack of a Cuban ethnic community in Germany. Cubans therefore are in a rather isolated space in which they cannot connect with natives, nor can they rely on their own ethnic group to access the labor market. Participants also noted intergroup distrust with other immigrant groups and intragroup distrust within the Cuban migrant group itself. This distrust among coethnics was expressed by a participant who said, "I never had the support of fellow Cubans, there is no community." Beyond sheer numbers, the participant alluded to

\footnotetext{
${ }^{20}$ Participant made a noise that denotes a fast process.

${ }^{21}$ Denotes friend/friendship.
} 
the term "community" specifically because he thought that Cubans in Germany lack camaraderie. This creates a further limitation of social networks that can facilitate and negotiate access to the German labor market for Cubans. Therefore, Cubans in Germany experience difficulties entering the mainstream labor market because of lack of social networks and cultural differences such as language. However, discrimination based on national-origin did not emerge as an issue. Rather, for most of my participants, being Cuban was viewed as an advantage in the labor market since it was believed that Germans view Cubans favorably. Additionally, many also believed that Cuban culture has ingrained in them a sense of ingenuity and a work ethic that is an advantage over other immigrants and over the native German population as well.

\section{Cuban-Germans in the Educational System}

I investigated the educational system in Germany from the vantage point of Cuban-German participants. Among participants who were raised in Germany and went through its school system, they all went through the Gymnasium school track. However, these participants had one parent who was a German native and either one or both parents who also spoke German fluently. As Becker (2011) argued, having at least one native parent positively influences native language attainment. These participants were raised in a household in which the German language was spoken regularly and where at least one parent was educated in the German school system. These circumstances placed them in a more advantageous position than migrants who have neither parent fluent in the native language nor who are familiar with the 
German educational system. As an example, one participant went to Gymnasium and then later graduated from a technical university. His father is German, while his Cuban mother is immigrated in the 1980s. Both parents are university professors. His advantageous social position was evidenced through the fact that he is a German citizenship, is native in the German language, and had parents who held privileged positions within the labor market. These advantages are of considerable importance because they facilitated his navigation of the educational system and his eventual entrance into the labor market. Other Cuban-German participants in this study found themselves in similar situations. Because I interviewed only adults, the CubanGermans who were raised in Germany and its educational system either had parents who immigrated during the pre-1990 immigration wave or migrated themselves during this wave.

Group cultural characteristics should be considered when discussing integration into the German educational system. Arguably, the German nation has institutionalized a Christian paradigm into its everyday practices. Alba (2005) suggests that the Christian archetype is institutionalized in Germany, as evident through practices such as Germany's country-wide Christmas markets. This deepseated Christian ideology seeps even into the German educational system, in which "Many, and in some regions most, kindergartens are run by churches and hence strike Christian tones" (Auernheimer, 2005, p. 78; see also Kennedy, 2005). When this religious ideology was brought up in my interviews, none of my participants expressed any distress or felt any prejudice. They were able to seamlessly integrate into the dominant socio-religious paradigm of the German educational system 
because of their group's ethnoreligious characteristics, which will be discussed in a later section. Germany views its educational system as a propagator of European identity (Faas, 2016, pp. 37-41). This ideological notion was emphasized by one Cuban-German participant in a focus group with his mother when asked if they saw themselves as either Latin American or European. The mother immediately answered European, but he took a moment to ponder his own self-perception, "I think culturally I am European. I was educated here in Germany which makes me culturally European. I think about my education, especially my studies in Philosophy, and I think it is what makes me European".

I found it fascinating that he related his educational background to the European supranational identity rather than just the German identity. He made no mention of physical attributes such as his blue eyes and blonde-reddish hair nor to his German ethnicity. Rather, it was the educational system that allowed him to feel European. As he integrated into the German educational system, he also integrated into a European identity and ideology. In sum, Cuban-German participants who went through the German educational system have integrated successfully. All participants went through the Gymnasium school track and the participant discussed above even considered the German educational system as part of his European identity. Additionally, considering that religious ideology is tied to the educational system, the participants felt no prejudice or discrimination towards them. 


\section{Cubans Married to Germans}

I included questions on marriage in the interviews because intermarriage is an important indicator of integration. Furthermore, intermarriage between Cubans and Germans not only carries a narrative about Cuban integration, but also about the mutual perceptions between Cubans and Germans. Out of all my participants, ${ }^{22} 11$ are/were married to Germans, six are married to Cubans, three were divorced before they immigrated, two were never married, and one is married to an immigrant from Colombia.

Of the 11 participants who are or were married to a German native, eight of them met their German partner in Cuba, while the other three met and married their German partner in Germany. A fairly balanced number of participants belonged to both migration waves, which is both surprising and understandable. Upon first reviewing the data, I was surprised because the second migration wave was led by intermarriage and family reunification and I expected a greater propensity for intermarriage within this wave. However, after reviewing my data I realized that participants from the first migration wave were also likely to intermarry. As many scholars have argued, barriers of difference are eroded the longer an immigrant stays in the receiving country (Dribe \& Lundh, 2008, p. 331; Klein, 2001, p. 328). In my study, those who were married to a German not only received their citizenship faster, but also had an easier time entering the German labor market. As Furtado and Theodoropoulus (2009) postulated, marriage to a native member of the receiving

\footnotetext{
${ }^{22}$ One of the participant that lived in East Germany but resides in the United States is included in these statistics. However, the other two participants, who lived in Poland and now resides in the United States and Cuba respectively, were not included in these statistics.
} 
country facilitates employment. Cubans married to Germans have the advantage of having personal mediators between them and the native society. In terms of language acquisition, networking, and navigating the German naturalization process, being married to a native helps. As one participant who married her German husband in Cuba and then migrated to Germany with him and their young son explained:

When I first came to Germany, the only people we [her and her son] had were my husband and his mother who spoke very little Spanish. I spent most of my time with my mother-in-law who helped me with everything and became like a second mother to me. I practiced my German with her every day and she taught me how to sew and stuff like that. She babysat my son and helped him with his homework while I was out finding work. I eventually found a job at the University of Postdam. When I divorced my husband, I already knew German and knew how to get around in Germany. I found my own apartment and even found a better academic position at the [current university].

This participant described her time with her mother-in-law as a learning experience during which she learned to do things like sewing and cooking. More importantly, she also learned how to speak German and become accustomed to the German way of life through her personal contact. Her son's integration was further expedited through contact with both his German father and grandmother. The participant described the moments she spent with her mother-in-law as monumental in the way her future was shaped and the way she integrated into Germany. As Immerfall (2017, p. 4) argued, "social networks are prerequisite for perceptions of having a place in a community." Having a personal relationship with a native citizen such as a husband and his mother was my participant's primary pathway toward overall integration. 
This pattern opposes how Gordon (1964) viewed intermarriage as the last step in integration. ${ }^{23}$ Intermarriage was the first step toward integration for this participant. Some scholars such as Klein (2001) even suggest that intermarriage can be a strategic move to legally integrate into the receiving country. Post-2000, marriage to a German citizen grants one residency and considerably shortens the time one must wait to apply for citizenship. This has been a suggested motivation, as one participant stated that intermarriage is "how many come to Germany. So, some specifically look for foreigners to marry to leave Cuba." My participants agreed that marriage with a German citizen was fortuitous, not only in terms of emigration and consequent citizenship but because of cultural ideologies. As Klein suggested, marriages are much more likely between those who share similar systems of beliefs and values. Nearly all my participants regarded themselves as European because as one claimed, "Cubans are not really Latin American, they are more European." This inclination towards a European self-identity probably stems from the longstanding Cuban colonial relationship to Spain where "Cubans explicitly recognize and embrace the Spanish legacy in their culture" (Grenier \& Pérez, 2003, p. 37; see also Eckstein \& Berg, 2009, p. 160-161). This mentality views European culture as holding certain values that are closely related to Cuban culture. It is also the reason behind some participants' choices in partners. One participant expressed that marriages between Cubans and Europeans were more successful than other groups because of cultural similarities. She described her German friend's first marriage as "disastrous" because

\footnotetext{
${ }^{23}$ The term assimilation would be more appropriate when speaking about Gordon (1964) rather than the term integration. However, for stylistic purposes, I have continued the use of the term integration.
} 
she was married to a Latin American who was abusive. She added, "You know how men from those countries like to hit women." She continued to explain that her friend's second marriage is to a Cuban and she is much happier because "they understand one another much better." O’Leary and Finnäs (2002, p. 236) also alluded to the fact the family can police their children's' choices of marriage partners. This was suggested by one participant who explained her migration narrative:

I went back to Cuba because my work contract finished, you were given a week after your contract ended to leave but I stayed longer because I was in the process to marry an Angolan man. We never married because my mother never filed the papers that were needed. Cuba was at war in Angola and my mom was worried about me marrying him. So, I went back to Cuba and there I met my German husband and everything worked out. I'm glad the paperwork was not filed, my mom was right, everything worked out in the end.

Another participant also recounted her family's reactions and how it

ultimately led to her decision to marry her German boyfriend:

He was so respectful and kind and that's what drew my attention to him but I ignored him when he asked to go on a date. I was young and happy spending my days at the university library studying. I didn't even think about marriage back then. But after months of him courting me, we began dating. I had spent so many years in Germany that I felt more comfortable with him than I did with Cuban men. When he met my family, he wore this white linen suit. Can you imagine a tall red-headed German standing in the middle of our living room wearing a white suit with flowers on hand? My mother instantly loved him! My father really liked how courteous and well-mannered he was. If I had it my sister's way, I would have been married to him right then and there. That's how much everyone approved of him. When he asked me to marry him, I wasn't sure about getting married or moving to Germany, but my family really pushed me towards it.

In conclusion, many participants were married to a German partner and those who were married to a Cuban partner migrated to Germany already as a couple.

Those in the first wave of migration were just as likely to intermarry as those in the 
second migration wave. At the beginning of this study, I anticipated that the second migration wave would be comprised of more intermarried participants due to the nature of the wave, but the number of intermarried participants was evenly distributed between both waves, displaying an overall proclivity towards intermarriage regardless of time of migration or degree of integration. Intermarriage was the first step towards the intermarried participants' integration and has fundamentally helped their integration process rather than being the last step in integration.

\section{Dating and Marrying a Non-native German Member}

Besides the fortuity of intermarriage such as the facilitation of emigration from Cuba, cultural ideologies, and family reinforcement for my participants' partner choices, other variables factor into the choice of a romantic partner. In this section, I explore my participants' romantic relationships. Of the three participants that divorced before immigrating to Germany, two were married to a Cuban and one to a Polish woman he met during his time as a guest worker in Poland. Two participants have never been married and one participant is married but to a non-German individual.

The majority expressed that they either had dated a German, are currently dating a German, or dated and/or married a member of another immigrant/European group. Only one participant reported he had dated a Cuban while living in Germany, whom he met online through mutual friends. This partiality toward out-group partners springs from two main reasons. The first explanation, drawing on O'Leary and Finnäs, (2002; see also Dribe \& Lundh, 2008; Song, 2009; Klein, 2001; Carol, 2013; Schacter, 2016), is that my participants do not live in a Cuban ethnic neighborhood 
because there are none in Germany. Instead, they live in heterogeneous

neighborhoods and are dispersed across the city. The second reason is derived from in-group size, which several scholars have spoken about (Klein, 2001; O’Leary \& Finnäs, 2002; Dribe \& Lundh, 2008; Song, 2009), in which the viable partner pool size is relatively small within the Cuban population. These two points limit the chances that Cubans in Germany can interact and date other Cubans and thus dictate their partiality. For example, the one Cuban-German participant who did date a Cuban, was introduced through a virtual location rather than in Germany. He met his partner through a mutual family friend on Facebook and dated long-distance because she lived in Miami. The couple eventually broke up and never united in Germany. This participant gave an insight to the co-ethnic dating situation:

I tried going to the salsa festival they have here in Berlin where people go on boats along the river and play and dance to salsa music. But the Cubans there have usually just arrived. That means lot of drunk and vulgar people. So vulgar that I couldn't step into the boat because me ericé. ${ }^{24}$

Besides availability of partners within the in-group, deviations within the group must be explored. The newly arrived Cubans who "are still living in Cuba mentally," as one participant described them, are culturally different from the Cubans who have resided in Germany for a longer period. My participant expressed that he would rather date a German or a member of another immigrant group who had a "European mindset" than a Cuban who had just arrived. He stressed that it did not matter what race or ethnicity the person was as long as she shared the same cultural ideologies. Song (2009) theorized that immigrants who have spent more time in the

\footnotetext{
${ }^{24}$ Denotes goosebumps.
} 
receiving country "may view new immigrants (even co-ethnic immigrants) as very different to themselves" (p. 336). Cubans in Germany do not tend to socialize with one another as often as other migrant groups do. One participant remarked, "Cubans do not come together, they do not want to associate with one another." When the topic of intermarriage was brought up, another participant replied, "I doubt a Cuban who did not already immigrate married would marry another Cuban." I investigated this line of thinking because of indications that Cubans in Germany distrust each other and because a racial-ethnic dimension might also factor in. Two phrases were uttered by a couple of participants who articulated the existence of prejudice within the Cuban community. The two phrases were "adelanta la raza",25 and "limpia la sangre," 26 which denote a preference toward marrying a German. These phrases symbolize the perception that Germans occupy a higher social and ethnic standing and to marry into this group also alleviated the spouses' and future children's social capital (Bourdieu, 1987) and racial status. Distrust, lack of camaraderie, and racial/ethnic politics were noted as reasons to deviate from intragroup relationships.

Furthermore, I noticed that the tendency to date and marry outside of their group was not only because of differences between Cubans in Germany but also between Cubans in Germany and the United States. The participant who dated a Cuban long distance from Miami ended their relationship when he went to visit her in Miami because he decided they were too different. He recounted the time spent with his ex-girlfriend in Miami in dismay, and he adamantly pointed out the differences in

\footnotetext{
25 Translates as "advance the race."

26 Translates as "clean the blood."
} 
relationships between Miami and Berlin. Moreover, one couple whose son was recently married to a Colombian immigrant was overjoyed that he married her and not his ex-Cuban girlfriend because,

Even though we've known her and her family for many years and they are wonderful people, Cuban Americans are different than Cuban Germans. Cuban Germans rent an apartment, don't own a car, and they live life debtfree. But the girl our son was dating kept asking "you don't own your own house? You don't have a car?" like it was some terrible thing! She still lives with her family in Miami and makes her mom buy her new clothes every time she goes out. Here in Berlin, we don't care about material things like they do over there.

This participant and his wife viewed their son's former Cuban girlfriend as a less viable partner than the out-group partner he is now married to because of perceived differences in the socioeconomic ideologies of both nations. In sum, Cuban immigrants in Germany are partial towards dating and marrying a member of an outgroup. The more integrated participants tended to view newly arrived Cubans as different; in addition, Cubans in Berlin were thought to also be different from Cubans in Miami. Further displaying the diversity of the Cuban diaspora across time and space.

\section{Cuban Religious Identity}

Most of my participants mentioned cultural similarities but left out religion as a factor behind their choice in romantic partner. I asked participants if religious endogamy was important to them. Most responded that religion did not matter to them. I noticed a dissociation between what I meant by "other religions" and what they thought encompassed a different religion. For example, one participant said, "I don't care about that. It doesn't matter if they're Catholic, Protestant, or 
Presbyterian," but when I asked if they cared if the person was Muslim, she responded:

Well, that's different. It's not the same to be Christian than to be Muslim. It's not about the religious aspect of it but because of the cultural aspect of it. Like sometimes in the summer you see a Muslim man screaming at a German girl for wearing a bikini top out on the streets. Cubans here are like Germans, we don't care about that stuff.

Even though the participants themselves did not consider religion an important variable in intermarriage or cross-dating, it ultimately proved it played a role. As the couple whose son recently married a Colombian immigrant articulated, their son met his wife at their Evangelical church in Germany. They were joyous at the notion that she was "just like us" because of their shared religion and values. The father continued to describe the various church events they participate in and how their daughter-in-law shares the same views on marriage and children as they did. For some of the non-denominational participants, religion, although not a defining variable, still factored into their decision about partners. The couple and their son, who actively participated in their denomination of choice, viewed religion as an important factor.

Of all my participants, none reported practicing or belonging to a nonChristian denomination. Fourteen reported that they were Catholic/Christian. ${ }^{27}$ Only five of these said they formally practiced the religion, while nine said they considered themselves Catholic/Christian but were non-practicing. Three participants belonged to the Evangelical church in Germany and were practicing and actively involved in

\footnotetext{
${ }^{27}$ I use these two religions together because some participants stated they were Christian but then went on to talk about Catholic saints and practices and other used the term interchangeably since Catholicism is a branch of Christianity.
} 
the church. Five were non-denominational and considered themselves just overall spiritual. Of those that were Catholic, there was indications that some practiced Santería. None reported to be Santeros. ${ }^{28}$ In Cuba, the lines between Catholicism and Santería are often blurred (Grenier \& Pérez, 2003). As Grenier and Pérez (2003, p. 39) illustrated, even Cubans who consider themselves Catholic will still relate Catholic saints to orishas $^{29}$ and worship accordingly.

One of the Evangelical participants noted that the "majority of Cubans here are idiosyncratic, non-practicing, and very few actually go to church." His church friends are of other Latin American backgrounds rather than Cuban. Many other participants did not see a direct link between religion and Cubans in Germany. The few who confirmed they were practicing Catholics stated that they only attended church on special days such as Ash Wednesday or Christmas. These conversations revealed references to religion and the wider German identity. One participant who was non-practicing and considered herself spiritually Catholic went as far as to say:

To be German and to be really integrated completely is to participate in things such as Advent and Easter. I didn't celebrate those Holidays back in Cuba but when I immigrated to Germany and was introduced to these celebrations I was so excited! That's when I feel really German, when Easter comes around and there are flowers and Easter eggs everywhere and restaurants have special menus for ostersonntag ${ }^{30} \ldots$ that's German.

This participant, although not practicing herself, viewed Christian religious celebrations as the cornerstone of German identity and integration. As Grenier and

\footnotetext{
${ }^{28}$ Denotes a person whose primary religion is defined by Santeria.

${ }^{29}$ Deities of the Yoruba.

${ }^{30}$ Translates to Easter Sunday
} 
Girard (2008, p. 531) argued, "the most successful ideologies become so ingrained in our lives that they are not questioned or even recognized as ideologies.” The nationwide public everyday display of Christianity defined Germany for her. This definition was further propagated because it also coincided with her own spirituality and self-identity.

Besides public displays of religion, some alluded to practicing deviations of standard Catholicism or Christian spirituality in their own private spaces. Take the practice of Santería, for example:

Cubans are not really religious in Germany. They believe in God and they practice but not really. There are some like brujeros ${ }^{31}$ and Santeros but they do that in their own home and in privacy so you don't really hear about it and they don't really talk about it either.

It was curious to observe that an Afro-Cuban religion such as Santería was still practiced in Germany by Cubans, but more interesting than that was that some did not feel a need to hide it. Although they practiced in the privacy of their own homes, they did not feel pressure to hide it. One participant even stated that, “Germans don’t differentiate Cubans; Even with Santería they tolerate it, some are even fascinated by them." It seems that Santería is deemed a cultural motif and incites either indifference or admiration. Santería is thus deemed an exotic religion rather than a threatening one in Germany.

I was also able to observation Cuban religious practices at a very popular Cuban restaurant and bar favored by Germans. When one walks into the restaurant, one immediately sees a statue of La Caridad del Cobre, patron saint of Cuba, up on a

\footnotetext{
31 Translates to Witch or Witch Doctor.
} 
pedestal. All around the statue were offerings of pennies, candy, sunflowers, alcohol, and candles. La Caridad del Cobre is loved and revered by Cubans, these offerings were to give thanks and bring good luck and fortune to not only the restaurant but to all who seek her protection. This religious display is an homage to Cuba because $L a$ Caridad del Cobre represents Cuba and the Cuban people. ${ }^{32}$ The most striking part of this scene was the German flag hanging proudly above the Cuban saint. It was a visual and affective symbol of the connection between both cultures.

\section{Identity}

When asked if they saw themselves as Cuban or German, all participants not of Cuban-German ethnicity, replied that they were Cuban. However, most of these participants replied indirectly ${ }^{33}$ that they were both. As a participant who immigrated in the first migration wave and is married to a German explained,

I see myself as Cuban and German because even though I still eat bistec ${ }^{34}$ and arroz con frijoles $^{35}$ at home, I've become German through the years. I still remember the first time I felt 'German'. It was during a soccer game. Germans are normally not expressive about national pride. They can be very shy about it. But during that soccer match, everyone was waving German flags and had the German flag painted on their faces man I still get emotional thinking about it! It was such a beautiful moment and I felt so proud to be here.

\footnotetext{
${ }^{32}$ La Cardid del Cobre is also worshiped in Santería as the Goddess of love and fertility.

${ }^{33}$ I operationalize "indirectly" if the participant articulated a fluid sense of blended identities through responses such as "I am a Cuban like a German".

${ }^{34}$ Cuban style thinly sliced steak.

${ }^{35}$ Rice and beans, which is a traditional Cuban dish.
} 
The participants who felt German attributed the time spent in Germany alongside emotional moments that made them feel part of the nation. Likewise, the concept of food was widespread when connecting themselves to their sense of Cubanness. The participants stated that they still eat Cuban-inspired food such as bistec. Two participants who often travel to Miami stated that they always bring back things such as Bustelo coffe $\mathrm{e}^{36}$ and guava paste ${ }^{37}$ because they are Cuban foods they often crave but cannot find in Germany. Beyond the concept of a simple craving, my participants invoked food as a form of nostalgia and an extension of their culture (Holtzman, 2006; see also Charon-Cardona, 2004). One participant remembered the way his grandmother used to make him el Quaker ${ }^{38}$ every day when he was a child before going to school. Whenever he eats it, he not only remembers his grandmother, but also remembers Cuba.

The term "indirectly" is used because even if a participant answered "Cuban," he or she would follow up with something such as "but I am not the typical Cuban, maybe more German." Most still regarded themselves as German in some way, even if not in a strict hyphenated category. One participant who first said she was Cuban and then later answered she was Latin American followed up with a German caveat to her self-identity. She remarked, "I am Cuban, but I feel like I was born here in Germany. Like I spent my whole life here.” Even though she did not directly state she was German, she referenced it. Another participant also measured his partiality

\footnotetext{
${ }^{36}$ Cuban coffee brand.

${ }^{37}$ A squared paste made of marmalade guava that is usually paired with cream cheese and spread on a soda cracker. It is also the preferred filling for the Cuban pastry, pastelito.

${ }^{38}$ References to oatmeal, as in Quaker Oatmeal.
} 
toward being German by announcing his detachment from his perception of what it means to be Cuban. Again, even though he did not directly state he was German or Cuban-German, his follow-up explanation referenced it indirectly:

I am not what you would consider a Cuban. I don't drink rum, I don't dance, I don't like to be loud, and I am more of a lone wolf. I am also very punctual, not like Cubans. In that way, I am like my German friends more than my Cuban friends. The only time I do not feel German is with the weather. The grey, the cold, muddy snow. I hate that.

The most complex answers to this nationality-based question came from children of intermarried couples who exhibited variations of their national identity. Of the five Cuban-Germans in this study, two replied "Cuban," one replied "German." one that he used to feel "Cuban" but considers himself "German," and one was unsure as how to answer. Binaisa (2013, p. 887) argued that engagement in transnationalism varies not only within the in-group but even within families of that in-group. This was true for my participants, especially within inter-ethnic families whose members self-identified as either German, Cuban, or indirectly CubanGerman. For example, one participant who had recently immigrated within the last six months, of Cuban-German ethnicity, explained it as, "I am Cuban of Cuban and German parents, so yeah, I'm Cuban-German." She argued that unlike her brother, who traveled often to Germany, she had spent all her life in Cuba and thus she considered herself Cuban first. She did not feel comfortable in Germany because people were not as sociable and she felt homesick. Her brother, on the other hand, considers himself German. Their father is Cuban and their mother is German. The brother was raised in Cuba until he was 16, then he moved to Germany, came back to 
Cuba after he finished his schooling, and then immigrated permanently years later. He stated that:

When I lived in Cuba I was "German" and when I was studying here in Germany I was called "Cuban." I used to consider myself Cuban but now after 30 years here, I am German. My girlfriend is German, my daughter is growing up here in Germany, I speak primarily German, my friends are German; I am German. But I have to admit, sometimes I can't stand Germans and sometimes I can't stand Cubans and that's when I realize I'm a product of both.

His surroundings, marriage, personal relationships, and primary use of language defined him as German. Although he admitted the salience of his identity transitions at times, he mostly views himself as German now. This contrasts with his sister's self-identification. She recently arrived in Germany and lacked the emotional connection to Germany and the German identity that her brother had. She was raised in Cuba, her ex-husband was Cuban, and she still considered as her friends those she left back in Cuba. She considered herself Cuban through an emotional and cultural definition, but Cuban-German through her parents' ethnic background. This is why her daughter, having been introduced to both cultures, considered herself Cuban. Because her mother saw herself primarily as Cuban and she was raised in a Cubancentric household, she self-identified as "Cuban with a German passport." Her husband, who is Cuban of Cuban parents, saw her as Cuban-German and looked at her a bit incredulously when she made this statement during the focus group. He even insisted on correcting her by saying she was Cuban-German because her grandmother was German, lives in Germany, and spoke German. She stayed firm in her selfdefined identity as Cuban. As Maxwell (2013, p. 236) stated, "the identities that become most salient in any given situation are the ones that are actively primed." For 
these three Cuban-German participants, time spent in either nation defined their most salient national identity.

Another family unit that held different identities were a mother and son whose answers starkly contrasted with one another. The mother was raised in Cuba and immigrated in the 1980s. Her son was born in Cuba but arrived in Germany as an infant, and his father is German. When I asked the mother if she considered herself Cuban or German, she quickly replied, "I am a special Cuban because I'm Cuban but I feel German." She confidently explained that although she was Cuban, she felt completely comfortable in Germany and with Germans. The son had a look of confusion on his face and carefully thought about his answers as if he himself was not sure. He stated:

That's a hard question to answer, because I'm not at home in either cultures. I don't fit in $100 \%$ anywhere. I have issues with things that are German and issues with things that are Cuban .... Like when a German says, "let's go to party", they don't mean what you might think they mean. A party for a German is sitting quietly while watching TV so when I arrive and put music on and dance they say things like "oh [Angel] ${ }^{39}$ arrived, you can tell he is here because it's not quiet anymore' and then they attribute my 'craziness' to me being Cuban.... But then when I am with Cubans, I don't feel completely comfortable with them either.... I am German but I do not understand Germans and I am Cuban but I am not comfortable with Cubans. I guess I could say I am both but really, I am either.

His mother, who was not raised in Germany, felt more German than he did. I stipulate that this is due to the mainstream tendency to reject "foreignness." He did not feel fully German as he perceived he acted differently from Germans, a sentiment produced and reinforced by his native friends' reaction. Native Germans attributed his uniqueness not to differences in personality but rather to differences in national origin

\footnotetext{
${ }^{39}$ Name has been changed to protect the participant's identity.
} 
and Otherness. He should be considered "German" because he speaks German, was educated in Germany, is a German citizen, and subscribes to a European ideology. He is still seen as German and yet also foreign at the same time. Conversely, he does not feel Cuban either because of the lack of a Cuban cultural connection, partly due to the lack of a Cuban community in Germany and partly because he lacked the personal and cultural experience of living in Cuba that reinforces biculturality. This participant immigrated at an extremely early age, which renders him nationally and culturally German. He still engages in Cubanidad through familiar connections, enough to be considered different by the native society, yet not enough to feel Cuban. Instead of dividing his feelings of belonging across his two cultural lineages and thus feeling Cuban-German, his feelings of exclusion were more salient and led him to feel neither Cuban nor German.

Another Cuban-German participant defined his identity in a unique way. Although he has lived in Cuba and travels often to Cuba, he considers himself "completely" German. His interview was brief because I was introduced to him during my participant observation and he asked if I wanted to interview him. He was also unavailable for a follow-up interview. During our short-lived conversation, in which he spoke in Spanish, he was adamant in saying that he was German regardless of his Cuban ancestry. I cannot speculate on the reasoning behind his identification. However, his interview allowed me to explore a possibility that identifying as fully German might allow an immigrant to subscribe to greater social capital. By social capital, I utilize Bourdieu's (1987) definition in which it “consists of resources based on connections and group membership" (p. 4). I also take inspiration from Waters' 
(1994) and her study on West Indian and Haitian second-generation immigrants in the United States. Waters found that some immigrants hid that they were Haitian to avoid being bullied at school. Because of "the peer culture of the neighborhood and the school, these teenagers describe a situation in which being American is higher social status than being ethnic" (Waters, 1994, p. 812).

Another participant referred to this sentiment when talking about her CubanGerman son $^{40}$ and how he saw himself as purely German growing up. She also articulated that her son "did not like me talking to him in Spanish in public," which reinforces the politics of language and how it drives inclusion and exclusion. Furthermore, one participant expressed that an individual's migrant background will always be a salient characteristic in Germany. She strongly remarked, "let me be clear, immigrants will never be seen as German. Everyone knows and has the knowledge that you are a foreigner no matter what." She further argued that regardless of the amount of time spent in Germany or how successful their integration was, immigrants will always be perceived as having a "migrationshintergrund."41 This expression further attests to the complexity of Germany's identity politics as its redefinition as a modern, inclusive country of immigration clashes with its ethnonationalist past.

\footnotetext{
${ }^{40}$ I did not interview her son firsthand because he was unavailable.

41 Translates as "migrant background."
} 


\section{Supranational Identity}

Most participants described themselves as "European." Three regarded themselves as Latin American and two outlier responses were given. The three participants who described themselves as Latin American are all part of the second migration wave, and one pointed out that "maybe after a while here I'll see myself as European." The less time a Cuban has lived in Germany, the less likely he or she considers him- or herself European. The two outlier responses are from both migration waves. When asked if they considered themselves either Latin American or European, their responses were, "I consider myself international" and "I am Caribbean." The participant who described herself as international was born and raised in Cuba, married a German, and immigrated to Germany in 1988. When asked why she considered herself international, she responded that, "people say I am very much like a German but between European and Latin American ... I have to say I am international. I travel a lot and have gotten a piece of everywhere I have been.”

She hesitated to describe herself as a member of a specific supranational entity, so she preferred to use "international" as an all-encompassing term. The participant who described himself as Caribbean is a Cuban musician who specializes in trans-Caribbean music and lives in both Seville and Berlin. For him, his identity is cemented in the marketability of his artistry. He let me know that being an AfroCuban musician in Germany made him popular. When I asked him if he preferred to identify as Caribbean or if he saw himself as Latin American also, he replied:

Cubans are not Latin American. They are part of the Caribbean. Which is why the Spanish love Cubans but not Latin Americans. The same with Germans. Cubans are better educated, have better manners, and like to advance more than Latin Americans. But if I had to choose between European or Latin 
American, I would say European because I am very much European. Ethnically I can say I am Caribbean but, personally I would say European if I had to choose.

This interview echoed the sentiment of most of the participants, who either outright stated or alluded to differences between Cubans and Latin Americans.

Grenier and Pérez (2003) described this as the "culture of exceptionalism" (p. 30) in which Cubans tended to consider themselves as unique. As one participant claimed, "Cubans are very different from Latin Americans and the Andes, you can't compare them." Another participant emphasized their difference but also mentioned an amity between the groups when she said:

Cubans are their own category. They are not Latin American because a lot of us have European roots like from Spain and Russia while Latin Americans do not. But if there is an injustice with a Latin American then I start to feel Latin American because there is still a sense of nationalism.

Although she created boundaries of distinction in relationship to ethnicity and colonial roots, she also indicated a sense of belonging to Latin America due to cultural similarities such as language. She later brought up instances of discrimination she encountered when speaking Spanish in public. Because of this, I believe that she connected with the Latin American supranational identity through the collective experience of being a Spanish speaker in Germany. She specifically referenced moments of "injustice" when she felt Latin American because those are moments in which a distinction of being "Cuban" did not matter.

The participants in this study had a greater propensity to identify as European rather than German. As Sperling (2013) argued, "the European identity may be seen as an umbrella term or an inclusive identity" (p. 73). This all-encompassing term, which one participant tried to achieve by using the term "international," allows 
Cubans in Germany to be both Cuban and insiders. As Cubans, they are immigrants, but as Europeans, they are immigrants who belong. Sperling (2013) notes that some of her participants in Spain did not identify as Spanish but rather as "Latin-European" (p. 73). None of my participants used the term "Latin-European," because most felt distinct from Latin Americans. Instead, my participants favored the terms "international," "Caribbean," and even a binational identity expressed through phrases such as "Cuban like a German." What it means to be "German" as perceived by the participants will be explored in the next section.

\section{What It Means to Be German}

Not a single participant, without German ancestry, reported having any preconceived notions of Germany before they immigrated. However, nearly all their descriptions were positive when asked to describe Germans. The most frequently used adjectives were "punctual," "intelligent," and "respectful." Punctuality was a description that the participants most commonly agreed upon. Other descriptions mentioned regularly referenced language, traditions, and ideology. Across only four interviews were the negative terms "cold," "unreasonable," "stuck in their ways," "linear thinking," and "rigid" used. The most prevalent negative descriptions among these four interviews were about the perceived rigidity or tunnel thinking of Germans.

It is sometimes frustrating for me because Cubans are flexible so it's hard to follow the rules here sometimes. Because Germans lack that Cuban imagination, they think one way and that is straight ahead and will not look at any other angles. That's how you can tell if someone is German, by the inflexibility of their thinking. 
The consensus, however, was overwhelmingly positive. My participants held

Germans in high regard and appeared to look up to the German way of life and embodiment. For many participants, being German was an admirable mental, cultural, and ideological state of being. One participant argued that,

To be German involves traditions and character traits like being on time, respectful, and intelligent. How you live your life is what makes you German. The Germans of before thought to be German you had to have blue eye, blonde hair, and white skin. But the Germans now are different. In the last 10 to 15 years Germans have become desensitized to diversity and are more tolerant. I am mulatico ${ }^{42}$ and I feel German because I am respectful and I like being on times, things like that. Now, if I visit certain places in Berlin then yeah maybe they won't see me as German but they do not represent all Germans.

Three of my participants defined Germans in physical terms in addition to

cultural traits. One participant gave the counter argument that:

Not that I associate Germans in the physical sense but I do think Germans still have an image of what it means to be German. I have light eyes, white skin, and reddish-blonde hair so I blend in and have never been discriminated against because of my physical appearance. If I didn't look the way I look, I don't think I would have been accepted as easily as I have.

A second participant added that the physical identification is not focused on

phenotype as much as on racial type:

You don't have to have blue eyes and blonde hair, there are lots of Germans with black hair and dark eyes. I think, though, if you are racially different like if your skin color is much more different, then that's when you hear Germans say "You're German, yes. But where are you really from?" Like you couldn't possibly just be German but you must be from somewhere else because of your skin color.

The third participant who attributed German-ness to particular physical traits expanded on both these participants' points when she remarked:

To be German you have to be physically German or European such as fair skin and features. You also have to know German fluently and have to have

\footnotetext{
${ }^{42}$ Denotes colorism, where the participant termed himself mixed race but "light skinned."
} 
the correct dialect and no accent. Turks born here speak a certain way that Germans will never speak like. Use words or sentence structures that Germans would never use. Or have an accent that will automatically label you as not German.

For this participant, the imagined construct of being German involved the ethnonationalist model that factors in ethnicity and culture as an embodied identity. Astonishingly, most of the participants did not share that same opinion. At first, it was surprising, considering that some held the belief that having a child with a German "adelanta la raza" or "limpia la sangre." This would have made me supposed that my participants shared the idea that being German had an inherent connection to race. I hypothesize that since the conversation on race and racism has been silenced and replaced with a conversation on culture (Müller, 2001; Silver, 2010; Miller, 2012), is why most of my participants did not regard German identity as a racial identity. Rather, it was more often related to a cultural identity that at times intersected with an ethnoreligious identity. The wide majority viewed themselves as European and Christian and subscribed to a European ideology that creates a sense of belonging in Germany regardless of their immigrant status. This is significant because it allows the participants to easily integrate into the mainstream social paradigm and explains why one participant stated that Cubans "blend" into Germany.

\section{Cuba and the Transnational Connection}

Transnationalism, as argued by Binaisa (2013), is the "connections that migrants maintain between their country of origin and their countr(ies) of settlement" (pp. 886-887). This study explored how extensive and vibrant the emotional connection to Cuba was for the participants. The durability of emotional ties 
immigrants share with their nation of origin impacts their sense of belonging in the receiving nation (Binaisa, 2013; see also Schneider \& Crul, 2010). As one of my participants remarked, "most Cubans were forced out of Cuba and some spent years dreaming about returning to Cuba. These Cubans do not have a home; they are without a place to call their own. So, these Cubans, of course, never integrated" In this participant's perception, the urge to return to Cuba, reflected their inability of "letting go" (Behar \& Suarez, 2008, p. 14) of their past lives in Cuba and thusly hindered their integration. This hindrance stemmed not from their transnational ties per se but from their inability to perceive Germany as their home. The sense of belonging was a vital point in identity since it could affect their integration, depending on how strongly they still felt about Cuba. My data suggest that the more time Cuban migrants spent in Germany, the lesser their transnational ties to Cuba were. Most of my participants agreed that the longer they were in Germany, the more they felt as outsiders in Cuba. Twelve of the participants have visited Cuba more than once since immigrating to Germany. Five reported having been back only once. Five stated they never went back at all. Most who had visited Cuba explained that their main reason for traveling back was to visit family. As a participant who immigrated in the 1980s remarked, "I visit Cuba sometimes just because I have family still there, if I did not have family I would never go back. The poverty, the backwards thinking ... it all makes me really uncomfortable." Another participant who immigrated in 2005 declared the same reason, “I visit family, I don't go because I miss Cuba. I don't really miss Cuba; I might see something like a picture of Cuba and I will feel nostalgic but that's all." One Cuban-German participant also expressed, "I've been to 
Cuba twice. Whenever I leave Cuba and enter my apartment here in Germany, it feels so good like a huge sigh of relief. My sister, along with her daughter, and her son-inlaw, and my parents are in Germany now so I doubt I'll be going back."

One participant, whom was not able to find a job nor was a German citizen, also remarked how uncomfortable he was when he visited Cuba. To him, home now meant Germany, "when you get used to the good, it's hard to go back to the bad." However, another participant who recently immigrated to Germany and missed her life in Cuba commented:

I miss the openness of Cuba and the friendliness. Here in Germany there is so much silence. I have been here for six months and I still do not have any clue who my neighbors are, I've never even seen them. Back in Cuba everyone said good morning to one another and had conversations. It is depressing here.

Even this isolation associated with her new country did not inspire her to want to return to live Cuba, however. When asked if she would one day like to move back Cuba, she replied:

No absolutely not, there is no future there. Besides, my daughter is my home and where she goes I go. But I would like to move somewhere else like Miami. We have family there and I just came back from visiting, I brought back pastelitos in a container and Cuban coffee! I feel so good there! I would love to live there if I could.

To this participant, home meant her daughter, but a sense of belonging was situated in a place that encompassed Cuban culture but was still was not Cuba. During the follow-up interviews, this family did move to Miami and expressed joy at living there. They wanted to be surrounded by more family, and the son-in-law, who had been unable to enter the German labor market, felt that moving to Miami would grant him better economic opportunities. So far, they have found an apartment, 
gained employment, and are enjoying the familiar culture. They appear to feel more of a sense of belonging in Miami than in Berlin because Miami encompasses both the comforts they enjoyed in Germany and the culture they longed for in Cuba.

Along these same lines, I asked my participants if they would stay in Germany for the rest of their lives or move somewhere else, possibly to a Cuban community such as Miami. The majority answered they would live in Germany "for the rest of my life," a phrase frequently used. Few outlier answers included, "I would retire to Spain," "if I win the lottery, I would go somewhere with sun," and "wherever my job takes me." Two more participants also expressed that employment was a primary factor in their decision for place of residence. Nevertheless, the consensus was that my study participants were happy in Germany and have made a life in Berlin that they did not feel particularly interested in leaving. The only displeasure they expressed with living in Germany mentioned in different interviews across different subjects, was the weather. The cold and often grey skies in Berlin present discomfort for some of my participants, and if they could, they would move to a more tolerable climate. Moreover, some participants preferred living in a city where the number of Cubans was limited. One participant expressed this quite vividly:

I will definitely stay in Germany for the rest of my life but I do want to visit Miami because I have a lot of friends there but I would not move there. I used to want to have more Cuban friends but now I don't really care. Having my family here is enough for me. They already call me all the time, bother me with all kinds of family drama, and chismosea $a^{43}$ enough for me to be glad I don't like in Miami where there are a lot of Cubans .... If you want to find more Cubans here, there is a Salsa festival in Berlin, I would not recommend you go to it though because it is filled with elementos malos. ${ }^{44}$

\footnotetext{
${ }^{43}$ Denotes gossiping.

${ }^{44}$ Translates to "bad elements" but denotes people of a low socioeconomic class and/or criminals that are seen as unfavorable.
} 
This sentiment was echoed by a few other participants who commented negatively about the salsa festivals on the river and across Berlin, describing the individuals attending them as "groseros"45 and "bajo mundo."46 They also pointed out that the Cubans who attend those festivals were usually recent immigrants who do not plan on staying in Germany. My participants perceived them as transitory immigrants whose primary goal was to "make money and then leave Germany." Since my participants do not have a community that reinforces transnational ties or social spaces in Germany that strengthen the connection, they were unlikely to remain connected with Cuba. The institutions of Cuban culture in Germany were Cuban restaurants and bars and some forms of popular entertainment such as the salsa festival, which some did not hold in high regard. The participants who did not prefer attending these cultural events tended to belong to the first migration wave, with the exception of those in the second migration wave who had higher educational backgrounds. This echoed Berg's (2011) findings that "intellectuals were more likely to distance themselves from such overtly ethnicized conception of Cubanness" (p. 31) in Spain.

Overall, the more time my participants spent in Germany among a heterogeneous society, the less transnational they become. I also noted a similarity between both migrations waves and the proclivity they had for living in Germany rather than in Cuba. This is similar to Berg (2011), who found that several of her

\footnotetext{
45 Translates as "rude."

46 Translates as "low earth," but denotes people who are deemed "low lives."
} 
participants did not wish to move back to Cuba after immigrating to Spain. However, it was noted that the newly arrived immigrants tended to feel less at home in Germany than those who have spent more time living there. Recent migrants were also more open to moving elsewhere. Also, those who have already integrated into the German labor market felt more secure about living in Germany rather than moving somewhere else, unless a promotion or a better economic opportunity led them there. Even then, as they had already established a life in Germany they were less flexible about uprooting and leaving. A participant who has worked in the same company for over a decade stated that when he was offered a good job with another company, "The position was good, but not good enough for me to leave Berlin." Those who could not integrate into the German labor market or did not feel at home were more flexible about moving to another country where they could find greater economic success and social belonging.

\section{Discrimination and Receptivity}

The first reaction my participants overwhelmingly gave when asked if they felt discriminated against in Germany was "No, never." Not a single direct "yes" was given. This was flabbergasting because previous answers and conversation had revealed that discrimination was indeed present in their lives. However, as one participant expressed, "I never really felt discriminated against. I never noticed any discrimination." The concept that they do not notice discrimination was articulated several times. They recounted experiences, however, that countered their claims. One participant said she never felt discriminated against, yet later, she made an opposite 
claim. She mentioned that "there are times that Germans drive me crazy! Like they

want to shame you just for being foreign." I realized that the very term

"discrimination" invoked an adverse reaction from my participants as if being

discriminated against meant they were doing something wrong or not integrating.

That very participant, when asked if she ever felt being mixed race attracted prejudice or discriminatory reactions in Germany, quickly responded, "no, I am not

acomplejada ${ }^{47}$. I am not discriminated against because I am sure of myself. You can only be discriminated against if you are weak in character."

Discrimination, for some of my participants, was a reactionary and relational interaction in which allowing oneself to be discriminated against says something negative about the person's character. The power dynamics shifted in the participant's mind to feelings of shame not toward the discriminator, but toward the discriminated person. This was alluded to in a few interviews, but a mother and son in one focus group interview stood out the most in this regard. The son, when asked about his upbringing in Germany and if he ever felt he did not belong or if the receptivity of native German were ever negative, adamantly said no. He rejected the thought altogether in his one-on-one interview. In the focus group interview, the mother looked at him for a moment and then responded:

Maybe he doesn't remember well but he suffered a lot growing up. Being an immigrant made him different in his friends' eyes and they teased him a lot because of it. I remember one time when he had friends over at our house and I was making them lunch, he comes up to me and asked me something in Spanish. The other two kids, his friends, started laughing and making fun of him because he spoke Spanish. He immediately became red in the face and kind of backed away. I asked those kids if they spoke another language and they almost arrogantly said no, so I told them, "well that means that [Angel] is

\footnotetext{
${ }^{47}$ Denotes having a complex.
} 
smarter than you two because he knows German and Spanish". They stopped laughing and look embarrassed.

The son argued later that he does not care when people say things or do things like that anymore because "it just means they are not bright and you should ignore them." I realized that asking if they were ever discriminated against was a broad term inflated with mixed emotions and confusion. I leaned toward a more spatial and neutral line of questioning, asking about any moments or spaces in which they felt belonging and in which they felt exclusion. The feelings of "place-belongingness," which "refers to a sense of feeling at home" (Gilmartin \& Migge, 2016, p. 148; see also Antonsich, 2010), have already been established because most participants regarded Berlin as their home. I now inquired into a further investigation of "the politics of belonging," which in turn "refers to socio-spatial processes of inclusion and/or exclusion" (Gilmartin \& Migge, 2016, p. 148; see also Antonsich, 2010). Stepping away from the oversimplified word "discrimination" and pursuing a more involved line of questioning resulted in richer data as shown in the following sections.

\section{Experiences of Inclusion}

When I asked my participants about certain moments or spaces in Germany in which they felt they belonged, all answers were not only about experiences but specifically about emotional experiences. None of the answers was spatial in nature, but rather described individualized affective situations. For example, one participant who immigrated in the 1980s and had his first child in Germany, viewed her birth as a rite of acceptance in Germany: 
The day my daughter was born; I was alone in the hospital. She was the only woman giving birth that day so there were no other fathers in the waiting room and I had no family or friends here with me so I was alone. It was a warm moment because here I was in Germany .... having my first child. Everyone [the German hospital staff] began celebrating when she was born and I felt so much joy. It was a moment I will never forget.

Not only was his first child born in Germany, which created an emotional tie to the nation, but he shared the experience with the nurses and doctors who acted as surrogates to the family and friends he did not have with him. This moment in his life defined his belonging through an interaction with the native population and through a specific set of emotions. Another participant argued that he always felt included in Germany because whenever he needed help, "a German is always there to help." Furthermore, feelings of belonging for my participants were often phrased in abstract terms tied to affective memories based on their migration experiences. Several participants chose to describe their feelings of inclusion through interpersonal interaction as much as through a juxtaposition of lived experience between Cuba and Germany. A Cuban married couple answered that they felt as if they belonged in Germany; they then related that feeling of belonging to the socioeconomic difference of both nations. Another participant said he had always admired Germany, even at moments such as when he first arrived and was waiting outside his uncle's apartment. He decided to scream his uncle's name from the street, even though his uncle lived on the fifth floor and all the neighbors began hushing him and threatening to call the police. He thought of that moment as "hilarious," and it made him aware of his new cultural surrounding. The moment he realized he had a place in Germany and would build his future there was when he came across a grocery store: 
Man, I was so [freaking ${ }^{48}$ ] pissed. I was looking at all these fruits and vegetables that were selling for close to nothing. I stood there with such anger because I thought damn all this can grow in Cuba en una escupida ${ }^{49}$ and here in Germany I bet it's a hassle. Yet you can buy them here easily and cheaply and in Cuban you can't find or afford them. I was so angry at Cuba at that moment and so [freaking] happy to here.

Many non-German born participant alluded to the differences in available resources and wealth between both nations as a source of both wonder and disappointment. For these participants, belonging was operationalized as the moments when they envisioned a future for themselves and found resources that were not available in Cuba. Along the same lines, some participants defined their belonging in a more practical and detailed account when the concept of race was introduced. Race is a topic that Germans do not generally like to discuss (Müller, 2001; see also Silver, 2010; Miller, 2012) in an effort to unsubscribe from ideologies of its infamous past. Similar to what Pérez Naranjo (2014) found, my participants were not as extraordinarily open to talking about race as they had been with every other issue. The only times I was specifically able to incite a response involving race was through the concept of inclusion. This is because my Afro-Cuban participants felt unequivocally more accepted and included in Germany than in Cuba. They explained, that in Germany, they never experienced moments of exclusion for being black, while in Cuba, they felt as though their blackness was their defining characteristic and often felt excluded and discriminated against because of it. Two participants cited the

\footnotetext{
${ }^{48}$ Did not say the word "freaking" but instead mouthed it and gave a hand gesture signifying how mad he was.

${ }^{49}$ Translates to "In a spit" and denotes that something happens easily and swiftly.
} 
airport in Cuba as a space of discrimination and exclusion because of their racial

category.

In Germany, people don't pay attention to the fact that I am black but in Cuba they do. Every time I am in a Cuban airport I am embarrassed and humiliated. I go through a more stricter regulations and treatment there than in European airports. I was there once and brought my guitar and gifts and things like that. They stopped me and began searching everything and I hear in the background "oye chequea a ese negro." much stuff and why I had a guitar.

Another participant also cited the discriminatory treatment in a Cuban airport:

That's why I stopped going back to Cuba the last time I went in 2013, the way they treat you in the airport is terrible. Being black in Cuba is a headache. I feel more comfortable in Germany than in Cuba because in Cuba I'm called racist terms and there is so much injustice. Not like here in Germany.

Inclusion and belonging in Germany were not only related to interpersonal interactions, but more widely to a juxtaposition between Cuba and Germany. My participants defined their belonging by invoking the difference in their situation after migration, especially in terms of resources and racial tension.

\section{Experiences of Exclusion}

To further gauge the boundaries of inclusion and exclusion, I was interested in exploring the moments and spaces in which my participants felt excluded in Germany. As opposed to feelings of inclusion, my participants had more specific memories and spatial categories of exclusion. In terms of spatiality, my participants cited "Marzahn" specifically and "some places in the east" as being generally unwelcoming toward foreigners. The presence of Neo-Nazis was the reason behind

\footnotetext{
${ }^{50}$ Translates to "hey, check out that black man." Note the use of black as a noun rather than an adjective which signifies a strong racist connotation.
} 
the general feelings of exclusion cited by participants. None of my participants reported any firsthand negative experiences in these areas, but they noted that they did not feel welcomed. Certain mannerisms such as a distant glare or an angry look are the extent of exclusion they had personally encountered in those areas. Besides relating space to feelings of exclusion, many narratives described personal moments of exclusion. A participant who immigrated in the early 1980s argued that she felt more excluded in the GDR than now:

I was with my friend and we were talking in Spanish and a German came and pushed my friend hard because of it. But East and West Germany are like black and white. I didn't think one country could be so different from one another. After, I did not experience the same attitudes. I think the closest I came to it was when I went to buy a metro ticket. I asked for just one but the attendant gave me two and when I corrected her she insulted me .... I think now when I feel like an outsider its usually because of differences in ways of life. Like when I joke and Germans take it seriously or how straightforward they can be to the point of rudeness. I was talking with my son [who was raised in Germany] the other day. I was making small talk so I told him I wanted to see The Danish Girl and he abruptly said, "then go see it" and looked at me like why would he care? Germans don't engage in small talk well. These reactions always catch me by surprise.

Another participant recounted a slightly opposing sentiment in regard to feelings of exclusion pre- and post- unification.

When the Wall came down, foreigners were treated like they were less than. People started hating East Germans and foreigners. There was so much hate. The first few years after the Wall I did feel weird and like a foreigner but now not so much. I only feel like a foreigner now when people talk about the Syrian crisis and on the issue of immigration negatively, it makes me sad.

Another participant related a similar story in present-day Berlin when he was in the metro station and someone pushed past him rather forcefully because he was speaking loudly in Spanish. In the same regard, another participant added that she sent her secretary, a Cuban-German, to the bank with 15,000 Euros to deposit. The 
bank refused to accept the money and barely even acknowledged her presence. When she called the director of the bank, he dismissed the incident as a misunderstanding. She knew that the reason behind the bank's actions was because the woman was talking on the phone in Spanish. Certain indicators of difference, such as language, incite undesirable reactions among native Germans that make my participants feel like outsiders. The idea of language was central in feelings of exclusion across several of my participants' interviews. Even participants who are fluent in German described the same language-induced exclusionary practices. Two participants, who have been in Germany since the 1980s and are fluent in German, stated that such moments are the most frustrating to them. One narrated their experience in a local bakery, "I was with [Maria] once and we were buying Brotchen ${ }^{51}$ and the woman kept on asking "Bitte? Bitte? Like she did not understand us." Another participant explained that linguistic exclusion sometimes occurs in his place of work, even though he has been working there for over a decade, "they are sly about it. They are not outwardly rude but they do this thing where they will lean closer and kind of push their ears towards you as if they didn't understand what you just said. It annoys me so much!"

Another participant argued that she feels that these microaggressions are aimed to strategically situate her as an outsider:

I know they understand me, I might have an accent but I speak German well ... maybe not perfect but well enough. Yet they go out of their way to pretend they don't understand you because of the slight accent on one word that you said. They don't want you to forget that you are not German, if you do, they will remind you. You even start to feel bad and questions yourself like maybe I don't know German as well as I thought.

\footnotetext{
${ }^{51}$ It is a small bread.
} 
Because language is often used as a marker of difference that situates a person as either an insider or outsider in Germany, these narrations were not surprising. What was surprising was that my participants were readily open to talk about cultural issues, but not about the issue of race. "No, Germans do not care I am black. Cubans, do though, I always hear 'el negrito' or 'la negrita,"' a participant remarked. Another supported, "I feel safe here. There are lots of groups against racism here.” I did not note any negative feedback in regard to racial politics. As also noted by Pérez Naranjo (2014, p. 82), whenever a participant recounted a discriminatory act based on race, it was followed up by an excuse for that act. Consider this story about a violent attack on an Afro-Cuban man:

One day a group of Nazis beat up a black Cuban really bad but it wasn't because he was Cuban but because he was black. Though honestly, if its 2:00 am and you are out drinking and you are around other guys who are drunk, of course you're going to run into trouble. In that situation, you can be white, black, whatever color and still get into trouble .... I know a lot of Nazis, they live in my building and they are nice ... until they get in a group and start drinking. I also made it known that I did not want trouble but if they ever messed with my family there will be trouble. So, the ones in my building know better than to mess with us.

A couple other participants also stated they either lived near or were familiar with Neo-Nazis in Germany and they did not feel any sense of danger. The very act of knowing a Neo-Nazi should have alarmed them because the presence of right-wing extremists indicates prejudice, discrimination, and possible violence. My participants were not bothered by their existence but rather considered it simply a random occurrence, as one Afro-Cuban described:

I was invited to play with my band at a birthday party. It was such a nice party, very luxurious. So, we go and play and then it was time for the host to make a toast to the guy whose party it was for and when he's done talking, he brings up his hand in a Nazi salute and then everyone else did too. At first, I 
was worried but then the host came and apologized to me in case I was offended. I told him that I wasn't and thanked him for booking me for the event. Naturally, I left as fast as I could and did not stay to push my luck .... No one has messes with me because I'm very respectful and I'm Cuban. Those who do get into trouble is probably because se lo buscaron. ${ }^{52}$

His statement included three recurrent themes. The first is that he made no mention of his race, which across these interviews acted as an invisible hand. It is a factor in receptivity, exclusionary boundaries, and integration, but it is reduced to a non-factor. The second point involves how discrimination is reproduced in nuanced ways. This is demonstrated by my participants describing moments when they felt as outsiders because of gestures such as asking to clarify what they said. The third theme arises from the fact that none of the participants reported discrimination or exclusion on the basis of national origin. "They make you feel bad because you are a foreigner, but not because you are Cuban, on the contrary," as someone remarked. Overall, my participants believed that German receptivity was positive toward them because they were Cuban. Even during the GDR era, Holtz (2014) argues that Cuban students were viewed favorably because of the "general interest in the revolution and its subjects" (Holtz, 2014, p. 475).

Additionally, the German imagination constructs Cuban identity in fetishizing terms by which they are deemed desirably exotic. They are different enough to be viewed as interesting yet similar enough not to be viewed as the dangerous Other (Said, 1978). During my participant observation, I quickly noticed Cuban bars and restaurants that prominently featured pictures of Fidel Castro and El Che. This was a conspicuous and curious form of decoration because these two figures are disliked

\footnotetext{
52 Translates to "they looked for it".
} 
within the Cuban émigré community. It would have been a source of scandal had a restaurant in Miami used such décor. When I inquired into this peculiarity, I was told Germans viewed these figures positively. They also said that Germans have an image of what it means to be Cuban that includes these figures, so these restaurants capitalize on it. Similar to Berg (2011), who found that being Cuban in Spain could be used as "a saleable commodity" (p. 132). I also observed that although there was salsa music in the background, when a group of older Germans entered the restaurant, the music changed. One waitress told the other to lower the volume or change the Spanish channel. I asked why the sudden change in music, to which one waitress responded that older Germans tended to have more "subdued tastes." They strategically positioned everything from the music, to the décor, and even the menu to appeal as exotic but to stay within the normative lines of the mainstream.

This favorable view toward Cubans by the German population was articulated in several instances. As one musician observed, "Germans love Cubans! I have a Cuban flag on my guitar case and everyone always stops to talk me and request I play Cuban songs." Another commented on the propensity of Cuban intermarriage because "German men go crazy trying to find a Cuban wife. You see these men go all the way to Cuba to find one." Furthermore, one participant even argued that "Germans think highly of Cubans because we integrate better than other groups and we are very much like them." I would argue that the German receptivity is overall positive because Germans perceive Cubans as a sexualized and exotic other that also encompasses a core European ideology. They are deemed a preferred immigrant group. As CharonCardona (2004) argued when exploring Cuban identity in Australia, "Cubans 'are not 
significant cultural others"” (p. 51) and Cuban culture is not produced by Cubans in Australia but by "subjectless multiculturalism" (p. 51). This is also true in Germany, where Cubans are seen as "acceptably" foreign. These findings show that while the participants felt accepted, they still experienced spaces and feelings of exclusion. Whereas none of these exclusionary experiences were attributed to national-origin, they were attributed to markers of differences such as language.

\section{Are Cubans Integrating in Germany?}

The findings of this study suggest that Cubans are overall integrating in Germany as established by the degree of success across the six integration measures; citizenship acquisition, language attainment, the labor market, intermarriage, religion and religious identity, and identity, belonging, and receptivity. This study also found that the first migration wave was more successfully integrated across all six integration measures than the second migration wave. The first migration wave is composed of those who immigrated pre-1990's, most notably during the bilateral agreement between the GDR and Cuba. Those who immigrated to the GDR through this bilateral agreement first arrived as either guest workers or as students. They were given a preparatory integration course to help them succeed in their host nation. The preparatory course included instruction in the German language as well as etiquette lessons. It is believed that the majority of the workers and students returned to Cuba when the Soviet Union fell. However, many later returned via the contacts and social networks they had established in Germany. Some others, never returned to Cuba and defected by staying in Germany permanently. All participants from this migration 
wave were naturalized, fluent in German, fully employed, and considered Germany as their home.

The second migration wave is composed of migration through marriage and family reunification. Most met their German partners in Cuba and then migrated to Germany. Others were either requested by the family member already present in Germany or-being Cuban-German — traveled with their German passport. One outlier situation within my participant pool is a married couple who traveled to Spain for a literary conference, defected, and later applied for political asylum in Germany. This migration wave varied in their degree of integration. Some participants have completely integrated while other have integrated either socially, economically, and/or legally but not all three. For example, one participant is a German citizen, is fully employed, but does not speak German. The same could be noted for the CubanGerman participants. Their migration wave determined their degree of integration. Cuban-Germans that migrated in the first wave have integrated almost seamlessly into Germany. Meanwhile Cuban-Germans, in the second wave, have integrated across some measures and have struggled across others. For example, one CubanGerman participant who immigrated in the second wave, identifies primarily with her Cuban heritage and does not consider Germany her home. Even though she is a German citizen and is fluent is German, she struggled with finding her place within Germany.

Every single participant perceived themselves as integrated. However, when asked if they thought other Cubans were integrating, a diversity of opinion emerged. 
Those that immigrated in the first wave, nearly all answered that Cubans were successfully integrating in Germany:

Cubans are more adaptable. Many are marrying Germans and they are "alemanizándose" 53 . They are becoming more German. Even Cuban criminals who have been in German prisons will try to speak German even if it is "hallo". Cubans are definitely integrating.

However, when asked the same question to those in the second wave, I found more differing answers. More participants answered "no" rather than "yes," as one participant explained "no, not really. Not many Cubans integrate because some leave a part of themselves in Cuba." The difference in perception of Cuban integration by the participants themselves supports the finding of this research as it reinforces the integration differences between both waves. However, integration means differently to different people, as it is relative and not a concrete universal concept; hence why its definition is a highly debated subject (Alencar \& Deuze, 2017, p.152). It is also not only relative but also relational. The participants' experiences and interpersonal interactions determine how they view integration. Nevertheless, the participants' perception on integration does speak to the diverging migration trajectories between both waves.

Regardless of the differences between migration waves and their integration variation, most Cubans are successfully integrating in Germany across all integration measures. As a group, Cubans in Germany are legally immigrating to Germany and acquiring German citizenship. Overall, they are attaining the German language either fluently or conversationally. Additionally, in general, Cubans in Germany are successful within the mainstream labor market. Furthermore, there was a propensity

\footnotetext{
${ }^{53}$ Translates to "Germanizing."
} 
towards intermarriage. In regard to religion, Cubans in Germany were not particularly religious and did not view their religious practices as a marker of difference. The hyphenated term "Cuban-German" was not used by Cubans — whom are not of Cuban-German heritage — to self-identify; instead, they tended to add a German identity marker to their Cuban identity. In terms of a supranational identity, they were likely to subscribe to a European identity. Overall, Cubans felt at home in Germany and perceived German receptivity as positive. 


\section{CONCLUSION}

This study is an ethnographic exploration of Cuban integration in Germany. Cubans present an alternative narrative of integration as they expand the conversation on integration in Germany as an understudied group. Moreover, the field of Cuban diaspora studies is widened to a non-traditionally studied country, attesting to the diversity of the diaspora. In this space, Cubans navigate complex identity politics and cultural difference as they negotiate access to mainstream institutions with limited coethnic social networks. The research presents different trajectories of integration for not only immigrants in Germany but Cubans globally, contributing to Integration Studies, Cuban Diaspora Studies, and Identity Studies. This chapter summarizes the findings of this ethnography, presents the implications of the study, and gives suggestions for future research.

\section{Main Findings}

This study concluded that Cubans are integrating in Germany with a difference in the degree of integration between the two migration waves. Using six measures of integration this study qualitatively examined Cuban legal, economic, and social integration in Germany.

The majority of the participants were German citizens and were either fluent or conversational in the German language. Regarding the labor market, the majority were employed either full time or were self-employed as a musician or a writer, for example. Two participants were unemployed and one participant that worked only part-time. One sentiment that arose across many interviews concerning the labor 
market was in relation to the advantage their nationality and cultural traits granted them. Firstly, the participants viewed being Cuban as advantageous because they perceived Germans to favor them above other immigrant groups. Secondly, the belief that Cubans held cultural qualities that give them an edge against Germans and other groups in the labor market was also prominent. Some of the descriptions used by my participants to describe the advantageous qualities of the in-group were "ingenious," "hard working," "want to advance," "resourceful," and "echando pa'lante."1

This study also noted that there was a proclivity towards intermarriage. The participants that were married to Cubans immigrated to Germany as a married couple already. Shared cultural similarities and ethnoreligious variables were noted as factors towards the proclivity towards intermarriage. The participants overall shared a favorable perception of Germans and considered them to be ideologically similar to Cubans. Furthermore, they believed that newly arrived Cubans were dissimilar to those that have resided longer and were more integrated. Some also viewed Cubans in Germany as different from Cubans in the United States in terms of cultural ideology. In terms of religion and religious identity, none of the participants reported to either belong or identify with a non-Christian denomination. The majority considered themselves Catholic/Christian, but only a family unit of three, who belonged to the Evangelical Church, actively practiced their religion and went to church regularly. The consensus for Cubans in Germany is that they are non-practicing and do not actively participate in institutionalized religion. This finding recalls Grenier \&

\footnotetext{
${ }^{1}$ Denotes someone that is extroverted, willing to do what it takes to move forward in life, and sharp. My participants used various forms of this expression.
} 
Pérez's (2003, p. 42) argument that religiosity has never been a defining characteristic of Cubans in the U.S.

Moreover, there were reports that some Cubans in Germany practice Santería in the privacy of their home. The lines between Catholicism and Santería are often blurred (Grenier \& Pérez, 2003), however, it was interesting to note that this popular Afro-Cuban religion was still practiced in Germany. Though it is privately observed, the participants did not think Germans disapproved of Santería. Additionally, through participant observation I noted public display of Cuban religious practices as $L a$ Caridad del Cobra, the patron Saint of Cuba, was prominently displayed in a Cuban restaurant. There were also several offerings to La Caridad del Cobra such as pennies, candy, and sunflowers with the German flag proudly displayed behind. $L a$ Caridad del Cobra represents Cuba and is loved by Cubans; thus, to have the German flag a part of this important Cuban religious and sociocultural embodiment, symbolizes a blending of cultures.

In terms of identity, the participants did not actively use the hyphenated identification of "Cuban-German." However, they were prone to indirectly reference their German identity. The answer "Cuban" was frequently followed qualification that signaled a sense of German-ness. They negotiated their blended identities discursively by other means besides a hyphenated term. Moreover, it was clear that the participants of Cuban-German ancestry struggled the most with negotiating their identities. Regarding a supranational identity, participants overwhelmingly consider themselves as European. Only three participants considered themselves Latin American. There were also two outlier responses in the form of "international" and 
"Caribbean." For the participants, being European and being Cubans are not mutually exclusive and envelope them in a sense of belonging in Germany through a shared European identity.

Beyond national and supranational identities, a striking finding in terms of politicized identity, emerged. While many Cubans fled to the U.S as political exiles, Cubans were invited to Germany as guest workers or as students. Therefore, Cubans in Germany never embodied an exile ideology in the way that Cubans in the U.S did. Cubans in Germany do not identify as strongly with the politics of Cuba. For example, some Cuban restaurants in Berlin have walls covered in images of Castro and the Revolution, yet Cubans are both employees and patrons. The identity of Cubans in Germany is not anchored in Cuban politics. This set a tone for their process of integration, especially concerning identity, belonging, and transnational ties. Furthermore, Cubans in general feel included and have a sense of belonging in Germany. Many even believe that they are given preferential treatment compared to other immigrants. The participants did not actively discuss discrimination and usually avoided the notion of race. Rather, they were more open to describing spaces and moments of exclusion, particularly moments incited through language.

\section{Implications of the Study and Future Research Suggestions}

Beyond expanding Integration Studies, Identity Studies, and Cuban Diaspora Studies, this study aimed to inspire change in integration policy and public opinion. Germany is a vibrant country at the helm of innovation, where my paternal lineage has hailed from and I hold in high regard. I have the deepest respect and appreciation 
for German culture. Therefore, the purpose of this study was to uncover an alternative narrative to better the understanding of integration in Germany because its spirit of acceptance and progress clashes with its recurrent problems regarding immigrant integration.

As shown by the ethnographic findings, Cubans embody this alternative narrative as they have successfully integrated across all important integration measures. The majority subscribes to a European supranational identity, view Germany as their home, and have weak transnational ties to Cuba. They also engage in intermarriage because they see a common thread between themselves and Germans, in addition to the favorable perception they had of Germans- a feeling they described as mutual. However, this study indicated that Cuban immigrants, regardless of time lived in Germany or how integrated they are, still do not see themselves as Cuban-German. Even then the participants of Cuban-German ancestry of this study were conflicted with their identity. This indicates a persistence of an ethnonationalist definition of the German identity. Moreover, some participants pointed to the difficulty of entering the labor market and found the recognition of a foreign degree and qualifications to be unattainable. German integration strategies can benefit from addressing structural impediments to integration such as unequal access to the mainstream labor market and further rework its identity politics. Furthermore, I suggest conducting future research as a comparative integration study between Cubans and another minority immigrant group in Germany. As this study can also be replicated in other European countries as well, I would also suggest a comparative analysis of a minority immigrant group across two or more European countries. 
The hope of this study was to contribute to the life journeys and understanding of the Cuban diaspora. To be able to tell the story of Cubans in Germany is an honor and the greatest privilege of my life. The Cuban people are courageous, hardworking, diverse, and full of interesting trajectories. To fully grasp these trajectories, studies on Cuban diaspora should expand to non-traditional destination countries. Examining a country with a different historical and geopolitical relationship to Cuba than the traditional destination countries, the U.S and Spain, enriches Cuban Diaspora Studies. Understudied locations diversify both the area of study and stories of those within the diaspora. Therefore, I would also suggest future research on the Cuban diaspora and its integration in places such as Australia. I would also suggest a cross-cultural comparative analysis between Cubans in Germany and Cubans in the U.S or between Cubans in Germany and Cubans in another European country such as France. 


\section{BIBLIOGRAPHY}

Abad, J. S., \& García-Moreno, C. (2016). "Me fui, aunque no por cuestiones economicas": migraciones a Espana de mujeres cubanas y ecuatorianas por motivos extraeconomicos. Latin American Research Review, (2), 128. https://doiorg.ezproxy.fiu.edu/10.1353/lar.2016.0018

Adams, P. (1989). Family Policy and Labor Migration in East and West Germany. Social Service Review, (2), 245. Retrieved from http://search.ebscohost.com/login.aspx?direct=true \&db=edsjsr\&AN=edsjsr.30012018 $\underline{\text { \&site}=e d s-l i v e}$

Alba, R. \& Foner, N. (2008). Immigrant Religion in the U.S. and Western Europe: Bridge or Barrier to Inclusion? International Migration Review, 42(2), 360-392. doi:10.1111/j.1747-7379.2008.00128.x

Alba, R. (2005). Bright vs. Blurred boundaries: Second-generation assimilation and Exclusion in France, Germany, and the United States. Ethnic \& Racial Studies, 28(1), 20-49. doi:10.1080/0141987042000280003

Alba, R. D., \& Nee, V. (2003). Remaking the American Mainstream: Assimilation and Contemporary Immigration. Cambridge, Mass.: Harvard University Press, 2003. Retrieved from http://search.ebscohost.com/login.aspx?direct=true \&db=cat06026a\&AN=fiu.0216179 $\underline{10 \& \text { site }=\text { eds-live }}$

Alba, R., \& Foner, N. (2016). Integration's challenges and opportunities in the Wealthy West. Journal of Ethnic \& Migration Studies, 42(1), 3-22. doi:10.1080/1369183X.2015.1083770

Alba, R., \& Nee, V. (1997). Rethinking assimilation theory for a new era of immigration. International Migration Review, 31(4), 826-874. doi:10.2307/2547416

Alencar, A., \& Deuze, M. (2017). News for Assimilation or Integration? Examining the Functions of News in Shaping Acculturation Experiences of Immigrants in the Netherlands and Spain. European Journal of Communication, 32(2), 151-166. Retrieved from https://www.ncbi.nlm.nih.gov/pmc/articles/PMC5439377/pdf/10.1177_02673231176 $\underline{\text { 89993.pdf }}$

Allport, G. W. (1954). The Nature of Prejudice. Cambridge, Mass., Addison-Wesley Pub. Co., 1954. Retrieved from http://http://search.ebscohost.com/login.aspx?direct=true $\& \mathrm{db}=$ cat06026a\&AN=fiu. 02 $\underline{0261819 \& \text { site }=\text { eds-live }}$ 
Anil, M. (2005). No More Foreigners? The Remaking of German Naturalization and Citizenship Law, 1990-2000. Dialectical Anthropology, (3/4), 453. Retrieved from http://http://search.ebscohost.com/login.aspx?direct=true \&db=edsjsr\&AN=edsjsr.297 90750\&site $=$ eds-live

Anil, M. (2007). Explaining the Naturalisation Practices of Turks in Germany in the Wake of the Citizenship Reform of 1999. Journal of Ethnic \& Migration Studies, 33(8), 1363-1376. doi:10.1080/13691830701614262

Antonsich, M., \& Matejskova, T. (2015). Immigration Societies and the Question of "the National". Ethnicities, 15(4), 495-508. https://doiorg.ezproxy.fiu.edu/10.1177/1468796815577705

Antonsich, Marco. (2010). Searching for Belonging - An Analytical Framework. Geography Compass 4 (6): 644-659. Retrieved from http://http://search.ebscohost.com/login.aspx?direct=true \&db=edo\&AN=ejs 21560070 $\underline{\text { \&site}=\text { eds-live }}$

Auernheimer, G. (2005). The German Education System: Dysfunctional for an Immigration Society. European Education, 37(4), 75-89. doi:10.2753/EUE10564934370406

Avci, G. (2006). Comparing Integration Policies and Outcomes: Turks in the Netherlands and Germany. Turkish Studies, 7(1), 67-84.

doi:10.1080/14683840500520592

Ayhan, K., \& Ayşegül, K. (2012). Is National Citizenship Withering Away? Social Affiliations and Labor Market Integration of Turkish-Origin Immigrants in Germany and France. German Studies Review, (1), 113. Retrieved from http://http://search.ebscohost.com/login.aspx?direct=true \&db=edsjsr\&AN=edsjsr.232 69611\&site=eds-live

Badwi, R., Ablo, A. D., \& Overå, R. (2018). The Importance and Limitations of Social Networks and Social Identities for Labour Market Integration: The case of Ghanaian immigrants in Bergen, Norway. Norwegian Journal of Geography, 72(1), 27-36. doi:10.1080/00291951.2017.1406402

Bail, Christopher A. 2008. The Configuration of Symbolic Boundaries Against Immigrants in Europe. American Sociological Review 73: 37-59. Retrieved from http://http://search.ebscohost.com/login.aspx?direct=true \&db=edsjsr\&AN=edsjsr.254 72513\&site $=$ eds-live

Ballarino, G., \& Panichella, N. (2015). The Occupational Integration of Male Migrants in Western European Countries: Assimilation or Persistent Disadvantage? International Migration, 53(2), 338-352. doi:10.1111/imig.12105 
Ballarino, G., \& Panichella, N. (2018). The Occupational Integration of Migrant Women in Western European Labour Markets. Acta Sociologica (Sage Publications, Ltd.), 61(2), 126-142. doi:10.1177/0001699317723441

Bauder, H. (2008). Neoliberalism and the Economic Utility of Immigration: Media Perspectives of Germany's Immigration Law. Antipode, 40(1), 55-78.

doi:10.1111/j.1467-8330.2008.00571.x

Becker, B. (2011). Cognitive and Language Skills of Turkish Children in Germany: A Comparison of the Second and Third Generation and Mixed Generational Groups.

International Migration Review, 45(2), 426-459. doi:10.1111/j.1747-

7379.2011.00853.x

Bell, E. (1999). The Negotiation of a Working Role in Organizational Ethnography. International Journal of Social Research Methodology, 2(1), 17-37. Retrieved from http://http://search.ebscohost.com/login.aspx?direct=true \&db=bth\&AN=22847809\&s ite $=$ eds-live

Berg, M. L. (2011). Diasporic Generations: Memory, Politics, and Nation Among Cubans in Spain. New York: Berghahn Books, 2011.

Berger, S., \& Lilleker, D. G. (2002). The British Labour Party and the German Democratic Republic During the Era of Non-recognition, 1949-1973. Historical Journal, 45(2), 433-458. Retrieved from http://search.ebscohost.com/login.aspx?direct=true \&db=edsjsr\&AN=edsjsr.3133652 $\underline{\text { site}=e d s-l i v e}$

Bertrand M., \& Mullainathan, S. (2004). Are Emily and Greg More Employable than Lakisha and Jamal? A Field Experiment on Labor Market Discrimination. The American Economic Review, (4), 991. Retrieved from http://search.ebscohost.com/login.aspx?direct=true \&db=edsjsr\&AN=edsjsr.3592802 $\underline{\text { \&site}=e d s-l i v e}$

Biedinger, N., Becker, B., \& Klein, O. (2015). Turkish-Language Ability of Children of Immigrants in Germany: Which Contexts of Exposure Influence Preschool Children's Acquisition of Their Heritage Language? Ethnic \& Racial Studies, 38(9), 1520-1538. doi:10.1080/01419870.2015.1005641

Binaisa, N. (2013). Ugandans in Britain Making 'New' Homes: Transnationalism, Place and Identity within Narratives of Integration. Journal of Ethnic \& Migration Studies, 39(6), 885-902. doi:10.1080/1369183X.2013.765649

Blackledge, A. (2000). Monolingual Ideologies in Multilingual States: Language, Hegemony and Social Justice in Western Liberal Democracies. Sociolinguistic Studies, 1(1), 25. 
Blackledge, A. (2009). "As a Country We Do Expect": The Further Extension of Language Testing Regimes in the United Kingdom. Language Assessment Quarterly, 6(1), 6-16. https://doi-org.ezproxy.fiu.edu/10.1080/15434300802606465

Bloemraad, I., Korteweg, A., \& Yurdakul, G. (2008). Citizenship and Immigration: Multiculturalism, Assimilation, and Challenges to the Nation-State. Annual Review of Sociology, 34, 153-179. https://doiorg.ezproxy.fiu.edu/10.1146/annurev.soc.34.040507.134608

Bonner, A., \& Tolhurst, G. (2002). Insider-Outsider Perspectives of Participant Observation. Nurse Researcher, 9(4), 7-19. Retrieved from http://http://search.ebscohost.com/login.aspx?direct=true \&db=rzh\&AN=106964974\& $\underline{\text { site }=\text { eds-live }}$

Bosma, U., Lucassen, J., \& Oostindie, G. (2012). Postcolonial Migrants and Identity Politics: Europe, Russia, Japan and the United States in Comparison. [E-reader Version]. New York: Berghahn Books, 2012. Retrieved from http://search.ebscohost.com/login.aspx?direct=true \&db=cat06026a\&AN=fiu.0015404 95\&site=eds-live

Boswell, C., \& Hough, D. (2008). Politicizing Migration: Opportunity or Liability for the Centre-Right in Germany? Journal of European Public Policy, 15(3), 331-348. https://doi-org.ezproxy.fiu.edu/10.1080/13501760701847382

Bourdieu, P. (1987). What Makes a Social Class? On the Theoretical and Practical Existence of Groups. Berkeley Journal of Sociology, 321. Retrieved from http://http://search.ebscohost.com/login.aspx?direct=true \&db=edsjsr\&AN=edsjsr.410 35356\&site=eds-live

Brian V. (2003). The Origins of the German Volk: Cultural Purity and National Identity in Nineteenth-Century Germany. German Studies Review, (2), 241. doi: $10.2307 / 1433324$

Brubaker, R. (1992). Citizenship and Nationhood in France and Germany. [E-reader Version]. Harvard University Press. Retrieved from http://search.ebscohost.com/login.aspx?direct=true \&db=cat06026a\&AN=fiu.0274334 79\&site=eds-live

Brubaker, R. (2001). The Return of Assimilation? Changing Perspectives on Immigration and its Sequels in France, Germany, and The United States. Ethnic \& Racial Studies, 24(4), 531-548. doi:10.1080/01419870120049770 
Brubaker, W. R. (1990). Immigration, Citizenship, and the Nation-State in France and Germany: A Comparative Historical Analysis. International Sociology, 5(4), 379407. Retrieved from

http://search.ebscohost.com/login.aspx?direct=true\&db=edswah\&AN=A1990EJ9460 0003\&site $=$ eds-live

Bucerius, S. M. (2013). Becoming a 'Trusted Outsider': Gender, Ethnicity, and Inequality in Ethnographic Research. Journal of Contemporary Ethnography, 42(6), 690-721. https://doi-org.ezproxy.fiu.edu/10.1177/0891241613497747

Bürgin, A. \& Erzene-Bürgin, D. (2013). Educated in Germany, Working in Turkey: The Emigration Motivations of Persons of Turkish Origin. German Politics, 22(4), 461. doi:10.1080/09644008.2013.853042

Calhoun, C. (1993). Nationalism and Civil Society: Democracy, Diversity and SelfDetermination. International Sociology, 8(4), 387-411. Retrieved from http://search.ebscohost.com/login.aspx?direct=true \&db=edswss\&AN=A1993MJ9750 0001\&site=eds-live

Carol, S. (2013). Intermarriage Attitudes Among Minority and Majority Groups in Western Europe: The Role of Attachment to the Religious In-Group. International Migration, 51(3), 67-83. doi:10.1111/imig.12090

Castles, S. (1986). The Guest-Worker in Western Europe - an Obituary. International Migration Review, 20, 761-778. doi:10.2307/2545735

Castles, S. (1992). The Australian Model of Immigration and Multiculturalism: Is It Applicable to Europe? International Migration Review, (2), 549-567. doi: $10.2307 / 2547071$

Castles, S. (2006). Guestworkers in Europe: A Resurrection? International Migration Review, 40(4), 741-766. Retrieved from http://search.ebscohost.com/login.aspx?direct=true \&db=edsgao\&AN=edsgcl.130197 25\&site $=$ eds-live

Çelik, Ç. (2015). "Having A German Passport Will Not Make Me German”: Reactive Ethnicity and Oppositional Identity Among Disadvantaged Male Turkish SecondGeneration Youth in Germany. Ethnic \& Racial Studies, 38(9), 1646-1662. doi:10.1080/01419870.2015.1018298

Charon Cardona, E. T. (2004). Re-encountering Cuban Tastes in Australia. Australian Journal Of Anthropology, 15(1), 40. Retrieved from http://search.ebscohost.com/login.aspx?direct=true \&db=a9h\&AN=12619229\&site=e ds-live 
Cheng, Li-Rong L. (2004). The Challenge of Hyphenated Identity. Topics in Language Disorders, 24(3), 216-224. Retrieved from http://search.ebscohost.com/login.aspx?direct=true \&db=mzh\&AN=2004932268\&site =eds-live

Chiswick, B. R. (1978). The Effect of Americanization on the Earnings of Foreign-Born Men. Journal of Political Economy, 86(5), 897. Retrieved from http://search.ebscohost.com/login.aspx?direct=true \&db=edsjsr\&AN=edsjsr.1828415 \&site=eds-live

Choo Chin, L. (2015). Détente, Recognition, and Citizenship: The Case of East Germany. Region, (2), 265. Retrieved from http://http://search.ebscohost.com/login.aspx?direct=true\&db=edsjsr\&AN=edsjsr.437 $37575 \&$ site $=$ eds-live

Christel Kesler, A. (2006). Social Policy and Immigrant Joblessness in Britain, Germany and Sweden. Social Forces, (2), 743. Retrieved from http://search.ebscohost.com/login.aspx?direct=true \&db=edsjsr\&AN=edsjsr.4494938 \&site=eds-live

Cobas, J. A., \& Duany, J. (1997). Cubans in Puerto Rico: Ethnic Economy and Cultural Identity. [E-reader Version]. Gainesville: University Press of Florida. Retrieved from http://search.ebscohost.com/login.aspx?direct=true \&db=nlebk\&AN=54857\&site=eds $\underline{\text { live }}$

Coester, M. (2010). Commentary: Right-Wing Extremism and Bias Crime in Germany. Journal of Ethnicity in Criminal Justice, 8(1), 49-69. Retrieved from http://http://search.ebscohost.com/login.aspx?direct=true \&db=swh\&AN=80035\&site =eds-live

Constant, A. F., Kahanec, M., Rinne, U., \& Zimmermann, K. F. (2011). Ethnicity, Job Search and Labor Market Reintegration of the Unemployed. International Journal of Manpower, 32(7), 753-776. https://doiorg.ezproxy.fiu.edu/http://www.emeraldinsight.com/loi/ijm

Crul, M., \& Schneider, J. (2010). Comparative Integration Context Theory: Participation and Belonging in New Diverse European Cities.

doi:10.1080/01419871003624068

Cunha, M. E., \& Cunha, R. E. (2008). The Role of Mediatory Myths in Sustaining Ideology: The Case of Cuba After the "Special Period". Culture \& Organization, 14(3), 207. doi:10.1080/14759550802270643

DeLyser, D. (2001). "Do You Really Live Here?" Thoughts on Insider Research. Geographical Review, (1/2), 441. doi:10.2307/3250847 
Diehl, C., \& Blohm, M. (2003). Rights or identity? Naturalization processes among "Labor Migrants" in Germany. International Migration Review, (1), 133.

Diehl, C., \& Schnell, R. (2006). "Reactive ethnicity" or "assimilation"? Statements, arguments, and first empirical evidence for labor migrants in Germany. (n.d).

International Migration Review, 40(4), 786-816.

Domínguez, J. I. (1989). To Make A World Safe for Revolution: Cuba's Foreign Policy. Cambridge, Mass.: Harvard University Press, 1989.

Drever, A. I., \& Hoffmeister, O. (2008). Immigrants and Social Networks in a JobScarce Environment: The Case of Germany. International Migration Review, 42(2), 425-448. doi:10.1111/j.1747-7379.2008.00130.x

Dribe, M., \& Lundh, C. (2008). Intermarriage and Immigrant Integration in Sweden An Exploratory Analysis. Acta Sociologica, 51(4), 329-354. https://doiorg.ezproxy.fiu.edu/10.1177/0001699308097377

Duany, J. (2017). Puerto Rico: What Everyone Needs to Know. New York, NY: Oxford University Press, 2017.

Duke, K. (2002). Getting Beyond the 'Official Line': Reflections on Dilemmas of Access, Knowledge and Power in Researching Policy Networks. Journal of Social Policy, 31(1), 39-60. Retrieved from http://search.ebscohost.com/login.aspx?direct=true\&db=edsgao\&AN=edsgcl.837948 $\underline{34 \& \text { site }=\text { eds-live }}$

Dwyer, S., \& Buckle, J. (2009). The Space Between: On Being an Insider-Outsider in Qualitative Research. International Journal of Qualitative Methods, (1), 54. doi:10.1177/160940690900800105

Easterday, L., Papademas, D., Schorr, L., \& Valentine, C. (1977). The Making of a Female Researcher. Journal of Contemporary Ethnography, 6(3), 333. doi:10.1177/089124167700600305

Eckstein, S., \& Berg, M. L. (2009). Cubans in the United States and Spain: The Diaspora Generational Divide. Diaspora: A Journal of Transnational Studies, 18(1/2), 159-183.

Eitler, P., Hitzer, B., \& Scheer, M. (2014). Feeling and Faith-Religious Emotions in German History. German History, 32(3), 343-352. Retrieved from http://search.ebscohost.com/login.aspx?direct=true \&db=a9h\&AN=97547037\&site=e ds-live 
Elff, M., \& Rossteutscher, S. (2011). Stability or Decline? Class, Religion and the Vote in Germany. German Politics, 20(1), 107-127.

doi:10.1080/09644008.2011.554109

Elrick, T., \& Ciobanu, O. (2009). Migration Networks and Policy Impacts: Insights From Romanian-Spanish Migrations. Global Networks, (1), 100. https://doiorg.ezproxy.fiu.edu/10.1111/j.1471-0374.2009.00244.x

Ersanilli, E., \& Koopmans, R. (2010). Rewarding Integration? Citizenship Regulations and the Socio-Cultural Integration of Immigrants in the Netherlands, France and Germany. Journal of Ethnic \& Migration Studies, 36(5), 773-791. doi:10.1080/13691831003764318

Faas, D. (2007). The Europeanisation of German Ethnic Identities: The Case of German and Turkish Students in Two Stuttgart Secondary Schools. International Studies in Sociology of Education, 17(1), 45-62. https://doiorg.ezproxy.fiu.edu/10.1080/09620210701433738

Faas, D. (2008). From Foreigner Pedagogy to Intercultural Education: An Analysis of the German Responses to Diversity and Its Impact on Schools and Students. European Educational Research Journal, 7(1), 108-123. Retrieved from http://search.ebscohost.com/login.aspx?direct=true \&db=eric\&AN=EJ795051\&site=e ds-live

Faas, D. (2016). Negotiating Political Identities. [E-reader Version]. Multiethnic Schools and Youth in Europe. London; New York: Routledge, 2016. Retrieved from http://search.ebscohost.com/login.aspx?direct=true \&db=cat06026a\&AN=fiu.0037746 99\&site=eds-live

Fagen, R. (1978). Cuba and the Soviet Union. The Wilson Quarterly, (1), 69. http://search.ebscohost.com/login.aspx?direct=true \&db=edsjsr\&AN=edsjsr.40255843 $\underline{\text { \&site}=e d s-l i v e}$

Faist, T. (1993). From School to Work: Public Policy and Underclass Formation Among Young Turks In Germany During The 1980s. International Migration Review, (2), 306. Retrieved from http://search.ebscohost.com/login.aspx?direct=true\&db=edsgao\&AN=edsgcl.144467 71\&site=eds-live

Flubacher, M., \& Yeung, S. (2016). Discourses of Integration: Language, Skills, And The Politics Of Difference. Multilingua: Journal of Cross-Cultural And Interlanguage Communication, (6), 599. doi:10.1515/multi-2015-0076 
Furtado, D., \& Theodoropoulos, N. (2009). I'll Marry You If You Get Me a Job: Marital Assimilation and Immigrant Employment Rates. International Journal of Manpower, 30(1-2), 116-126. https://doiorg.ezproxy.fiu.edu/10.1108/01437720910948438

García-Moreno, C. (2015). Trayectorias Laborales de las Mujeres Migrantes Cubanas En España / Working Trajectories of Migrant Cuban Women in Spain. Migraciones Internacionales, (1), 189. Retrieved from http://search.ebscohost.com/login.aspx?direct=true\&db=edssci\&AN=edssci.S1665.89 $\underline{062015000100007 \& \text { site }=\text { eds-live }}$

Geertz, C. (1973). The Interpretation of Cultures: Selected Essays. [E-reader Version]. Basic Books. Retrieved from http://http://search.ebscohost.com/login.aspx?direct=true \&db=edsacl\&AN=edsacl.he $\underline{\text { b01005\&site }=\text { eds-live }}$

Gilmartin, M., \& Migge, B. (2016). Migrant Mothers and The Geographies Of Belonging. Gender Place and Culture, 23(2), 147-161. https://doiorg.ezproxy.fiu.edu/10.1080/0966369X.2014.991700

Girard, C., \& Grenier, G. (2008). Insulating an Ideology: The Enclave Effect on South Florida's Cuban Americans. Hispanic Journal of Behavioral Sciences, 30(4), 530-543. Retrieved from http://search.ebscohost.com/login.aspx?direct=true \&db=edsgao\&AN=edsgcl.188158 619\&site=eds-live

Glaser, B. G., \& Strauss, A. L. (1967). The Discovery of Grounded Theory: Strategies for Qualitative Research. Chicago. Aldine Pub. Co.

Glazer, N., \& Moynihan, D. 1. (Daniel Patrick), 1927-2003. (1970). Beyond the Melting Pot: The Negroes, Puerto Ricans, Jews, Italians, and Irish of New York City. [E-reader Version]. M.I.T. Press. Retrieved from http://search.ebscohost.com/login.aspx?direct=true \&db=edsacl\&AN=edsacl.heb0179 $\underline{5 \& \text { site}=e d s-l i v e}$

Glazer, N. (1993). Is Assimilation Dead? The Annals of the American Academy of Political and Social Science, 530, 122-136. Retrieved from http://www.jstor.org.ezproxy.fiu.edu/stable/1047681

Gold, R. L. (1958). Roles in Sociological Field Observations. Social Forces, (3), $217-$ 223. https://doi-org.ezproxy.fiu.edu/10.2307/2573808

Goldberg, A., Mourinho, D. \& Kulke, U. (1996). Labor Market Discrimination Against Foreign Workers in Germany. ILO Working Papers, 7. 
Goodman, S. W. (2010). Integration Requirements for Integration's Sake?

Identifying, Categorising and Comparing Civic Integration Policies. Journal of Ethnic \& Migration Studies, 36(5), 753-772. https://doi-

org.ezproxy.fiu.edu/10.1080/13691831003764300

Gordon, M. (1964). Assimilation in American life: The Role of Race, Religion, And National Origins. New York, Oxford University Press.

Granovetter, M. S. (1973). The Strength of Weak Ties. American Journal of Sociology, (6), 1360. Retrieved from http://search.ebscohost.com/login.aspx?direct=true\&db=edsjsr\&AN=edsjsr.2776392 $\underline{\text { \&site}=e d s-l i v e}$

Green, S. (2007). Divergent Traditions, Converging Responses: Immigration and Integration Policy in the UK and Germany. German Politics, 16(1), 95-115. doi:10.1080/09644000701197991

Grenier, G. J. (2006). The Creation and Maintenance of the Cuban American "Exile Ideology": Evidence from the FIU Cuba Poll 2004. Journal of American Ethnic History, 25(2/3), 209-224. Retrieved from http://search.ebscohost.com/login.aspx?direct=true \&db=edsjsr\&AN=edsjsr.27501696 $\underline{\text { \&site}=e d s-l i v e}$

Grenier, G. J., \& Pérez, L. (2003). The Legacy of Exile: Cubans In The United States. Boston: Allyn and Bacon, c2003

Grossoehme, D. H. (2014). Overview of Qualitative Research. Journal of Health Care Chaplaincy, 20(3), 109-122. doi:10.1080/08854726.2014.925660

Gruning, B. (2010). The Art of Narrating and The Question of Cultural Acknowledgment: The Case of Die Kinder Von Golzow and a Reunified Germany. The Sociological Review, 44. Retrieved from http://search.ebscohost.com/login.aspx?direct=true\&db=edsgao\&AN=edsgcl.260559 $\underline{010 \& \text { site }=\text { eds-live }}$

Gutiérrez, I. (2015). Immigration and Population in Canada: A Dependent Relationship Case Study of Cuban Immigration. MEDICC Review, (4), 53. Retrieved from http://http://search.ebscohost.com/login.aspx?direct=true\&db=edssci\&AN=edssci.S1 $\underline{555.79602015000400013 \& \text { site }=\text { eds-live }}$

Hagemann, K. (2004). Francophobia and Patriotism: Anti-French Images and Sentiments in Prussia and Northern Germany during the Anti-Napoleonic Wars. French History, 18(4), 404. Retrieved from http://search.ebscohost.com/login.aspx?direct=true \&db=hia\&AN=44440168\&site=ed $\underline{\text { s-live }}$ 
Haller, W., Portes, A., \& Lynch, S. (2011). Dreams Fulfilled, Dreams Shattered: Determinants of Segmented Assimilation in the Second Generation. Social Forces, (3), 733. Retrieved from http://search.ebscohost.com/login.aspx?direct=true\&db=edsjsr\&AN=edsjsr.41290085 $\underline{\text { site}=e d s-l i v e}$

Holtz, M. (2014). The Cuban Experience in East Germany: Academic Migration from 1960 to 2000. Bulletin of Latin American Research, (4), 468. doi:10.1111/blar.12206

Holtzman, J. (2006). Food and Memory. Annual Review of Anthropology, 361. Retrieved from http://://search.ebscohost.com/login.aspx?direct=true\&db=edsjsr\&AN=edsjsr.250649 29\&site=eds-live

Huschke, S. (2014). Fragile Fabric: Illegality Knowledge, Social Capital and Healthseeking of Undocumented Latin American Migrants in Berlin. Journal of Ethnic \& Migration Studies, 40(12), 2010. doi:10.1080/1369183X.2014.907740

Immerfall, S. (2017). Citizenship and Belonging: An Analysis of Immigrants' Integration Beliefs and Membership Meaning in South-West Germany. Glocalism: Journal of Culture, Politics and Innovation, (2), doi:10.12893/gjcpi.2017.2.4

Ireland, P. R. (1997). Socialism, Unification Policy and the Rise of Racism in Eastern Germany. International Migration Review, 31(3), 541-568. Retrieved from http://search.ebscohost.com/login.aspx?direct=true\&db=edsgao\&AN=edsgcl.204132 $\underline{16 \& \text { site }=\text { eds-live }}$

Kaas, L., \& Manger, C. (2011). Ethnic Discrimination in Germany's Labour Market: A Field Experiment. doi:10.1111/j.1468-0475.2011.00538.x

Kalmijn, M. (1998). Intermarriage and Homogamy: Causes, Patterns, and Trends. Annual Review of Sociology, 24, 395. Retrieved from http://http://search.ebscohost.com/login.aspx?direct=true\&db=bth\&AN=1056947\&sit $\underline{\mathrm{e}=\mathrm{eds}-\text { live }}$

Kivisto, P. (2004). What is The Canonical Theory of Assimilation? Journal of The History of The Behavioral Sciences, 40(2), 149. doi:10.1002 /jhbs.20013

Klein, T. (2001). Intermarriages between Germans and Foreigners in Germany. Journal of Comparative Family Studies, 32(3), 325-346. Retrieved from http://search.ebscohost.com/login.aspx?direct=true \&db=edswss\&AN=000169413900 $\underline{001 \& \text { site }=\text { eds-live }}$

Kogan, I. (2004). Labour Market Careers of Immigrants In Germany And The United Kingdom. Journal of International Migration And Integration / Revue De 
L'integration Et De La Migration Internationale, (4), 417. Retrieved from http://search.ebscohost.com/login.aspx?direct=true\&db=edsgao\&AN=edsgcl.206220 $\underline{207 \& \text { site }=\text { eds-live }}$

Kogan, I. (2007), A Study of Immigrants' Employment Careers In West Germany Using The Sequence Analysis Technique. (n.d). Social Science Research, 36(2), 491511. https://doi-org.ezproxy.fiu.edu/10.1016/j.ssresearch.2006.03.004

Kogan, I. (2011). New Immigrants - Old Disadvantage Patterns? Labour Market Integration of Recent Immigrants into Germany. International Migration, 49(1), 91117. doi:10.1111/j.1468-2435.2010.00609.

Korteweg, A., \& Yurdakul, G. (2009). Islam, Gender, And Immigrant Integration: Boundary Drawing in Discourses on Honour Killing in the Netherlands and Germany. Ethnic and Racial Studies, 32(2), 218-238. https://doiorg.ezproxy.fiu.edu/10.1080/01419870802065218

Kracl, C. L. (2012). Review or True? Using Higher-Level Thinking Questions In Social Studies Instruction. The Social Studies, (2), 57. Retrieved from http://http://search.ebscohost.com/login.aspx?direct=true \&db=eric\&AN=EJ953900\& site=eds-live

Kurthen, H. (1995). Germany at The Crossroads: National Identity and The Challenges of Immigration. International Migration Review, 29, 914-938. doi:10.2307/2547732

Kurthen, H., \& Heisler, B. S. (2009). Immigrant Integration: Comparative Evidence from the United States and Germany. Ethnic and Racial Studies, 32(1), 139-170. https://doi-org.ezproxy.fiu.edu/10.1080/01419870802298439

Leary, M. R., Twenge, J. M., \& Quinlivan, E. (2006). Interpersonal Rejection as a Determinant of Anger and Aggression. Personality \& Social Psychology Review, 10(2), 111-132. Retrieved from http://search.ebscohost.com/login.aspx?direct=true \&db=edswss\&AN=000237232500 $\underline{002 \& \text { site }=\text { eds-live }}$

Lee, D. (1997). Interviewing Men: Vulnerabilities and Dilemmas. Women's Studies International Forum, 553-564. https://doi.org/10.1016/S0277-5395(97)00043-5

Lee, J. \& Ingold, T. (2006). Fieldwork on Foot: Perceiving, Routing, Socializing. In Simon M. Coleman \& Peter Collins (Eds.), Locating the field. Space, Place and Context in Anthropology, 67-86, Oxford: Berg.

Lee, J., \& Bean, F. D. (2004). America's Changing Color Lines: Immigration, Race/Ethnicity, and Multiracial Identification. Annual Review of Sociology, 30, 221242. doi:10.1146/annurev.soc.30.012703.110519 
Lohmeier, C., \& Pentzold, C. (2014). Making Mediated Memory Work: CubanAmericans, Miami Media and the Doings Of Diaspora Memories. Media, Culture \& Society, (6), 776. https://doi-org.ezproxy.fiu.edu/10.1177/0163443713518574

Lucassen, L., \& Laarman, C. (2009). Immigration, intermarriage and the changing face of Europe in the post war period. The History of The Family, 14, 52-68.

doi:10.1016/j.hisfam.2008.12.001

Luthra, R. R. (2013). Explaining Ethnic Inequality in the German Labor Market: Labor Market Institutions, Context of Reception, and Boundaries. European Sociological Review, 29(5), 1095. https://doi-org.ezproxy.fiu.edu/10.1093/esr/jcs081

Mac Con Uladh, D. T. (2005). Guests of the Socialist Nation? Foreign Students and Workers in the GDR, 1949-1990. (Doctoral dissertation). Retrieved from http://search.ebscohost.com/login.aspx?direct=true \&db=edsble\&AN=edsble. 429347 $\underline{\& \text { site}=e d s-l i v e}$

Macias, J. (1996). Resurgence of Ethnic Nationalism in California and Germany: The Impact on Recent Progress in Education. Anthropology \& Education Quarterly, (2), 232. Retrieved from http://search.ebscohost.com/login.aspx?direct=true\&db=edsjsr\&AN=edsjsr.3195732 $\underline{\text { \&site}=e d s-l i v e}$

Malinowski, B. (2004). A Diary in The Strict Sense of The Term. London: Routledge, 2004

Marcus, George E. (1995). Ethnography in/of the World System: The Emergence of Multi-Sited Ethnography. Annual Review of Anthropology, 95. Retrieved from http://http://search.ebscohost.com/login.aspx?direct=true\&db=edsjsr\&AN=edsjsr.215 $\underline{5931 \& \text { site }=\text { eds-live }}$

Martinez Jr., R., Lee, M. T., \& Nielsen, A. L. (2001). Revisiting the Scarface Legacy: The Victim/Offender Relationship and Mariel Homicides in Miami. Hispanic Journal of Behavioral Sciences, 23(1), 37. Retrieved from http://search.ebscohost.com/login.aspx?direct=true \&db=edswss\&AN=000166479100 $\underline{003 \& \text { site }=\text { eds-live }}$

Massey, D. (1995). The New Immigration and Ethnicity in the United States. Population and Development Review, (3), 631. doi:10.2307/2137753

Maxwell, R. (2017). (n.d) Occupations, National Identity, and Immigrant Integration. Comparative Political Studies, 50(2), 232-263. https://doiorg.ezproxy.fiu.edu/10.1177/0010414016655535 
Mayer, K. U., Müller, W., \& Pollak, R. (2007). Chapter Ten: Germany: Institutional Change and Inequalities of Access in Higher Education. In, Stratification in Higher Education (p. 240). Retrieved from

http://search.ebscohost.com/login.aspx?direct=true \&db=eue \&AN=31894206\&site=e $\underline{\text { ds-live }}$

McHugh, K., Miyares, I., \& Skop, E. (1997). The Magnetism of Miami: Segmented Paths in Cuban Migration. Geographical Review, (4), 504. doi:10.2307/215228

Miller, J. A. (2012). (n.d.). On Track for West Germany: Turkish 'Guest-worker' Rail Transportation to West Germany in the Postwar Period. German History, 30(4), 550. https://doi-org.ezproxy.fiu.edu/10.1093/gerhis/ghs074

Morse, J. (1995). The Significance of Saturation. Qualitative Health Research, 5(2), 147-149. Retrieved from

http://search.ebscohost.com/login.aspx?direct=true \&db=rzh\&AN=107411099\&site=e ds-live

Morse, J. (2015). "Data Were Saturated . . ". Qualitative Health Research, 25(5), 587-588. doi:10.1177/1049732315576699

Moynihan, B., Gaboury, M., \& Onken, K. (2008). Undocumented and Unprotected Immigrant Women and Children In Harm's Way. Journal of Forensic Nursing, 4(3), 123-129. Retrieved from

http://search.ebscohost.com/login.aspx?direct=true\&db=edsgao\&AN=edsgcl.187441 976\&site $=$ eds-live

Müller, U. A. (2011). Far Away So Close: Race, Whiteness, and German Identity. Identities, 18(6), 620-645. https://doiorg.ezproxy.fiu.edu/10.1080/1070289X.2011.672863

Mushaben, J. M. (2010). Rethinking Citizenship and Identity: "What it Means to be German" since the Fall of the Wall. German Politics, 19(1), 72. doi:10.1080/09644001003588689

Nackerud, L., Springer, A., Larrison, C., \& Issac, A. (1999). The End of the Cuban Contradiction in U.S. Refugee Policy. International Migration Review, 33(1), 176192. Retrieved from

http://search.ebscohost.com/login.aspx?direct=true \&db=cmedm\&AN=12294979\&sit $\underline{\mathrm{e}=\text { eds-live }}$

Neckerman, K. M., Carter, P., \& Lee, J. (1999). Segmented Assimilation and Minority Cultures of Mobility. Ethnic \& Racial Studies, 22(6), 945-965.

doi:10.1080/01419879932919 
O'Leary, R., \& Finnäs, F. (2002). Education, Social Integration and MinorityMajority Group Intermarriage. Sociology, (2), 235. Retrieved from http://search.ebscohost.com/login.aspx?direct=true \&db=edsjsr\&AN=edsjsr.42858090 $\underline{\text { site}=e d s-l i v e}$

Öner, S. (2014). Influential Internal and External Factors in German Policy Towards Turkey's EU Membership: More Than "Privileged Partnership"; Less Than Full Membership? Eastern Journal of European Studies, 5(2), 95-118. Retrieved from http://search.ebscohost.com/login.aspx?direct=true \&db=edsdoj\&AN=edsdoj.8c57503 8f8034b64a9d4c72c6b713978\&site=eds-live

Ozuekren, S., \& Ergoz-Karahan, E. (2010). Housing Experiences of Turkish (Im)migrants in Berlin and Istanbul: Internal Differentiation and Segregation. Journal of Ethnic \& Migration Studies, 36(2), 355-372. doi:10.1080/13691830903387477

Pagnini, D., \& Morgan, P. (1990). Intermarriage and Social Distance Among U.S. Immigrants at the Turn of the Century. American Journal of Sociology, (2), 405. Retrieved from http://search.ebscohost.com/login.aspx?direct=true\&db=edsjsr \&AN=edsjsr.2781107 $\underline{\text { site}=e d s-l i v e}$

Palloni, A., Massey, D. S., \& Ceballos, M. (2001). Social capital and International Migration: A Test Using Information on Family Networks. American Journal of Sociology, 106(5), 1262-1298. doi:10.1086/320817

Pante, M. (2014). Female Researchers in a Masculine Space: Managing Discomforts and Negotiating Positionalities. Philippine Sociological Review, 65. Retrieved from http://search.ebscohost.com/login.aspx?direct=true\&db=edsjsr\&AN=edsjsr.43486388 $\underline{\text { site}=e d s-l i v e}$

Pătrașcu, C. (2015). Refugee Representations Across European Media: Discursive Constructions of Immigration. Public Administration \& Regional Studies, 16(2), 4250. Retrieved from http://search.ebscohost.com/login.aspx?direct=true \&db=bth\&AN=117029245\&site=e ds-live

Pedraza-Bailey, S. (1985). Cuba's Exiles: Portrait of a Refugee Migration. International Migration Review, 19(1), 4-34. Retrieved from http://search.ebscohost.com/login.aspx?direct=true\&db=edb\&AN=16485186\&site=e ds-live

Pérez Naranjo, Y. L. (2014). Cuban Migration in Germany (Doctoral dissertation). Retrieved from http://www.diss.fu-berlin.de/diss/receive/FUDISS_thesis_000000097353 
Pérez, L. (1986). Cubans in the United States. Annals of the American Academy Of Political \& Social Science, 48, 7126-137. Retrieved from

http://search.ebscohost.com/login.aspx?direct=true\&db=edsjsr\&AN=edsjsr.1046058 $\underline{\text { site}=e d s-l i v e}$

Perrone, D. (2010). Gender and Sexuality in the Field: A Female Ethnographer's Experience Researching Drug Use in Dance Clubs. Substance Use \& Misuse, 45(5), 717-735. Retrieved from http://search.ebscohost.com/login.aspx?direct=true \&db=s3h\&AN=48491009\&site=e ds-live

Piller, I. (2001). Naturalization Language Testing and its Basis in Ideologies of National Identity and Citizenship. International Journal of Bilingualism, (3), 259. Retrieved from http://search.ebscohost.com/login.aspx?direct=true\&db=edsgao\&AN=edsgcl.833426 $\underline{75 \& \text { site }=\text { eds-live }}$

Pink, S. (2008). Mobilising Visual Ethnography: Making Routes, Making Place and Making Images. Forum: Qualitative Social Research, 9 (3). Retrieved from http://search.ebscohost.com/login.aspx?direct=true \&db=edsdoj\&AN=edsdoj.58291c4 b30e5496b8ed0375ea9bd6db9\&site=eds-live

Plonien, K. (2000). “Germany's River, but not Germany's Border”-The Rhine as a National Myth in Early 19th Century German Literature. National Identities, 2(1), 8186. doi:10.1080/146089400113463

Pochon-Berger, E., Lenz. P. (2014). Language requirements and Language Testing for Immigration and Integration Purposes: A Synthesis of Academic Literature.

Pollack, D. (2002). The Change in Religion and Church in Eastern Germany after 1989: A Research Note. Sociology of Religion, (3), 373. Retrieved from http://search.ebscohost.com/login.aspx?direct=true\&db=edsjsr\&AN=edsjsr.3712475 $\underline{\text { \&site}=e d s-l i v e}$

Portes, A. \& Fernández-Kelly, P. (2008). No Margin for Error: Educational and Occupational Achievement among Disadvantaged Children of Immigrants. The Annals of The American Academy of Political And Social Science, 12. doi:10.1177/0002716208322577

Portes, A. (1969). Dilemmas of A Golden Exile: Integration of Cuban Refugee Families in Milwaukee. American Sociological Review, 34, 505-518. Retrieved from http://http://search.ebscohost.com/login.aspx?direct=true \&db=edsjsr\&AN=edsjsr.209 1960\&site=eds-live 
Portes, A. (1984). The Rise of Ethnicity: Determinants of Ethnic Perceptions Among Cuban Exiles in Miami. American Sociological Review, (3), 383. Retrieved from http://search.ebscohost.com/login.aspx?direct=true\&db=edsjsr\&AN=edsjsr. 2095282 $\underline{\text { site}=e d s-l i v e}$

Portes, A. (1987). The Social Origins of The Cuban Enclave Economy of Miami. Sociological Perspectives, 30(4), 340. Retrieved from http://search.ebscohost.com/login.aspx?direct=true \&db=edb\&AN=10623987\&site=e ds-live

Portes, A., \& Bach, R. L. (1985). Latin Journey: Cuban And Mexican Immigrants in The United States. Berkeley: University of California Press, c1985. Retrieved from http://search.ebscohost.com/login.aspx?direct=true \&db=cat06026a\&AN=fiu.0204026 $\underline{64 \& \text { site }=\text { eds-live }}$

Portes, A., \& Puhrmann, A. (2015). A Bifurcated Enclave: The Economic Evolution of the Cuban and Cuban American Population of Metropolitan Miami. Cuban Studies, 43, 40-63. https://doi-org.ezproxy.fiu.edu/10.1353/cub.2015.0010

Portes, A., \& Rumbaut, R. G. (2001). Legacies: The Story of The Immigrant Second Generation. [E-reader Version]. Berkeley: University of California Press; New York: Russell Sage Foundation, 2001, Retrieved from http://http://search.ebscohost.com/login.aspx?direct=true\&db=edsacl\&AN=edsacl.he $\underline{\text { b31535\&site }=\text { eds-live }}$

Portes, A., \& Zhou, M. (1993). The New Second Generation: Segmented Assimilation and Its Variants. The Annals of The American Academy of Political and Social Science, 74. Retrieved from http://search.ebscohost.com/login.aspx?direct=true\&db=edsjsr\&AN=edsjsr.1047678 $\underline{\text { site}=e d s-l i v e}$

Purdy, L. \& Jones, R. (2011) Changing Personas and Evolving Identities: The Contestation and Renegotiation of Researcher Roles in Fieldwork. Sport, Education and Society, 18:3, 292-310, doi:10.1080/13573322.2011.586688

Pütz, P. (2008). Transculturality as practice: Turkish entrepreneurs in Germany. In: Al-Hamarneh, A. \& Thielmann, J. Islam and Muslims in Germany. Leiden und Boston 2008 (Brill) S. 511-535.

Reershemius, G. (2011). A New Role for Low German? Language Insertion as Bilingual Practice in The Process of Language Shift. Journal of Sociolinguistics, (3), 383. Retrieved from

http://search.ebscohost.com/login.aspx?direct=true \&db=edsgao\&AN=edsgcl.260557 $\underline{075 \& \text { site }=\text { eds-live }}$ 
Reeves, C. (2010). A Difficult Negotiation: Fieldwork Relations with Gatekeepers. Qualitative Research, 10(3), 315-331. https://doi-

org.ezproxy.fiu.edu/10.1177/1468794109360150

Riphahn. R., Sander. M., Wunder. C. (2013). The welfare Use of Immigrants and Natives in Germany: The Case of Turkish Immigrants. International Journal of Manpower, (1), 70. doi:10.1108/01437721311319665

Park, R. (1914). Racial Assimilation in Secondary Groups with Particular Reference to the Negro. American Journal of Sociology, (5), 606. Retrieved from http://search.ebscohost.com/login.aspx?direct=true \&db=edsjsr\&AN=edsjsr.2763128 \&site=eds-live

Rosenthal, G., \& Köttig, M. (2009). Migration and Questions of Belonging. Migrants in Germany and Florida. Forum: Qualitative Social Research, 10(3). Retrieved from http://search.ebscohost.com/login.aspx?direct=true \&db=edsdoj\&AN=edsdoj.b96f359 $\underline{\text { 8ff3c4a9c97d3b5771f738e 75\&site }=\text { eds-live }}$

Rumbaut, R. G. (2004). Ages, Life Stages, and Generational Cohorts: Decomposing The Immigrant First And Second Generations in The United States. International Migration Review, (3), 1160. Retrieved from http://search.ebscohost.com/login.aspx?direct=true $\&$ db=edsgao\&AN=edsgcl.126240 $\underline{320 \& \text { site }=\text { eds-live }}$

Said, E. W. (1978). Orientalism. New York: Pantheon Books, c1978.

Schachter, A. (2016). From 'Different' To 'Similar': An Experimental Approach to Understanding Assimilation. American Sociological Review, (5), 981.

doi:10.1177/0003122416659248

Seifert, W. (1997). Admission Policy, Patterns of Migration and Integration: The German And French Case Compared. New Community, (4), 441. Retrieved from http://search.ebscohost.com/login.aspx?direct=true \&db=edb\&AN=75970188\&site=e ds-live

Shohamy, E. G. (2006). Language Policy: Hidden Agendas and New Approaches. London: Routledge.

Silver, H. (2010). The Social Integration of Germany Since Unification. German Politics and Society, (1), 165. Retrieved from http://search.ebscohost.com/login.aspx?direct=true \&db=edsgao\&AN=edsgcl.223597 995\&site=eds-live 
Simoni, V. (2016). Economization, Moralization, and the Changing Moral Economies of "Capitalism" and "Communism" Among Cuban Migrants in Spain.

Anthropological Theory, 16(4), 454-475. https://doiorg.ezproxy.fiu.edu/10.1177/1463499616684053

Skop, E. H. (2001). (n.d.). Race and Place in the Adaptation of Mariel Exiles. International Migration Review, (2). Retrieved from http://search.ebscohost.com/login.aspx?direct=true \&db=edswss\&AN=000169831400 $\underline{003 \& \text { site }=\text { eds-live }}$

Sluka, J. A. (1990). Participant Observation in Violent Social Contexts. Human Organization, 49(2), 114. Retrieved from http://search.ebscohost.com/login.aspx?direct=true\&db=edsjsr\&AN=edsjsr.44126442 $\underline{\text { site}=\text { eds-live }}$

Smallwood, J., \& Schooler, J. W. (2006). The Restless Mind. Psychological Bulletin, 132(6), 946-958. doi:10.1037/0033-2909.132.6.94

Smallwood, J., \& Schooler, J. W. (2015). The Science of Mind Wandering: Empirically Navigating the Stream of Consciousness. Annual Review of Psychology, 66, 487-518. doi:10.1146/annurev-psych-010814-015331

Song, M. (2009). Is Intermarriage a Good Indicator of Integration? Journal of Ethnic \& Migration Studies, 35(2), 331-348. doi:10.1080/13691830802586476

Song, M. (2010). What Happens After Segmented Assimilation? An Exploration of Intermarriage and 'Mixed Race' Young People in Britain. Ethnic \& Racial Studies, 33(7). doi:10.1080/01419871003625271

Song, M. (2016). Multiracial People and Their Partners in Britain: Extending the link between Intermarriage and Integration? Ethnicities, 16(4), 631-648.

doi:10.1177/1468796816638399

Soyer, M. (2014). Off the Corner and Into the Kitchen: Entering a Male-Dominated Research Setting as a Woman. Qualitative Research, 14(4), 459-472.

doi: $10.1177 / 1468794113488130$

Soysal, Y. N. (2012). Citizenship, Immigration, and the European Social Project: Rights and Obligations of Individuality. The British Journal of Sociology, (1), 1. Retrieved from http://search.ebscohost.com/login.aspx?direct=true\&db=edsgao\&AN=edsgcl.282433 $\underline{504 \& \text { site }=\text { eds-live }}$ 
Sperling, J. (2013). Belonging, Beyond the Nation: The Significance and Meaning Of European Identity for Latin American-Origin Youth in Spain. National Identities, 15(1), 67. doi:10.1080/14608944.2012.733155

Springwood, C., \& King, C. R. (2001). Unsettling Engagements: On the Ends of Rapport in Critical Ethnography. Qualitative Inquiry, (4), 403. Retrieved from http://search.ebscohost.com/login.aspx?direct=true\&db=edsgao\&AN=edsgcl.792826 $\underline{73 \& \text { site }=\text { eds-live }}$

Statham, P. (2016). How Ordinary People View Muslim Group Rights in Britain, The Netherlands, France And Germany: Significant "Gaps" Between Majorities and Muslims? Journal of Ethnic and Migration Studies, 42(2), 217-236. https://doiorg.ezproxy.fiu.edu/10.1080/1369183X.2015.1082288

Stefan, I. (2017). Citizenship and Belonging: An Analysis of Immigrants Integration Beliefs and Membership Meaning in South-West Germany. Glocalism: Journal of Culture, Politics and Innovation, (2), doi:10.12893/gjcpi.2017.2.4

Stryker, S. \& Burke, P. (2000). The Past, Present, and Future of an Identity Theory. Social Psychology Quarterly, (4), 284. Retrieved from http://http://search.ebscohost.com/login.aspx?direct=true \&db=edsjsr\&AN=edsjsr.269 5840\&site $=$ eds-live

Suárez, L. M., \& Behar, R. (2008). The Portable Island: Cubans At Home in The World. New York, NY: Palgrave Macmillan, 2008.

Timseena, B. (2009). Participant Observation in Field Research: An Overview. Nepalese Journal of Qualitative Research Methods, 3, 75-86. Retrieved from http://search.ebscohost.com/login.aspx?direct=true \&db=a9h\&AN=64433518\&site=e ds-live

Valdez, C. R., Padilla, B., \& Valentine, J. L. (2013). Consequences of Arizona's Immigration Policy on Social Capital Among Mexican Mothers with Unauthorized Immigration Status. Hispanic Journal of Behavioral Sciences, 35(3), 303-322. doi:10.1177/0739986313488312

Verdugo, R. R., \& Mueller, C. (2009). Education, Social Embeddedness, and the Integration of the Turkish Community in Germany: An Analysis of Homeland Identity. European Education, 40(4), 3-22. Retrieved from http://search.ebscohost.com/login.aspx?direct=true \&db=eric\&AN=EJ844198\&site=e $\underline{\text { ds-live }}$

Vick, B. (2003). The Origins of the German Volk: Cultural Purity and National Identity in Nineteenth-Century Germany. German Studies Review, 26(2), 241-256. doi: $10.2307 / 1433324$ 
Warren, C. A., \& Rasmussen, P. K. (1977). Sex and Gender in Field Research. Journal of Contemporary Ethnography, 6(3), 349. doi:10.1177/089124167700600306

Waters, M. C. (1994). Ethnic and Racial Identities of Second-Generation Black Immigrants In New York City. International Migration Review, 28, 795-820. doi: $10.2307 / 2547158$

Weikart, R. (2003). Progress Through Racial Extermination: Social Darwinism, Eugenics, and Pacifism in Germany, 1860-1918. German Studies Review, (2), 273. doi: $10.2307 / 1433326$

Wilkes, L. (1999). Metropolitan Researchers Undertaking Rural Research: Benefits and Pitfalls. Australian Journal of Rural Health, 7(3), 181-185. Retrieved from http://search.ebscohost.com/login.aspx?direct=true\&db=rzh\&AN=107096220\&site=e ds-live

William, H., Alejandro, P., \& Scott M., L. (2011). Dreams Fulfilled, Dreams Shattered: Determinants of Segmented Assimilation in the Second Generation. Social Forces, (3), 733. Retrieved from http://search.ebscohost.com/login.aspx?direct=true \&db=edsjsr\&AN=edsjsr.41290085 $\underline{\text { \&site}=e d s-l i v e}$

Williams, D. (2013). Germanness or Rights? Second Generation Young Adults and Citizenship in Contemporary Germany. German Politics and Society, (2), 30. doi:10.3167/gps.2013.310204

Williams, H. (2014). Changing the National Narrative: Evolution in Citizenship and Integration in Germany, 2000-10. Journal of Contemporary History, 49(1), 54-74. doi:10.1177/0022009413505658

Williams, T., Dunlap, E., Johnson, B. D., \& Hamid, A. (1992). Personal Safety in Dangerous Places. Journal of Contemporary Ethnography, (3), 343. Retrieved from http://search.ebscohost.com/login.aspx?direct=true \&db=edsgao\&AN=edsgcl.129529 $\underline{07 \& \text { site }=\text { eds-live }}$

Wilson, K., \& Portes, A. (1980). Immigrant Enclaves: An Analysis of the Labor Market Experiences of Cubans in Miami. American Journal of Sociology, (2), 295. Retrieved from http://search.ebscohost.com/login.aspx?direct=true\&db=edsjsr\&AN=edsjsr.2778666 $\underline{\text { \&site}=e d s-l i v e}$

Woltman, K., \& Newbold, K. B. (2009). Of Flights and Flotillas: Assimilation and Race in the Cuban Diaspora. Professional Geographer, 61(1), 70-86. doi:10.1080/00330120802520244 
Worbs, S. (2003). The Second Generation in Germany: Between School and Labor Market. International Migration Review, 37(4), 1011-1038. doi:10.1111/j.17477379.2003.tb00168.x

Wright, M. (2011). Diversity and the Imagined Community: Immigrant Diversity and Conceptions of National Identity. Political Psychology, (5), 837. Retrieved from http://search.ebscohost.com/login.aspx?direct=true \&db=edsjsr\&AN=edsjsr.41262948 $\underline{\& s i t e=e d s-l i v e}$

Xuereb, K. (2011). European Cultural Policy and Migration: Why Should Cultural Policy in the European Union Address the Impact of Migration on Identity and Social Integration? International Migration, (2), 28. Retrieved from http://search.ebscohost.com/login.aspx?direct=true\&db=edsgao\&AN=edsgcl.251671 926\&site=eds-live

Zazilska-Florczuk, M., \& Ciechanowicz, A. (2011). One Country, Two Societies? Germany Twenty Years After Reunification. OSW Study 35/2011. Retrieved from http://search.ebscohost.com/login.aspx?direct=true \&db=edsupe \&AN=edsupe. 58085 $\underline{\text { \&site}=e d s-l i v e}$

Zhou, M. (1997). Segmented Assimilation: Issues, Controversies, and Recent Research on The New Second Generation. International Migration Review, (4), 975. Retrieved from http://search.ebscohost.com/login.aspx?direct=true\&db=edsgao\&AN=edsgcl.206087 $\underline{00 \& \text { site }=\text { eds-live }}$

Zolberg, A., \& Woon, L. (1999). Why Islam is like Spanish: cultural incorporation in Europe and the United States. Politics \& Society, 27(1), 5-38. Retrieved from http://search.ebscohost.com/login.aspx?direct=true \&db=apn\&AN=ALTP107000\&sit e=eds-live 


\section{APPENDIX}

\section{Appendix A}

Demographic Questions asked:

1) How old are you?

a. What is your race?

b. What is your sex?

2) What is your highest level of degree or schooling?

a. In what country did you complete your education?

3) What is your occupation?

4) What country were you born in?

a. If you were born outside of Germany, when did you immigrate to Germany?

5) What is your mother tongue/native language?

a. Do you speak Spanish?

b. Do you Speak German?

6) Are you a German citizen, resident, temporary work/student visa, refugee, or undocumented?

7) Are you married?

a. What is your spouse's nationality?

b. Do you have children?

c. Do you have any other family in Germany?

8) What neighborhood do you live in?

9) Do you have any religious or political affiliations? 


\section{Appendix B}

Demographics of Participants

\begin{tabular}{llll}
\hline Characteristics & $\begin{array}{l}\text { Number of } \\
\text { Participants }\end{array}$ & $\begin{array}{c}\text { *First Wave of } \\
\text { Immigration }\end{array}$ & $\begin{array}{c}\text { *Second Wave of } \\
\text { Immigration }\end{array}$ \\
\hline $\begin{array}{l}\text { Sex } \\
\text { Female }\end{array}$ & 12 & 3 & 8 \\
Male & 13 & 5 & 6 \\
Age & & & 5 \\
20-39 & 6 & 1 & 7 \\
$40-49$ & 9 & 2 & 1 \\
50-Onwards & 10 & 6 & 7 \\
Race & 16 & & 3 \\
White & 4 & 1 & 3 \\
Black & 5 & 1 & \\
Mixed & & & \\
\hline
\end{tabular}

* The two female participants and one male participant that were not residing in Germany will not be counted in the First/Second Migration Wave columns.

\section{Appendix C}

Semi-Structured and Open-Ended Questions

1) What is your fluency in the German language?

a. What language do you prefer to speak in? Why?

b. What language do you primarily speak in your household?

c. Do you feel pressured to speak German at work or in social settings?

2) Do you consider yourself German or Cuban? 
3) Do you see yourself as European or Latin American?

4) What does being German mean to you?

5) What does integration mean to you?

6) Do you see yourself as integrated in Germany?

a. Do you participate in any social clubs or political affiliations?

b. In your opinion, do you think other Cuban immigrants in Germany are integrating usefully?

c. Do you think your race is a factor impacting your integration or acceptance in Germany?

7) How did you immigrate to Germany? Describe your immigration experience.

a. What do these experiences mean to you? Why are they so memorable?

b. (If immigrated and not born) Before immigrating to Germany, did you have any preconceived notions of Germany or Germans?

c. Did the reality live up to your expectations?

8) Tell me about some of the most memorable experiences you've had in Germany.

9) Have you ever had moments in Germany when you felt really at home?

10) Have you ever had moments in Germany when you felt where you felt like an outsider?

a. Are there certain spaces in which you feel discriminated against? 
b. Work? School? Public or private spaces? During cultural activities?

c. Are there areas or neighborhoods in Berlin where you feel unwelcome in?

11) Have you developed any meaningful relationships in Germany?

a. With whom? How did they develop?

b. What nationality and/or ethnicity are your friends and significant relationships mostly?

c. Do you have a preference?

12) Have you visited Cuba since you have lived in Germany?

a. Do you think life in Cuba is different from life in Germany?

b. Do you miss Cuba? Is there nostalgia?

c. Would you prefer to live in a city like Miami, where there is a huge Cuban community?

d. Do you see yourself staying in Germany in the future?

13) Do you think Cuban immigrants in Berlin are different from other immigrant groups in Germany?

a. Do you think there are similarities between Cuban immigrants and Turkish immigrants in Berlin?

b. Do you see yourself as more similar or share more of a camaraderie with native Germans or with other immigrant groups? 


\section{Appendix D}

Participants by Migration Waves

Migration Wave Number of

Participants

First Wave of Immigration $\quad 9 *$

Second Wave of Immigration 13

* This does not include one participant that lived in East Germany but now resides in the United States nor the two participants that lived in Poland during the 1980's.

\section{Appendix E}

Citizenship Acquisition, Language Attainment, and Labor Market Findings Across the Two Migration Waves

\begin{tabular}{llll}
\hline Measure of Integration & $\begin{array}{l}\text { Number of } \\
\text { Participants }\end{array}$ & $\begin{array}{l}\text { First Wave of } \\
\text { Immigration }\end{array}$ & $\begin{array}{l}\text { Second Wave } \\
\text { of } \\
\text { Immigration }\end{array}$ \\
\hline German Citizen & 18 & 9 & 9 \\
Non-German Citizen & 4 & 0 & 4 \\
*Fluent/Conversational & 18 & 10 & 8 \\
Non-Fluent/Conversational & 5 & 0 & 5 \\
**Employed & 20 & 9 & 11 \\
Unemployed & 2 & 0 & 2 \\
\hline
\end{tabular}

* Including the participant that lived in East Germany but now resides in the United States.

** Includes full-time employment, part-time employment, self-employment, and contractual employment. 
VITA

\section{ANA MARY RUSCH}

Born, Havana, Cuba

2012

B.A., International Relations Cum Laude Second Majors: Geography and Political Science

Florida International University

Miami, Florida

2012-2014

Graduate Teaching Assistant

Women's Studies Center

Florida International University

Miami, Florida

2014

M.A., Global and Sociocultural Studies

Florida International University

Miami, Florida

2014-2016

Teaching Assistant

Global and Sociocultural Studies Department Florida International University

Miami, Florida

2015-2018

Doctoral Candidate

Florida International University

Miami, Florida

2016-

Adjunct Professor

Global and Sociocultural Studies Department Florida International University

Miami, Florida 